\title{
Personal networks of chronic patients
}

Citation for published version (APA):

Janssen, M. A. (1992). Personal networks of chronic patients. [Doctoral Thesis, Maastricht University]. Rijksuniversiteit Limburg. https://doi.org/10.26481/dis.19920319mj

Document status and date:

Published: 01/01/1992

DOI:

10.26481/dis.19920319mj

Document Version:

Publisher's PDF, also known as Version of record

\section{Please check the document version of this publication:}

- A submitted manuscript is the version of the article upon submission and before peer-review. There can be important differences between the submitted version and the official published version of record.

People interested in the research are advised to contact the author for the final version of the publication, or visit the DOI to the publisher's website.

- The final author version and the galley proof are versions of the publication after peer review.

- The final published version features the final layout of the paper including the volume, issue and page numbers.

Link to publication

\footnotetext{
General rights rights.

- You may freely distribute the URL identifying the publication in the public portal. please follow below link for the End User Agreement:

www.umlib.nl/taverne-license

Take down policy

If you believe that this document breaches copyright please contact us at:

repository@maastrichtuniversity.nl

providing details and we will investigate your claim.
}

Copyright and moral rights for the publications made accessible in the public portal are retained by the authors and/or other copyright owners and it is a condition of accessing publications that users recognise and abide by the legal requirements associated with these

- Users may download and print one copy of any publication from the public portal for the purpose of private study or research.

- You may not further distribute the material or use it for any profit-making activity or commercial gain

If the publication is distributed under the terms of Article $25 \mathrm{fa}$ of the Dutch Copyright Act, indicated by the "Taverne" license above, 


\section{Personal networks of chronic patients}

\section{PROEFSCHRIFT}

ter verkrijging van de graad van doctor aan de Rijksuniversiteit Limburg te Maastricht, op gezag van de Rector Magnificus, Prof. mr. M.J. Cohen, volgens het besluit van het College van Dekanen, in het openbaar te verdedigen op donderdag, 19 maart 1992 om 14.00 uur

door

Miriam Janssen

geboren te Beek in 1963 


\section{Promotor:}

Prof. dr. H. Philipsen

Co-promotor:

Dr. R.J.G. Halfenis

Beoordelingscommissie:

Prof. dr. G.J. Kok, voorzitter

Prof. dr. A.P.W.M. Appels

Prof. dr. C.P.M. Knipscheer, Vrije Universiteit Amsterdam

Dr. P. Pop

Prof. dr. J.A.M. Winnubst, Rijksumiversiteit Utrecht

Janssen, Miriam

Personal networks of chronic patients / Miriam Janssen. -

Maastricht : Datawyse. - III.

Thesis Maastricht. - With ref. - With summary in Dutch.

ISBN $90-9004852-9$

NUGI 651

Subject heading: personal networks; chronic patients.

produktie: Datawyse Maastricht

omslagontwerp: Reklameburo Artifex - Gorinchem; gebaseerd op werk van E. Deutekom

druk: Krips Repro Meppel

In de drukkosten van het proefschrift werd bijgedragen door het Nationaal Reumafonds. 


\section{Dankwoord}

Dit proefschrift is het resultaat van een vijf jaar durend onderzoek. Het zou zeker niet tot stand zijn gekomen zonder de emotionele en praktische steun die ik heb ondervonden van een groot aantal mensen. Enkelen wil ik in dit dankwoord met naam noemen.

Op de eerste plaats is dat mijn promotor Hans Philipsen, die mij de kans heeft gegeven dit onderzoek te verrichten en mij heeft gestimuleerd het tot een goed einde te brengen. Als het nodig was, kon ik bij hem terecht, waarbij hij steeds weer bruikbare suggesties deed. Daarnaast wil ik mijn co-promotor Ruud Halfens noemen, die in een latere fase bij het onderzoek betrokken raakte. Hij bleek een kritisch lezer te zijn, wat ik als prettig heb ervaren.

Ook will ik de 119 mensen bedanken die bereid waren om in een aantal, vaak langdurige, gesprekken mij van een grote hoeveelheid informatie te voorzien. Zonder hun trouwe medewerking zou het onderzoek niet mogelijk zijn geweest.

De specialisten in de ziekenhuizen van Maastricht en Heerlen wil ik bedanken voor de goede samenwerking, die ertoe heeft geleid dat de beoogde patiëntenaantallen werden bereikt.

Verder wil ik de leden van de beoordelingscommissie bedanken, voor de manier waarop ze mijn concept van commentaar hebben voorzien. Hun suggesties hebben bijgedragen tot de verbetering van de kwaliteit van dit proefschrift.

Dit laatste geldt ook voor Bob Wilkinson, die het proefschrift heeft bekeken op het gebruikte Engels.

In dit dankwoord wil ik ook mijn naaste collega's in Maastricht en Utrecht noemen. Elselien Deutekom bleek in de Maastrichtse jaren een goede kamergenote, die altijd open stond voor het bespreken van mijn ideeën met betrekking tot het onderzoek. Naast Elselien droeg Karen Cox belangrijk bij aan mijn "kwaliteit van leven" vanwege de vele uren die ze luisterde naar mijn onderzoekservaringen, waarbij ze niet naliet kritische vragen te stellen. We hebben samen heel wat koffie naar binnen gewerkt en ik hoop dat we dit gebruik in de toekomst nog lang zullen voortzetten.

In Utrecht zorgde de steun van de 'NKB-ers' ervoor dat de eindstreep daadwerkelijk werd gehaald. Het laatste anderhalf jaar stimuleerden ze me door hun interesse en gezelligheid tot het afronden van dit proefschrift. Voor de 
benodigde praktische steun zorgde Robert Hulsman, die een groot aantal van de figuren in dit boek produceerde.

Mijn dank gaat ook uit naar mijn ouders, die een belangrijke rol hebben gespeeld in het tot stand komen van dit proefschrift. Ze hebben mij in staat gesteld te studeren en me in mijn studie en mijn werk altijd gestimuleerd.

Aan het eind wan dit dankwoord wil ik opmerken dat ook bij het schrijven van een proefschrift de partner een belangrijke rol speelt. Paul, ik wil je bedanken voor de grote steun die je in al die jaren bent geweest. Met name je vertrouwen in de goede afloop van dit promotie-avontuur was voor mij belangrijk. 


\section{Contents}

\section{Dankwoord}

1

Introduction

2

Theoretical framework

2.1 Theoretical perspectives

2.1 .1

Exchange theory and health status

2.1 .2

Interaction theory and health status

$\begin{array}{ll}2.1 .3 & \text { Role theory and health status } \\ 2.1 .4\end{array}$

$\begin{array}{ll}2.1 .4 \text { Conclusion } & 20\end{array}$

2.2 Personal network 21

$\begin{array}{lll}2.2 .1 & \text { Size } & 22\end{array}$

$\begin{array}{lll}2.2 .2 & \text { Composition } & 22\end{array}$

$\begin{array}{lll}2.2 .3 \text { Content } & 23 \\ 2.2 .4 & \text { Reciprocity }\end{array}$

$\begin{array}{lll}2.2 .4 & \text { Reciprocity } & 24\end{array}$

$\begin{array}{lll}2.3 & \text { Health status } & 25\end{array}$

$\begin{array}{ll}2.3 .1 & \text { Dimensions with regard to impairment } \\ 2.3 .2 & 26\end{array}$

$\begin{array}{ll}\text { 2.3.2 Dimensions with regard to disability/handicap } & 27\end{array}$

$\begin{array}{ll}2.4 \quad \text { Coping, social position, and life events } & 28\end{array}$

$\begin{array}{lll}2.4 .1 & \text { Coping } & 28\end{array}$

$\begin{array}{ll}2.4 .2 & \text { Social position } \\ 2.4 .2 . & 29\end{array}$

$\begin{array}{lll}2.4 .2 .1 & \text { Gender } & 30\end{array}$

$\begin{array}{lll}2.4 .2 .2 & \text { Social class } & 30\end{array}$

2.4.2.3 Age 31

2.4.2.4 Marital status and family composition 31

2.4.3 Life events other than the onset of health deviation 32

$\begin{array}{ll}2.5 & \text { Network changes following health deviation } \\ 2.5 .1 & 33\end{array}$

$\begin{array}{lll}2.5 .1 & \text { Size } & 33\end{array}$

$\begin{array}{ll}2.5 .2 \text { Composition } & 34 \\ 2.5 .34\end{array}$

$\begin{array}{ll}2.5 .3 & 35 \\ 2.5 .4 & \text { Content }\end{array}$

$\begin{array}{lll}2.5 .4 & \text { Reciprocity } & 35 \\ 2.6 & \text { Discussion and hypotheses }\end{array}$

$\begin{array}{lll}2.6 & \text { Discussion and hypotheses } & 36\end{array}$ 
3.1 Sample and research procedures 40

3.2 Measurement instrument $\quad 45$

3.2.1 Personal network 45

3.2.2 Health deviation related questionnaire 46

$\begin{array}{lll}3.2 .3 & \text { Sickness Impact Profile } & 47\end{array}$

3.2.4 Utrecht Coping Questionnaire 48

3.2.5 Social position and life events 49

4 Description of the data 52

4.1 Social position $\quad 52$

4.1.1 Gender $\quad 52$

4.1.2 Social class $\quad 53$

4.1.3 Age $\quad 53$

4.1.4 Marital status $\quad 54$

4.1.5 Family composition $\quad 54$

4.2 Personal network 55

4.2.1 Size $\quad 55$

4.2.2 Composition $\quad 56$

$\begin{array}{lll}4.2 .3 & \text { Content } & 58\end{array}$

$\begin{array}{lll}4.2 .4 & \text { Reciprocity } & 60\end{array}$

4.2.5 Relation between the network variables 61

4.3 Health status 63

4.3.1 Sickness Impact Profile 64

4.3.2 Subjective health 66

4.3.3 Duration of the health deviation 67

4.3.4 Relation between health status variables 67

4.4 Coping 69

4.5 Life events $\quad 69$

$\begin{array}{lll}4.6 \text { Discussion } & 70\end{array}$

$5 \quad$ Health status and personal network 72

$\begin{array}{lll}5.1 & \text { Comparing healthy respondents' and patients' networks } & 73\end{array}$

$\begin{array}{lll}5.1 .1 & \text { Network size } & 73\end{array}$

$\begin{array}{ll}\text { 5.1.2 Network composition } & 73\end{array}$

5.1.3 Support and network reciprocity 75

$\begin{array}{lll}5.2 & \text { Comparing AS and Crohn patients' networks } & 77\end{array}$

$\begin{array}{lll}5.2 .1 & \text { Network size } & 77\end{array}$

$\begin{array}{lll}5.2 .2 & \text { Network composition } & 77\end{array}$

$\begin{array}{lll}5.2 .3 & \text { Support and network reciprocity } & 78\end{array}$

$\begin{array}{lll}5.3 & \text { Duration of the health deviation and personal network } & 79\end{array}$ 
5.3.1 Network size $\quad 80$

5.3.2 Network composition $\quad 80$

$\begin{array}{lll}\text { 5.3.3 Support and network reciprocity } & 81\end{array}$

$5.4 \quad$ Perceived disability level and personall network 83

5.4.1 Network size $\quad 83$

5.4.2 Network composition 84

$\begin{array}{lll}5.4 .3 & \text { Support and network reciprocity } & 85\end{array}$

5.5 Functional course and network changes $\quad 86$

5.5.1 Network size $\quad 86$

5.5.2 Network composition $\quad 86$

$\begin{array}{lll}\text { 5.5.3 Support and network reciprocity } & 87\end{array}$

$\begin{array}{llr}5.6 & \text { Discussion } & 89\end{array}$

$\begin{array}{lll}5.6 .1 & \text { Size } & 90\end{array}$

$\begin{array}{lll}5.6 .2 & \text { Composition } & 90\end{array}$

$\begin{array}{lll}\text { 5.6.3 Support } & 91\end{array}$

\begin{tabular}{ll}
5.6 .4 & Reciprocity \\
\hline 2
\end{tabular}

6 The effect of coping, social position and life events 93

6.1 Relation between coping, social position and life events 93

6.2 Relation between influencing variables and health status 94

6.3 Relation between influencing variables and network 95

6.4 Comparing healthy respondents' and patients' networks 98

6.4.1 Network size 99

$\begin{array}{ll}6.4 .2 & \text { Network composition } \\ 6.4 .3 & 100\end{array}$

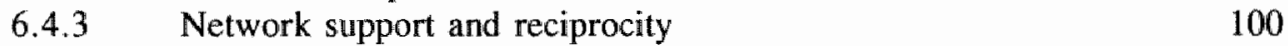

6.4.4 Summary $\quad 103$

6.5 Comparing AS and Crohn patients' networks 104

6.5.1 Network size 104

$\begin{array}{ll}6.5 .2 & \text { Network composition } \\ 6.5 .3 & 105\end{array}$

6.5.3 Network support and reciprocity 105

$\begin{array}{lll}6.5 .4 & \text { Summary } & 106\end{array}$

6.6 Duration of the health deviation and personal network 107

$\begin{array}{lll}\text { 6.6.1 Network size } & 107\end{array}$

$\begin{array}{lll}6.6 .2 & \text { Network composition } & 107\end{array}$

$\begin{array}{ll}\text { 6.6.3 Network support and reciprocity } & 107\end{array}$

$\begin{array}{lll}6.6 .4 & \text { Summary } & 109\end{array}$

6.7 Perceived disability level and personal network 110

$\begin{array}{lll}6.7 .1 & \text { Network size } & 110\end{array}$

6.7.2 Network composition $\quad 110$

6.7.3 Network support and reciprocity 111

$\begin{array}{lll}6.7 .4 & \text { Summary } & 112\end{array}$

$\begin{array}{lll}6.8 & \text { Functional course and network changes } & 113\end{array}$ 
$\begin{array}{ll}6.8 .1 & 113\end{array}$

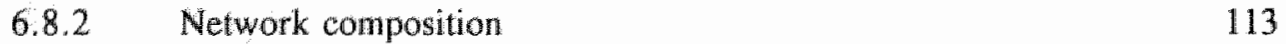

6.8.3 Network support and reciprocity 113

$\begin{array}{lll}6.8 .4 & \text { Summary } & 115\end{array}$

6.9 Discussion $\quad 115$

6.9.1 Size 115

$\begin{array}{ll}6.9 .2 \text { Composition } & 116\end{array}$

$\begin{array}{lll}6.9 .3 & \text { Support } & 117\end{array}$

$\begin{array}{lll}6.9 .4 & \text { Reciprocity } & 118\end{array}$

$7 \quad$ Summary, conclusion and discussion 119

$\begin{array}{lll}7.1 & \text { Summary } & 119\end{array}$

7.2 Evaluation of the study 121

7.2.1 Comparing healthy persons' and patients' networks 121

$\begin{array}{ll}7.2 .2 & \text { Comparing AS and Crohn patients" networks } \\ & 122\end{array}$

$\begin{array}{lll}7.2 .3 & \text { Duration of the health deviation and personal network } & 124\end{array}$

$\begin{array}{lll}7.2 .4 & \text { Perceived disability level and personal network } & 125\end{array}$

$\begin{array}{lll}7.2 .5 & \text { Functional course and network changes } & 126\end{array}$

7.2.6 The relative strength of the relation between health status

$\begin{array}{lll}7.2 .7 & \text { Conclusion } & 128\end{array}$

7.3 Theoretical considerations 131

$\begin{array}{lll}7.4 & \text { Methodological considerations } & 133\end{array}$

$\begin{array}{lll}7.4 .1 & \text { Sample } & 133\end{array}$

$\begin{array}{ll}\text { 7.4.2 Procedure } & 133\end{array}$

$\begin{array}{lll}7.4 .3 & \text { Measurement instrument } & 134\end{array}$

$\begin{array}{lll}7.4 .4 & 135\end{array}$

$\begin{array}{ll}7.5 & \text { Practical implications } \\ & 135\end{array}$

7.6 Recommendations with regard to further research $\quad 136$

$8 \quad$ Samenvatting, conclusie en discussie 137

$\begin{array}{lll}8.1 & \text { Samenvatting } & 137\end{array}$

8.2 Evaluatie van het onderzoek 139

8.2.1 Vergelijking netwerken van gezonden en patiënten 139

8.2.2 Vergelijking netwerken van AS- en Crohnpatiënten 141

8.2.3 Duur van de afwijking van gezondheid en het persoonlijk netwerk 142

8.2.4 Ervaren niveau van dysfunctioneren en het persoonlijk netwerk 143

8.2.5 Beloop van het functioneren en veranderingen in het netwerk 145

8.2.6 De relatieve sterkte van het verband tussen gezondheidstoestand

8.2.7 Conclusie 
8.3 Theoretische overwegingen $\quad 150$

8.4 Methodologische opmerkingen 152

8.4.1 Respondenten 152

$\begin{array}{lll}\text { 8.4.2 Procedures } & 153\end{array}$

$\begin{array}{lll}\text { 8.4.3 Meetinstrument } & 153\end{array}$

$\begin{array}{ll}\text { 8.4.4 Gegevensverwerking } & 154\end{array}$

$\begin{array}{lll}8.5 & \text { Praktische aanbevelingen } & 155\end{array}$

8.6 Aanbevelingen voor verder onderzoek 155

$\begin{array}{lr}\text { References } & 157\end{array}$

$\begin{array}{lr}\text { Appendices } & 162\end{array}$

$\begin{array}{ll}\text { Curriculum vitae } & 176\end{array}$ 



\section{Introduction}

In recent years, the relationship between personal networks and health status has attracted considerable attention. In part this has focused on whether there is a positive relationship between social support and health status. It is hypothesized that social support protects people from health deviation' or, when a person suffers a health deviation, social support is positively related to more favorable outcomes of the health deviation. Less attention has been given to the reverse relationship: what changes occur in personal networks and social support as a result of (chronic) health deviation?

It is known that the personall network is subject to changes; the number of relationships can increase or decrease and the intensity and frequency of a certain relationship can change. Normally a person's network changes gradually, but sometimes the changes take place quickly and are more profound. This sort of change is usually the result of a life event, such as the onset of a chronic somatic health deviation.

The development of a chronic somatic - disabling - health deviation causes many changes in the individual and affects his/her relationship with his/her environment. The person is altered in all aspects of his or her being, not only physically but also socially and behaviorally. He or she is no longer able to perform several roles, tasks and responsibilities and becomes dependent on other persons who take these over. The patient becomes more and more dependent on other persons while becoming less capable of meeting other persons needs. This goes for kin and colleagues as well as for friends and neighbors.

The aim of the present study is to gain more information about the development of dependency balances and the structure and function of personal networks of chronic somatic patients. It would be interesting to map network changes following the onset of the health deviation. However, this demands a research design with a large number of healthy respondents whose personal networks and health status have to be assessed over a longer period. Probably, some of them will develop a health deviation during this period, so changes in personal network following the

This book uses the concept of health deviation (Orem, 1985) throughout whenever we refer to disease, illness and sickness in general (see section 2.3). 
onset of the health deviation can be mapped. Such a design would demand considerable amounts of time and money and therefore it is hardly feasible. That is the reason why we chose to study persons that already have a disease and to map their network changes along with changes in their health status. This objective was formulated in terms of the following question:

a. What changes occur in personal networks of people whose dependency on other persons increases following a disease?

Personal relationships are characterized by an emotional and instrumental dimension. The emotional dimension concerns, for instance, understanding, trust, love, security. The instrumental dimension concerns practical aid, such as financial aid or housekeeping. Both aspects will be present in a relationship, but not to the same degree. That is the reason why we are interestedl in the following question:

b. To what extent do the changes in the personal network of the patient occur equally for the predominantly instrumental relationships and the predominantly emotional relationships?

Furthermore, diseases differ in the impact they have on a person's life. A serious, disabling, life-threatening disease probably will have a more profound impact on a person's life and as such on his or her personal network than a less serious disease that is also less disabling and not life-threatening at all. Hence account has been taken of the following question in this study:

c. To what extent are the changes in the personal network of the patient related to the niature of the disease?

Finally, to get an idea of the changes in the personal network following the onset of a disease, patients may be compared to healthy persons. Thus, the last research question in this study is as follows:

d. To what extent do personal networks of patients differ from those of healthy persons?

To answer these questions the investigation has been divided in two parts, firstly a transwersal study and secondly a longitudinal study.

The transversal part consists of a comparison of the personal networks of two groups of chronic patients and the networks of a group of healthy persons. The purpose of this part of the study is to map the respondents' networks and relate the network characteristics to the respondents' health status.

The purpose of the longitudinal part of the study is to map the changes in the 
personal network of the patient that take place as a result of (changes in) the health status following the first measurement. Data were collected half a year and a year after the first measurement.

The conceptual model used in both the transversal and the longitudinal parts of the study is presented in figure 1.1.

The core concepts in the model are health status and personal network. Personal network is presented as the dependent variable, health status as the independent. As already stated, the reverse relationship can also exist. Because the latter relationship is not part of this study, the relevant arrow has been omitted from the model.

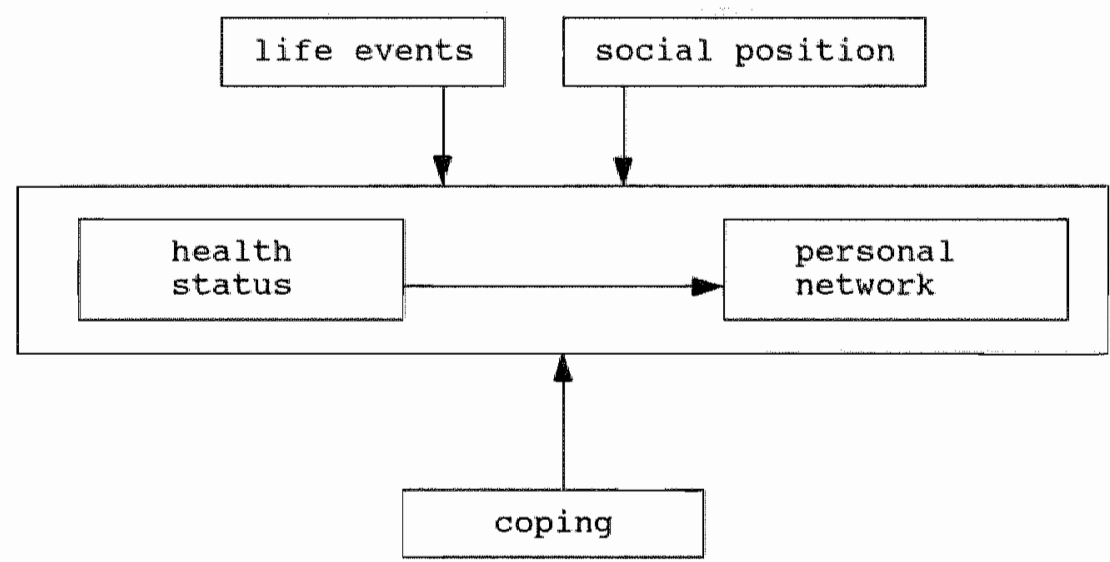

Figure 1.1 Conceptual research model

Furthermore the model contains three concepts that have not been referred to in the preceding text, namely, coping, life events and social position. These are all factors which may have an effect on the relation between health status and personal network and therefore must be taken into account. Their role with respect to the relationship between health status and personal network will be discussed in chapter 2.

Chapter 2 also contains a description of the theoretical framework used in this study, a description of the concepts in the research model and an overview of studies conducted by other researchers with regard to health status and personal network.

In chapter 3 the research design and instrument are described, followed in chapter 4 by a description of the data.

Chapters 5 and 6 contain the analyses with regard to the research hypotheses as formulated in chapter 2 . Chapter 5 presents the analyses with regard to the relation between health status and personal network; Chapter 6 discusses the influence of 
coping, life events and social position on this relation.

Chapter 7 provides a summary of the major findings of the study together with some theoretical and methodological considerations.

Respondents are referred to as he and him with a view to ease of reading, but it should be made clear that many of the participants were female. 


\section{Theoretical framework}

This chapter focuses on the relationship between health status and personal network. We will discuss some theoretical perspectives concerning changes in network structure and function following a chronic somatic health deviation. Subsequently, the concepts personal network and health status will be elaborated followed by those of coping, social position and life events. A review will be given of what is already known about the relationship between health status and personal network with regard to network changes following somatic health deviation.

\subsection{Theoretical perspectives}

In sociology, anthropology and psychology many theoretical perspectives have been developed that can be applied to the study of personal networks. These theories can be divided into:

- theories that explain network structure and predict network changes by the structure of the network, for instance, transitivity theory (Davis and Leinhardt, 1972; Leinhardt, 1973); and

- theories that try to explain network phenomena with the help of the nature of the relationships between network members (e.g. Fischer, 1977).

With respect to the research questions - network changes in view of the function of the relationships - it is the latter type of theories that is of interest to this study. A review of the literature indicated three theories frequently mentioned in relation to network (changes):

- exchange theory (Tilden, 1985; Cohen and Syme, 1985; Fischer, 1977; Kapferer, 1973);

- interaction theory (Fischer, 1977; Mitchell, 1969), comprehensively discussed by Adams (1967) with regard to social networks;

- role theory (Fischer, 1977; Whitten and Wolfe, 1974; Chrisman, 1969).

These theories form the theoretical framework for our study and will be discussed with respect to (chronic) somatic health deviation in the following subsections. 


\subsubsection{Exchange theory and health status}

Generally, exchange theory depicts social life as bargaining and negotiating with the emphasis on resources, costs, and rewards. In the exchange process, relationships are established that involve mutual trust and an interlocking selfinterest (Warshay, 1975).

In this section we will discuss two theoretical perspectives which are related to exchange theory: dependency balances and social capital.

With respect to the idea of dependency balances this study follows de Swaan's (1982) description of dependency balances. In common with other authors, de Swaan regards people as nodal points within a network of dependency relationships. These dependency relationships develop during the life course, whereas children and the elderly are more dependent on others than vice versa, and the adult's relationships are more or less in balance.

The development of a chronic health deviation causes many changes in the individual and affects his relationship with his environment. The person is altered in all aspects of his being, not only physically but also socially and behaviorally. He becomes dependent on other people. As long as that dependence involves a satisfactory degree of reciprocity, namely, others also being dependent on the patient, their situation does not differ from that of any other person. Without such reciprocity, however, the patient becomes more and more dependent and the existing equilibrium of the dependency balance is disturbed. In case of a somatic health deviation, this is especially the case for the interactions characterized by instrumental exchange (see 2.2.3). Because the patient will be less capable of reciprocating those exchanges, the expressive aspects of his relationships with others will become more important in maintaining such relationships. If the patient is not capable of giving a new content to relationships based on instrumental exchange, he will mean less to the members of this network, who at first were dependent on him for their needs. Because the patient is no longer capable of fulfilling their needs, they search for other persons with whom they enter into new dependency relationships. They will no longer need the patient. This applies to colleagues, family members, friends, and others. The more severe the health deviation is, the less the patient can care for other persons and for himself. A great part of the care for the patient is provided by members of his network who are not paid for that care. The patient becomes an obligation on his environment. When the health deviation becomes worse, the expectation disappears that the delivered care will ever be repaid. In this respect the idea of social capital seems important.

The idea of social capital is based on the notion that people do not give their goods to others just for pleasure, but also with a view to future compensation, according to the expected value of future help (Coleman, 1988; Flap, 1987). Health deviation influences the mechanism of social capital: if the patient becomes 
dependent on others, they have to invest more in the patient while at the same time the expected future value diminishes. The patient depends on the willingness of others to give more than they receive in their relationship with the patient, and on their willingness to prolong the timespan in which they want to receive from the patient. In the case of chronic health deviation the period during which the equilibrium is disturbed is longer, and, following the discussion about social capital, those relationships in which the patient has less credit will probably fade. The way in which people determine the future value of a relationship is as yet unknown. It is expected to be dependent on the type of the relationship. It has been proved that in business and friendship relationships the direct costs and the future value of the relationship are important indicators of stability (Rusbult, $1980 \mathrm{a}, 1980 \mathrm{~b}$ ). Relationships with kin are mostly maintained even if there is no future value, even if the investments are high (Ikels, 1988). This solvency might be explained by the type of interaction the patient and his network member are linked by. Knipscheer (1980) makes a division between kin ties and achieved ties. Relatives are gained by birth and they feel an obligation to maintain the relationship. Contacts with achieved ties, like friends and neighbors, are less durable. If exchanges with achieved relationships are not reciprocated, the relationship may fade, because most people do not like only to receive or only to give (Knipscheer, 1980; Joosten, van der Horst and de Witte, 1986). In this regard we can distinguish balance reciprocity (Willer and Anderson, 1981), found in achieved relationships, and the general reciprocity (Tietjen, 1985) that is found in the relationships with relatives. Balance reciprocity means that if a person invests in a relationship this investment is expected to be paid back within an acceptable period of time. General reciprocity means that the time span in which received investments must be paid back is very long, if not infinite (Knipscheer, 1980; Joosten, van der Horst and de Witte, 1986).

The types of interaction are discussed extensively in the next section.

\subsubsection{Interaction theory and health status}

The individual's personal network consists of those persons with whom he maintains contact and has some form of social bond. Theories of interaction involvement usually begin with a posited relation between affection and interaction. A second social psychological attribute of social relations is consensus, or the sharing of common values, interests, and attitudes. Secord and Backman (1964) reported tendencies to be attracted to those with attitudes similar to one's own, or to distort modest similarity in the direction of greater congruence when there is a strong affectional bond. Besides relationships based on consensus and affection, Homans (1961) recognized that there may be frequent interaction without liking: the obligatory relationship. 
An approach important to the concepts of consensus and obligation is the distinction between Gemeinschaft and Gesellschaft, or between mechanical and organic solidarity as bases for societal integration (Durkheim, 1933). Gross (1956) labels these two types of interpersonal integration principles symbiosis and consensus. Symbiosis is a relation of interdependence, a relation based upon common need. As long as the need persists, the symbiotic tie remains. A consensual tie is based upon agreement, upon common values. A disharmony will break up a consensual group, and a change in attitude, lessening consensus likewise weakens consensual relationships.

Adams (1967) discussed interaction theory in relation to the social network. He argues that consensus does not account for all positive or attractional social relations; with obligation-symbiosis as an additional, but constraining, factor. $\mathrm{He}$ argues that 'obligation and need, when coupled with long-term involvement and continuing interest, evolves into a positive or affectional force": positive concern. He argues that affectional or positive concern is the dominant characteristic of intimate kinship, and consensus and affection the essence of close friendship.

Consensus ranges from one or a few shared activities, in which case involvement is mild, to a basic similarity of values or attitudes and interests, which would seem to provide for considerable interpersonal attraction. Concern is an affectional force, ranging from a vague sentiment that contact ought to be maintained with an individual, in which case attraction is relatively mild, to a combination of mutual aid potential and desire for frequent contact, which indicates intense emotional involvement and affectional closeness. Consensus and concern are not empirically mutually exclusive, but are found in differing degrees in the same social relationship. The closest social relationships are likely to be those in which both consensus and concern are strong, as, for example, relations between children and parents. Those social relationships in which the positive concern component is strong are most likely to persist in spite of complications of time, space, or social position. Since this component is frequently strongest in relations with members of one's own family, particularly parents, these are the social relations which manifest the greatest persistence. The least persistent relationship is apt to be the one in which concern is minimal and in which the primary activity occurs without a basic value consensus (Adams, 1967).

From the point of view of interaction theory we can argue that relationships with intimate kin and close friends will persist following the onset of a somatic health deviation, because affection, positive concern and consensus are strong. The relationships with effective and nominal kin, and non-kin network members other than close friends are more likely to change or fade following a health deviation, because positive concern and consensus are probably less strong. Especially those relations which are based on consensus, in the sense of a few shared activities, will change or fade, because the patient may no longer be able to perform all the activities he used to perform, particularly in the case of a disabling health 
deviation. When the activity the relationship was based on no longer exists, there is a great likelihood that the person's network member searches for someone else with whom he can engage in that activity and as a result his contact with the patient fades.

\subsubsection{Role theory and health status}

A role consists of the total of norms and expectations people have of persons in a certain situation. An individual can be seen as a performer of several roles, e.g. spouse, neighbor, colleague. One behaves towards others on the basis of the role that is central at the moment.

Role is probably one of the most important determinants of interpersonal relationships: via his roles the individual manipulates his network of social relationships. By initiating a new role, the individual may establish several new relationships, or by ending a role he may free himself of several old ones (Holzhauer and van Minden, 1985; Boissevain and Mitchell, 1973).

When a person suffers a health deviation - depending on the nature of the health deviation and the type of roles he performs - he will no longer be able to perform several of his roles.

There are two characteristics of the health deviation which are important to role performance: severity and duration of the deviation.

Severity of the health deviation can be expressed in the degree to which it is disabling. When a health deviation is not disabling, the person is capable of fulfilling his roles, and as such his relationships with other persons will not be affected. However, the more disabling the health deviation, the more aspects of the individual's roles will be affected. As a result the individual's roles change or must be taken over by someone else. For instance, a person, employed to lift heavy materials, will have to quit his job the moment that he gets a hernia. As a result he loses his role as a colleague and his relationships with his (ex-)colleagues will fade (away).

Duration of the health deviation is important, because in the case of a temporary health deviation, the patient is only temporarilly unable to fulfill his role obligations, and once the health deviation has passed, he will probably revert to his 'old' roles (Walker, MacBride and Vachon, 1977). In the case of chronic health deviation, however, the change in roles will probably last forever.

In relation to role theory, the concept of the sick role is important. Parsons (1951) formulated sick role as a system of institutionalized expectations associated with health deviation. The first such expectation is defined by Parsons as 'exemption from normal social role responsibilities". The second aspect is that the person cannot 'help' his condition and, therefore, must be 'taken care of'. The third element is the definition of the state of being ill as itself undesirable, with its 
obligations to "want to get well". Finally, the fourth element is the obligation - in proportion to the severity of the condition - to seek technically competent help, namely, in the most usual case, that of a physician, and to co-operate with him in the process of trying to get well.

From the above description of the sick role, we can draw the conclusion that the patient not only loses some roles or some aspects of his roles, but also gets a new role in which he builds new relationships with health professionals (patient role). As performer of the sick role, the patient will probably also come into contact with other patients, with whom he will have a more or less strong relationship.

Role theory can be used to explain changes in a person's network by changes in roles that person performs. When the person endures a (chronic) health deviation, his roles and the roles of the other persons he is involved with will be affected and as such his personal network.

\subsubsection{Conclusion}

In the preceding sections three theories were discussed that may be applied to explain changes in network structure and function following health deviation. In this section we will describe some hypothetical ideas we derived from these theories. The final hypotheses are presented in section 2.6.

More serious health deviation results in temporary or permanent loss of physical, psychollogical and/or social function. Several roles, tasks and responsibilities can no longer be performed by the patient, and have to be taken over by other persons (Bruhn, 1977; Walker, MacBride and Vachon, 1977; Vincent, 1963). This results in a disturbance of the existing dependency balance and the more serious the health deviation, the greater the chance that the role-relations will be affected (Jaco, 1979; van Eijk, 1980; Bruhn, 1977). According to exchange theory, the disequilibrium in the dependency balance will weaken some relationships and in the longer run some of these relations will fade away. We can argue that

following a chronic health deviation

- the patient gives less and receives more support, and as a result

- the network becomes less balanced, and therefore

- the number of members in the patients' network decreases

depending on the degree to which the health deviation is disabling.

In section 2.1 .2 we saw that those relations in which positive concern is strong are most likely to persist in spite of complications of time, space, or social position. Adams (1967) states that positive concern is frequently strongest in relations with members of one's own family. In this respect we argue that 
following a chronic healih deviation

- the person's network will contain relatively fewer non-kin informal network members

depending on the degree of functional disability.

Finally we would affirm that besides changing or disappearing relationships there will be new relationships. The patient becomes more dependent on other persons. In the case of lasting health deviation, health care professionals like physicians and nurses will take over some roles, tasks and/or responsibilities of the patient. These health care professionals become part of the patient's network. In this regard we refer to Parson's (1951) concept of the sick-role, described in section 2.1.3.

Following a chronic health deviation

- the person's network will contain health care professionals.

The hypothetical ideas presented in this chapter will be elaborated in section 2.6 . At first we will elaborate the concepts of personal network and health status.

\subsection{Personal network}

The concept of network implies points and links between these points. Mitchell (1969) defines a social network as: 'a specific set of linkages among a defined set of persons, with the additional property that the characteristics of these linkages as a whole may be used to interpret the social behavior of the persons involved'. He stresses that the social network as a whole is hard to study and there is a need to define that part of the network one is interested in. Barnes (1979) calls this a partial network. In the case where the totality of social relationships of one focal person is concerned, Barnes no longer speaks in terms of social networks, but he uses the concepts of zones and stars. He distinguishes primary stars and zones, secondary, tertiary, and so on. The primary star consists of all persons who are involved in a direct relationship with the focal person. The primary zone consists of the primary star including the relationships between all persons within the primary star. Other authors, among whom Bott (1971) and Mitchell (1969), use the concept of personal or ego-centered network when the individual is taken as the focal point. The personal network is defined as: 'a flexibly bounded grouping of individuals comprising at least a focal person, everyone the focal person knows or interacts with, the set of relationships between those individuals and the focal person, and the set of relationships that exists independently of the focal person" (Erickson, 1975).

There is a distinction between structural and functional network characteristics (see: Mitchell, 1969; Tolsdorf, 1976; Walker, MacBride and Vachon, 1977; 
Ormel, 1984). Structural characteristics act as a means to discover network patterns: anchorage, size, composition, reachability or dispersion, density and homogenity. Functional network characteristics refer to the nature of the links that join people together: content, reciprocity, intensity, frequency and durability. Of these characteristics network size, composition, content and reciprocity are most important with regard to the theoretical framework described in section 2.1 and are discussed in the following subsections.

\subsubsection{Size}

The size of a personal network is the number of persons with whom an individual maintains social contact. Because a personal network may contain 1000-2000 persons (Boissevain, 1974), in network research, its size is usually delimited with the help of certain criteria like contact frequency between network members or network sector (see section 2.2.3). Network size is only meaningful when the relational characteristics for deciding who belongs to the network and who does not have been clarified (van Sonderen, 1989).

Burt (1986) states that larger networks contain more especially close relations compared with smaller networks, while at the same time they contain more less close relations. He concludes that closeness neither decreases nor increases with network size. Thus we might conclude that the effect of health deviation on network size will be the same for smaller and larger networks. On the basis of interaction theory, however, the effect of health deviation on network size in case of a larger network is expected to be greater than the effect on small networks. Because in an absolute sense the larger network contains more less close relations than a smaller network, it may be expected that there are more relationships that fade following health deviation.

\subsubsection{Composition}

The personal network is usually divided into several 'sub-networks', by means of differences in structure and function of the several linkages in the network. A division in network groups that is often referred to in network literature, is that of Litwak and Szelenyi (1969). They distinguish neighborhood, kin, peer and nuclear family group (i.e. husband, wife and young children). Firth and Djamour (1956) further subdivide the kin group into intimate kin (with whom contact is frequent, attachment is strong and communication is open), effective kin (contact is maintained, but attachment and communication are relatively shallow), and nominal kin (known to exist, but with whom contact and involvement are minimal or non- 
existent). Bott (1971) states that the more distant the relative; the more objective differences receive consideration and determine involvement.

Mann (1954) further subdivides the neighborhood group into manifest and latent neighbors. Manifest relationships with neighbors are said to be comparable with friendship rellationships; latent neighborhood relationships have a kind of friendliness without actual contact, but with the possibility of assistance.

Litwak (1985) divides friends into short-time friends (those who have been friends less than three years), intermediate friends (friends for $3-20$ years) and long-term friends (friends longer than 20 years).

Neighborhood, kin, friends and nuclear family group are referred to as primary group networks. In contrast to these primary groups, Litwak (1985) distinguishes formal organizations, including all people who are paid for their help (e.g. physician, nurse). Primary group networks are usually referred to as the informal network, formal organizations as the formal network (Jaco, 1979; Bott, 1971; Litwak, 1985).

The divisions made in this section are not static: neighbors may become friends, friends may become relatives through marriage, and relatives may become friends.

According to the theories discussed in section 2.1 the non-kin informal network will decrease following a health deviation. On the basis of role theory, we may add that formal network members (e.g. physician, nurse) become part of the network.

\subsubsection{Content}

Social relationships are usually directed at a certain goal or interest. Their content consists of the meanings the persons in the network give their relationships in virtue of characteristics the other person possesses or the exchange content (Jaco, 1979).

The links between the individuals are distinguished by the normative context in which interaction takes place (discussed in sections 2.1.2 and 2.1.3), kinship, friendship, and so on (see 2.2.2), or by the exchange content, referred to in section 2.1.1 and further elaborated in the definition of social support: support accessible to an individual through social ties to other individuals, groups and the larger community (Lin, Dean and Ensel, 1981), usually divided into emotional and instrumental support (e.g. Dean and Lin, 1977).

Litwak and Szelenyi (1969) describe the structure and function of kin, friends, neighbors and the primary family group. It is argued that neighbors have a function in emergency situations and all those services which are based on people living in the same territory, because they live at a small geographic distance. The kin group comprises people related in semi-permanent biological or legal ways. 
Because of the permanence they can help best where the task involves long-term ties. Peer group contacts are neither permanent nor face-to-face, and have affectivity as their major base of strength. Friends can best handle matters involving continuous fluctuation. Contacts within the nuclear family group are face-to-face, permanent, and affective, but because of the limitation in size, the nuclear family group is not able to handle crucial problems.

With regard to Dean and Lin's (1977) distinction between relationships that are predominantly instrumental and those that are predominantly emotional, the concepts of uniplexity and multiplexity are important. These concern the extent to which relationships involve more than one type of content (Tolsdorf, 1976). Relatives in general perform both instrumental and emotional functions, with an emphasis on emotional aspects (Mootz, 1981; van Agthoven, 1985). Van Agthoven (1985) furthermore found that neighbors performed an instrumental role (related to housekeeping), and friends a psycho-social, emotional role. The three most common intimate or confiding relationships are those of spouse, close family, and friends. These also seem to be utilized most extensively for discussion of different types of problems (McFarlane, Neale, Norman, Roy and Streiner, 1981). Spouses tend to be the first discussion partner cited (Burt, 1986).

Usually it is assumed that multiplex relations are more enduring, supportive, and intimate, because they provide more exchanges (e.g. Boissevain, 1974). We therefore argue that relationships that are emotional as well as instrumental have a greater chance of continuity following health deviation than relationships that are only emotional or only instrumental. Furthermore, in the light of the discussion in section 2.1, we expect that, following somatic health deviation, instrumental relationships are more likely to fade than emotional relationships, because it will probably be the instrumental content of the relationship that is most frequently affected by the health deviation.

\subsubsection{Reciprocity}

As stated in section 2.1.1, many authors have noted that social support is not supplied without reciprocal obligation. Both giving and receiving support usually involve implicit expectations of reciprocity, and costs of time, energy, services, or goods are mentally catalogued for later interactions. It is stated that achieved relationships (e.g. friends, neighbors) may fade if they are not reciprocated, because most people do not like only to receive or only to give. In this regard we discussed the concepts of balance reciprocity and general reciprocity. For a more extensive discussion see section 2.1.1.

Networks with reciprocal links are associated with a greater degree of perceived support (Maxwell, 1982). Reciprocity occurs more within informal relationships 
(kin, friends, neighbors) than within formal relationships (with professionals) (Tilden, 1985). McFarlane, Neale, Norman, Roy and Streiner (1981) found that reciprocity of relationships seemed to be most prevalent among married people.

From this discussion we can formulate the following expectations.

- The patient's relationships with non-kin network members fade if he is not able to reciprocate support he receives.

- The greater the amount of reciprocity, the greater the degree of perceived support.

- Informal relations give more support than formal relations.

\subsection{Health status}

In defining health status it is prudent to pay attention to both health as well as health deviation. Several definitions of the health concept may be found in literature, e.g. health as the absence of illness and disease, health as strength, health as functional fitness (Williams, 1983), 'health as the state of optimum capacity of an individual for the effective performance of the roles and tasks for which he has been socialized" (Parsons, 1958). It shows that the health concept can be defined objectively, subjectively and socially (see Joosten, 1989 for a more extensive description). The same applies to the definitions of health deviation, described by Philipsen (1969), who distinguishes four meanings of the concept of health deviation:

- health deviation as the presence of a disease, which can be objectively diagnosed;

- health deviation as the state of feeling ill, taking the subjective feelings of a person as central point: in exceptional cases one can be ill without having a disease;

- health deviation as help seeking behavior: seeking help of for instance medication or physician;

- health deviation as the unfitness to perform normal roles (e.g. work, school) implying acceptance of the patient role (see 2.1.3 Parson's concept of the sick role).

In a study of the quality of life of chronic patients, Strauss (1975) found that these patients adapt their definition of good health to their physical capacities. Therefore, with respect to chronic health deviation it seems important to define health status in a way in which functional ability is part of the definition. A definition frequently used in present-day research that incorporates functional ability is the one devised by the World Health Organization: the International Classification of Impairments, Disabilities and Handicaps (ICIDH). This classification is not based on diseases, but on the consequences of disease or accident. Impairments are defined as the absence or deviation of a psychologic, 
physiologic, or anatomic structure or function. Disabilities are deficits in action or skills. In the case where impairments and/or disabilities put someone in a socially disadvantageous position, or hinder his normal role-performance; they become a handicap (Dechesne, 1985).

Describing health status in terms of impairment, disability and handicap brings into focus the fact that there are several health dimensions we must take into account in studying network changes following chronic health deviation (Verwoerdt, 1972; Moos and Tsu, 1977). These dimensions can be ordered with respect to impairment and disability and handicap, and are described in sections 2.3 .1 and 2.3.2.

\subsubsection{Dimensions with regard to impairment}

Four dimensions can be distinguished that are important with regard to impairment:

\section{extent to which the impairment is life-threatening}

Life-threatening disease leads to interactional awkwardnesses (e.g. about talking of potential death) that increase the potential for lessened contact (Strauss, 1975), thus affecting the patient's network.

\section{the rate of progression of the impairment in the course of time}

Slowly developing conditions allow more time for adaptation compared with rapidly progressing impairment (Verwoerdt, 1972). It can be argued that slowly developing impairments are accompanied by slow changes in roles and dependency balances, thus giving the patient and his network members more time to adapt to these changes and to give their relationships a new content. Therefore, there is a greater chance that these relationships will be continued over time compared to rapidly progressing impairments.

\section{localization of the effects: hidden or within sight}

When the patient's symptoms are invisible or the fact of his disease is unknown to others, then he has the option of 'passing', that is, he can engage in normal interaction because nobody will define him as nonnormal (Strauss, 1975; Philipsen, 1970). When symptoms are visible the normal role expectations are affected and through labeling may lead to stigmatization (Philipsen, 1970). We may therefore expect that if impairment symptoms are visible the relationships with other persons are more affected than if symptoms are hidden, and thus lead to more network changes following impairment. 


\section{degree of dependency on medical technology/hospitalization}

As argued in section 2.1, chronic thealth deviation leads to changes in dependency balances between the chronic patient and his network members, and changes in roles. Roles must be reallocated, a new balance must be established. Hospitalization of the patient will again disrapt normal relationships with kin and non-kin (Moos and Tsu, 1977; Davidson and Young, 1985; van Eijk, 1980; Jaco, 1979; Thompson and Haran, 1984), thus leading to - temporary - network changes (e.g. contact frequency, social support).

\subsubsection{Dimensions with regard to disability/handicap}

With regard to disability/handicap three dimensions may be distinguished:

\section{the degree of functional disability}

As already argued in section 2.1 , a chronic patient who is not functionally disabled may continue to perform his roles, tasks and responsibilities. However, the more the patient is functionally disabled, the less he will be able to continue normal role-performance, and the more dependent he will become on other persons. Also opportunities for social interaction are often limited by inability to get to places where people meet (Coulton, 1979; Davidson and Young, 1985). This has led us to assume that the more functionally disabled the chronic patient, the greater the implications of his disease on his personal network, entailing not only changes in existing relationships, but also the entrance of professionals into the network.

\section{duration of the functional disability}

This dimension was also discussed in section 2.1, where it was averred that duration of the health deviation is related to permanence of role changes. Furthermore it was related to the two principles of exchange: balance reciprocity and general reciprocity. We have argued that in the case of long lasting disability, those relationships based on balance reciprocity fade, because investments made by the patient's network member cannot be expected to be paid back within an acceptable time period. Duration of disability is then expected to be related to network size and composition.

\section{age at which the disability occurred}

Here we refer to section 2.4 where life-cycle variations in patterns of close relationships are described. In the early years of life, the child begins to operate almost exclusively within the confines of the family. As he grows up, his spheres of relationships grow, yet he remains firmly rooted within the family. With the approach of adolescence, the importance of the peer group increases and he becomes linked to new non-kin relationships (Shulman, 1975). From this we 
deduce that when impaiment occurs in adolescence and is accompanied with functional disability the process of making non-kin relationships will be affected. Because of the disability the adolescent will not be able to engage in several social activities (e.g. sports, going out) and as such has less opportunity to make contacts with non-kin. His network will probably be one where kin relationships predominate.

In cases the impairment occurs in a later stage of the life-cycle, when the person has had the opportunity to develop his network in a 'normal' way, the changes which occur following impairment will depend on network structure and function (as discussed in the preceding sections).

In sections 2.2 and 2.3 the concepts of personal network and health status were discussed. Before giving a review of what is already known about the relationship between these two concepts with regard to network changes following health deviation, it is necessary to describe the concepts of coping, social position and life events, mentioned in chapter 1 as possibly influencing the relationship between health status and personal network.

\subsection{Coping, social position, and life events}

In the literature, there are a number of concepts frequently mentioned as influencing personal networks as well as health status. In studying the relationship between health status and personal network it seems obvious to pay attention to these influencing variables: coping, social position, and life events. In the following subsections these concepts are discussed with regard to their role towards the relationship between health status and personal network.

\subsubsection{Coping}

Coping can be defined as the ways in which people handle life-strains (Lazarus, 1977; Pearlin and Schooler, 1978). Pearlin and Schooler (1978) distinguish three types of coping:

- elimination or modification of conditions giving rise to problems;

- perceptually controlling the meaning of experience in a manner that neutralizes its problematic character; and

- keeping the emotional consequences of problems within manageable bounds.

Individuals employ complex combinations of these types to cope with stress (Lazarus, 1977; Schreurs, Tellegen and van de Willige, 1984).

Wortman (1984) mentioned coping style as a characteristic of the stressed person that may be an important factor in whether one receives social support from his 
network members. Billings and Moos (1981) found that people who used avoidant coping reported having fewer social resources. In their study of correlates of social support receipt, Dunkel-Schetter, Folkman and Lazarus (1987) found that individual's ways of coping appeared to be associated with all types of social support received. They distinguish problem-focused and emotion-focused coping. Use of problem-focused coping in stressful episodes was associated with more informational support, assistance and emotional support. More sources of support were reported in situations in which subjects coped by seeking support. Emotionfocused coping was associated with less social support. The authors argue that the way an individual copes in a stressful situation may provide cues to members of his or her personal network regarding the person's needs and desires for support and they conclude that members of an individual's network are responsive to the ways an individual copes.

These findings show that coping influences the amount of support an individual receives in experiencing life-strains as well as the number of network members providing support. We thus expect that different ways of coping with chronic health deviation will lead to differences in experienced support and therefore include coping in our study.

\subsubsection{Social position}

There have been several studies investigating the relationship between sociodemographic characteristics and the structure and function of personal networks. Personal networks would appear to be affected by gender, social class, and life-cycle stage as determined by age, marital status and family composition. The concept of social position is used in the model to indicate the interrelatedness of these characteristics. Together they determine the individual's position in society and, as such, the access the individual has to social resources. Gender and age for instance are related to marital status and family composition. These in turn are related to the presence of such social resources as spouse, children and family in-law. In this section the relation between each characteristic and the personal network is described. Furthermore attention is paid to the role of these characteristics towards network changes and support following health deviation. We note that the characteristics listed are also related to health status, but since our main interest is in studying network changes following health deviation (taking the role of influencing variables into account) we pay no further attention to the relationship between social position and health status. 


\subsubsection{Gender}

We can distinguish several aspects with regard to the relationship between gender and network (changes). In the first place, McFarlane, Neale, Norman, Roy and Streiner (1981) found that the personal network of healthy persons consisted of about nine people, but waried in composition due to sex. Women's networks were composed of more family and neighbors than men's, while men reported more work-related individuals. It is likely that this difference in composition may lead to a difference in network changes following health deviation. In the light of the discussion in section 2.1 we might expect that women's networks decrease less following health deviation than men's, because of the difference in the number of family members in the network.

In the second place, Vincent (1963) found that when the husband is ill, his wife will add his care and some of his father-performance tasks to her own performance-tasks, while the wife cannot depend on her husband to take care of her, or to assume any of her mother-housekeeping tasks (see also Jaco, 1979; van Agthoven, 1986). This leads to the conclusion that in the case of women being ill, the help of a professional caregiver will be called upon sooner than in the case of men's illness. This is supported by Verhaak, van Busschbach and Kortenhoeven (1985) who find that women receive more professional care than men. We therefore expect that the number of professional network members in women's networks will be greater compared to men's networks. Van Agthoven (1986) argues that support is mainly considered as women's business, which brings us to the third aspect: people get more support from women than from men (House, Umberson and Landis, 1988; van Agthoven, 1986).

\subsubsection{Social class}

In his investigation of the relationship between social class and network, van Eijk (1980) finds that the higher the socio-economic class, the more (healthy) persons have intensive contacts with kin and friends, indicating their network is less vulnerable to health deviation compared to the networks of the lower class (see section 2.1.2). MoGeough, Edwards, Chamberlain and Nogeire's (1980) finding that lung cancer patients with only high school degrees tended to be more socially isolated than those with a college degree or some college experience may serve to support this.

With regard to the amount of support available, Croog, Lipson and Levine (1972) found that social class did not appear to be significantly associated with types of aid from various sources (kin as well as non-kin). Bell and Boat (1957), however, reported that $76 \%$ of the low income and $84 \%$ of the high income subjects in their study could count on extended family aid in cases of illnesses lasting a month or 
longer. Finlayson (1976) furthermore found that manual families could be seen as having access to a narrower range of informal support.

Although operationalized in different ways (education, occupation, income), social class seems to be influencing the amount of emotional and instrumental support available from the network, in that higher social class is related to a greater amount of support.

\subsubsection{Age}

As stated in section 2.3.2 life-cycle variations lead to changes in structure and function of someone's network. Each life-stage is characterized by the constitution and maintenance of a set of intimate relationships, which are tuned to the needs and activities of the life-stage (Shulman, 1975). Age and life-stage play an important part in determining the size and nature of the relationships in the personal network, contact frequency and degree of intimacy (Hoyt and Babchuk, 1983). Norbeck (1981) notes that the size of the social support network increased during the years of young adulthood and was stable during the years from 35-55. Similarly Shulman (1975), in studying networks of healthy individuals between 18 and 65 years of age, found that the stability of network composition over a oneyear period increases with age. Due, for instance, to retirement or to network members dying, network size may decrease in older age (Knipscheer, 1980; Litwak, 1985).

With regard to social support, Croog, Lipson and Levine (1972) noted an inverse association between age of the patient and receipt of aid from parents, siblings, and in-laws. In regard to moral support and receipt of services from parents, negative significant associations with age were also found. The authors conclude that the younger patients also had younger parents, and these were more able to provide support than the more elderly parents of older patients.

\subsubsection{Marital status and family composition}

Because marital status and family composition are closely connected, we will discuss them together.

McFarlane and his colleagues, in their study (1981) of healthy persons' networks, paid attention to the effect of marital status on network composition. The main, reasonably predictable, difference in the networks of married people compared to those of single, divorced and widowed people was the spouse's inclusion. Married people also reported more work-related individuals. Single people had more friends than the other groups, while widowed and divorced people had more professionals in their networks. Reciprocity of relationships seemed to be most 
prevalent among the married group. Professionals seem to be an important source of support for the divorced group, helping to fill in gaps left by the informal network of family, friends, and coworkers. These findings indicate that, irrespective of health deviation, widowed and divorced peoples' networks contain more professionals. This must be taken into account in analyzing the results of our study. In addition to McFarlane et al. (1981), Verhaak, van Busschbach and Kortenhoeven (1985) found that individuals who are living with other people receive more informal support, while individuals living alone receive more professional support.

Another aspect, important with regard to personall networks and related to marital status, is the presence of children and their age. As in the case of the spouse, the main difference between having or not having children, is the inclusion of the children in the personal network. With regard to the available support, the age of the child(ren) is important. In section 2.1.1 we described the development of dependency balances, stating that young children are dependent on adults to care for them. When the caring adult gets a health deviation, the young child will not be able to take care of him and vice versa. Support from other persons, informal or formal (dependent on gender; see section 2.4.2.1), will be needed for both child and adult. When the child grows up, an equilibrium is reached in the dependency balance. When the adult gets a health deviation, the child is capable of taking care for both himself and the adult. To summarize, having children and these children growing up results in an important potential of support (see van Tilburg, 1988).

\subsubsection{Life events other than the onset of health deviation}

During the life cycle the individual experiences several life-change events, such as beginning or ending school, getting a job, marriage, childbirth, health deviation or death of spouse or relatives, children leaving the home, retirement (e.g. Holmes and Rahe, 1967). Each of these events demands an adaptation on the part of the individual and as a result may lead to changes in his relationships with other people (van Tilburg, 1988). In sections 2.4 .2 .3 and 2.4.2.4, this has already been discussed with regard to age, marital status and family composition. In addition we note that contact frequency with relatives and close friends stays the same when two individuals become a couple, but contact frequency with less close friends and acquaintances decreases (Milardo, Johnson and Huston, 1983). With regard to divorce, several researchers find that following divorce there is usually an increase in contact, but there are also individuals who get socially isolated (e.g. Oosterbaan and Zeldenrust, 1985; Weeda and Groenewold, 1986).

There are several other life events that influence a person's network. Death of the spouse, a close family member or a close friend are all life events that imply the 
loss of an important network member (indirectly resulting in rearranging the personal network), whereas child birth or getting a new job, besides indirect consequences, directly result in new network members.

In short, there are several life events other than health deviation that (may) lead to network changes. In studying the relation between health status and personal network, they have to be taken into account.

\subsection{Network changes following health deviation}

In this section a review is given of what is already known about the relationship between health deviation and personal network with regard to network changes following health deviation.

There have only been a few longitudinal studies investigating network changes following health deviation, and even fewer studies have been conducted comparing the networks of persons with different diseases, or comparing patients' networks with healthy persons' networks. Most knowledge of patients' networks has been obtained from cross-sectional studies. Therefore, there is only little information to present about network dynamics following health deviation. However, a number of cross-sectional studies have been conducted that have some interesting findings with regard to our own study. In the next subsections these research findings will be presented along with the results of the few longitudinal studies. The information is ordered according to the network characteristics described in section 2.2.

\subsubsection{Size}

According to section 2.1, we expect networks to decrease following health deviation. An important finding with regard to network size reported in several studies is the loneliness and social isolation the chronic patient is confronted with (Coulton, 1979; Thompson and Haran, 1984; Davidson and Young, 1985; Vroom and v.d. Net, 1978; van Agthoven, 1986). Many patients discussed the lack of opportunities to engage in interesting pastimes, to accomplish tasks or to achieve goals. Opportunities for social interaction were often limited by inability to get to places where people meet (Coulton, 1979; Thompson and Haran, 1984). The provision of aids to daily living tended to imprison the patient in his home, whereas he needed a change of surroundings and the sight of new faces (Thompson and Haran, 1984). Van Agthoven (1986) reports that chronic patients have the feeling they are no longer important: several friends stay away; the patient receives fewer visitors and is himself less capable of paying visits to his network members.

Although these data are collected through transversal research, they indicate that a 
person's network indeed decreases when he gets a health deviation.

We furthermore expect that larger networks decrease more following health deviation, but are also more supportive (see section 2.2.1). Supportiveness was the only aspect on which data could be traced. Lindsey, Ahmed and Dodd (1985) in their study of cancer patients found a significant relationship between network size and affirmation and aid, indicating that larger networks are indeed more supportive.

Some interesting findings have been reported with regard to impairment and disability/handicap dimensions, particularly concerning duration and severity.

Joosten, van der Horst and de Witte (1986) and de Witte, Joosten and van der Horst (1986) describe the networks of rheumatoid arthritis (RA) patients (mean age $57.2 ; 70 \%$ female) and spinal cord lesion (SCL) patients (mean age 33.5; 89\% male), some of whom were admitted to a rehabilitation center. They found that SCL patients' networks are larger compared to those of RA patients. Even correcting the data for age and gender, this difference stays the same. Furthermore, the average network size of patients admitted into the rehabilitation center is smaller compared to that of patients discharged from the rehabilitation center. Patients seriously hindered in their ability to write or speak were found to have smaller networks compared to patients that are only moderately hindered in their ability to communicate. When considering the relationship between duration of the health deviation and network size, they find that duration is negatively related to network size.

These findings support our expectations with respect to severity and duration of the health deviation and hospitalization, as described in section 2.3 .

\subsubsection{Composition}

We hypothesized that non-kin relationships are likely to fade following health deviation, whereas professional health care providers enter the network. Furthermore we expect that a network made up of a diversity of kinds of members is more supportive than a network with fewer kinds of members.

Joosten, van der Horst and de Witte (1986) found that RA patients have fewer friends than SCL patients. Only 15 percent of the RA patients' network members are friends, and almost 75 percent are relatives. The number of friends in the SCL patients' network almost equals the number of relatives. The lower percentage of friends in the RA patients' networks might be explained by the duration of their health deviation. Most RA patients had already had their health deviation for a longer period and for that reason it is possible that less close contacts with friends and acquaintances, neighbors and colleagues had already vanished, and only the relationships with relatives were continued.

With regard to formal network members, Lindsey, Ahmed and Dodd (1985) in 
their study of Egyptian cancer patients, found that no patient, although all patients were hospitalized, included a formal network member, not even a health care provider. It must be noted that only that part of the personal network known as the support network was studied. Tilden (1985) suggests that the mutual give-and-take in noncontractual interactions comes to mind when people think of social support. We might conclude that the professional health care provider(s) is part of the total personal network, but is likely to be 'forgotten' when listing support network members.

The data of Joosten, van der Horst and de Witte (1986) indicate that hospitalization may lead to new relationships, namely with fellow-patients, usually referred to as friends.

\subsubsection{Content}

We expect that relationships that are both emotional and instrumental (e.g. relatives) are less likelly to fade than relationships that are originally predominantly emotional (e.g. friends) or instrumental (e.g. neighbors).

We refer to section 2.5.2 where the network composition of RA and SCL patients is described. The data give an indication that uniplex relationships (with friends) indeed are more likely to fade than multiplex relationships with relatives.

\subsubsection{Reciprocity}

With regard to reciprocity a number of expectations may be deduced.

De Witte, Joosten and van der Horst (1986) describe the reciprocity in the relations of RA and SCL patients. Their data indicate that kin relations are indeed less vulnerable to a lack of reciprocity than non-kin relationships, as argued in section 2.2.4.

We found no studies with regard to the relationship between reciprocity and perceived support. With regard to the expectation that informal relations give more support in health deviation than formal relations, Ros (1989) has reported that the amount of emotional support given by the spouse is higher than that given by a physician, but the amount of informational support by the physician is higher than that by the spouse. This may be seen in the light of Lindsey, Ahmed and Dodd's (1985) finding that professionals are not listed as support network members. We conclude that although professionals may be supportive, this is not actually experienced as such by the patient, except when they are asked in a direct way (as Ros did in his study).

The last expectation concerned the supportiveness of the several network members. Schilltmans and Evers (1989), in their study of RA patients, observe that the 
spouse gives most support, friends and neighbors least. Similarly, van Agthoven (1986) finds that 44 percent of the informal supporters of patients in care of a community nurse are spouses, 25 percent are relatives, and 25 percent are neighbors. Croog, Lipson and Levine (1972), in their longitudinal study of 293 men who experienced a first Myocardial Infarction, state that one might speculate that regardless of the level of difficulty of the patient, family members were likely to assist him. Friends and neighbors might simply respond most when the situation requires, rallying around those whose need is evident. They also found that those patients who received a high degree of aid from parents also reported a high level of aid from the remaining categories of persons in the kin as well as the non-kin categories.

\subsection{Discussion and hypotheses}

In this chapter we described the relationship between health status and personal network, together with some influencing variables. We thus elaborated the model presented in chapter 1. Figure 2.1 presents the elaborated research model, referred to as the operational research model.

As described in section 2.5, there have only been a few studies which have investigated network changes following health deviation. Furthermore, most of these studies are cross-sectional, seldom comparing differing groups of patients or patients and healthy people. Similarly, very little is known about the relationship between dimensions of health deviation and network characteristics. This led us to the study this dissertation is based on.

As already stated in chapter 1 , the study is divided in a transwersal and a longitudinal part. The transversal part of the study consists of a comparison of the personal networks of two groups of chronic patients and the networks of a group of healthy people. Using the theories described in section 2.1 , especially the hypothetical ideas described in section 2.1.4, and the information presented in the subsequent sections a number of hypotheses were formulated.

In section 2.1 we argued that chronic health deviation, depending on the severity, means that the patient can care less for other persons and for himself. The patient gives less support and receives more, resulting in a change in the dependency balance. Exchange theory led us to expect a decrease in network members following a health deviation. With the help of interaction theory we predicted that this decrease would mainly concern non-kin informal network members. Finally, role-theory led us to the expectation that the number of formal network members will increase following health deviation. Our first hypothesis is: 


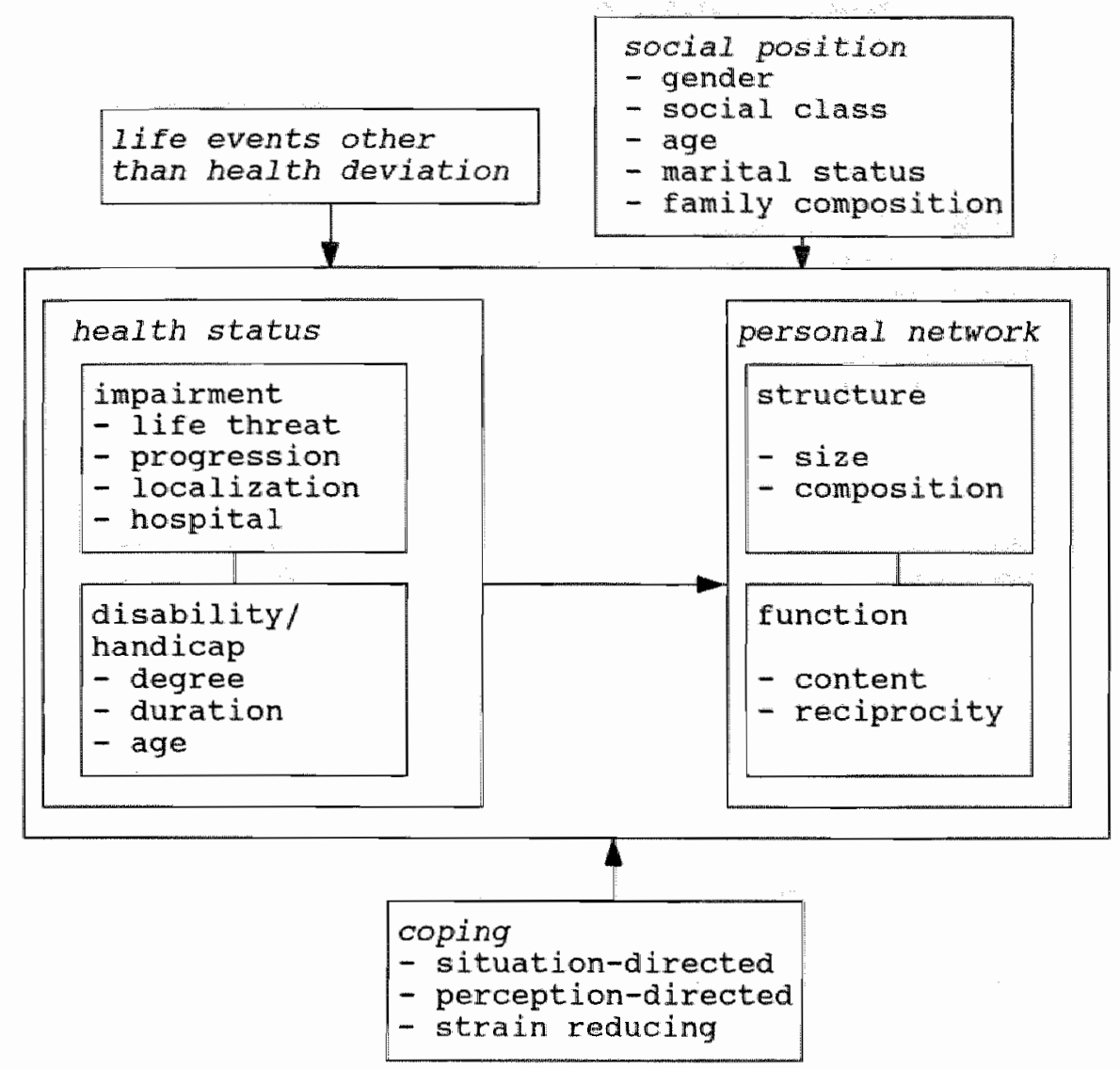

Figure 2.1 Operational research model

Hypothesis 1:

Patients' networks:

a. are less balanced, because patients give Jess and receive more support;

b. are smaller;

c. contain relatively fewer non-kin informal network members; and

d. contain more formal network members than the personal networks of healthy persons.

In section 2.3. I it was stated that life-threatening, rapidly progressive and visible impairments are more likely to affect the personal network than non-lifethreatening, slowly progressive and hidden impairments. Furthermore, hospitalization seemed to have an extra disruptive effect on relationships. That is the reason 
we expect that different impairments will lead to different network changes. The accompanying hypothesis is:

\section{Hypothesis 2:}

The more the disease is life-threatening, rapidly progressive, visible and accompanied by hospitalization:

a. the less support the patient gives and the more he receives and therefore the less balanced the neiwork;

b. the smaller the personal network;

c. the smaller the relative number of non-kin informal network members; and

d. the greater the number of formal network members.

In section 2.1.3 the importance of duration of the health deviation was stressed. It was described that chronic health deviation leads to other persons taking over several roles, tasks and responsibilities the patient performed before. As a result the patient becomes more and more dependent. Using the theoretical framework described in section 2.1 this leads us to the following hypothesis:

\section{Hypothesis 3:}

The longer the health deviation exists:

a. the less support the patient gives and the more he receives and thus the less balanced the network;

b. the smaller the personal network;

c. the relatively fewer non-kin informal network members; and

d. the relatively more formal network members.

We stated in section 2.1 that the more disabling a health deviation the more the patient becomes dependent on other persons. Using the theoretical framework this leads to hypothesis 4 .

\section{Hypothesis 4:}

The higher the disability levell:

a. the less supporl given and the more support received and therefore the more unbalanced the network;

b. the smaller the network;

c. the smaller the relative number of non-kin informal network members; and

d. the higher the relative number of formal network members.

The purpose of the longitudinal part of the study is to map the changes in the personal network of the patient that take place as a result of (changes in) the health deviation. From section 2.1 we deduce that when the disability increases the patient becomes more dependent on his network members and his roles are more 
affected. As a consequence, those relationships that are vulnerable to such changes will fade, and formal caregivers enter into the network.

Taking into account what has been said with regard to the degree of disability, we formulate the following hypothesis.

\section{Hypothesis 5:}

If the functional disability increases:

a. the amount of support given decreases and the amount received increases and thus the imbalance in the patient's network increases; and as a consequence

b. the number of network members decreases;

c. the relative number of non-kin informal network members decreases; and

d. the number of formal network members increases.

The hypotheses presented above are all related to the relationship between health status and personal network. As stated in section 2.4, coping, social position and other life events may influence this relationship, and are therefore part of the research model. However, because we are basically interested in the relationship between health status and personal network, we formulated no separate hypotheses with regard to the other concepts in the research model. They have been included in the model to show that the relationship between health status and personal network will be controlled for their possible effects.

The way in which health status and personal network are measured, as well as that of the measurement of coping, social position and other life events, is described in the following chapter, along with the research design. 


\section{Research design and instrument}

As already stated in the preceding chapters, this study is divided in a transversal part and a longitudinal part. Because research questions and hypotheses, as well as the research model, have already been presented in chapters 1 and 2 , this chapter is confined to the description of the sample, research procedures and measurement instrument.

\subsection{Sample and research procedures}

We restricted the study to persons between 25 and 55 years of age, because individuals between these age limits usually have stable networks, consisting of a diversity of network members (e.g. spouse, parents, children). Furthermore, having a chronic health deviation is not as common in this age category as it is in an older population.

With regard to the hypotheses, the criteria used to select chronic somatic diseases for investigation were that they be characterized by a great diversity in severity, and that they differ with regard to their course. Furthermore, the study focused on diseases which have not yet been comprehensively studied, such as rheumatoid arthritis and myocardial infarction. The last criterion we employed to select diseases concerned the longitudinal character of the study, in that it was critical that the patient would not die of the disease at short notice. We thus selected Crohn's disease, Ankylosing Spondylitis (AS) and Cerebro-vascular Accident (CVA). The aim was to interview 45 patients in every disease category. Literature and field observations indicated that this could be realized with regard to AS and Crohn's disease: the number of patients under treatment who were between 25 and 55 years of age was high enough to obtain 45 respondents in every group and the co-operation with the medical specialists was good. With regard to CVA, however, it proved to be hard to obtain a number of 45 respondents because the medical specialists were more protective towards their patients and because most CVA patients did not meet the age criterion set in the study. Furthermore, CVA demanded the development of a totally different interview instrument and procedure. Therefore, the study had to be limited to Crohn and AS. 
Crohn's disease is an inflammatory bowel disease, the cause of which remains unknown. It is a life-long disabling condition that cycles unpredictably between exacerbations and remissions (Tytgat, Groote, Tongeren and Vantrappen, 1985; Gazzard, Price, Libby and Dawson, 1978). There may be acute episodes of illness which require hospitalization, but mainly the burden of treatment rests on the daily medical regimen which is implemented by the patient himself at home. The individual faces physical discomfort, pain, fatigue, various sorts of physiological dysfunction, and even life-threatening episodes (Gazzard, Price, Libby and Dawson, 1978; Tytgat, Groote, Tongeren and Vantrappen, 1985). The syniptoms are debilitating and result in loss of time from school and work, multiple hospitalizations and possible surgery (Sparacino, 1984). Patients worry about odors, soiling clothing, frequent bowel movements (Joachim and Milne, 1987). An individual with active disease is always concerned about the location of the closest restroom and frequently will not go out of his home because of this restrictions (Simmons, 1984). Because of the unpredictable symptoms, persons with Crohn's disease are either unavailable or unreliably available for various time-bound arrangements. Frequently, illness symptoms require last-minute adjustments to arrangements. Furthermore, the disease requires multiple contacts with health care professionals over years (Wilson, 1984). The majority of patients experience onset between the ages of 15 and 25 (Sparacino, 1984).

Ankylosing Spondylitis (AS) is a rheumatic disease that affects the spine and may lead to some degree of stiffness of the back. It is a form of inflammation which affects the spine, usually beginning in its lower part. The cause is unknown. In an early stage AS leads to pain and stiffness in the back. Initially pain and stiffness are localized in the lower part of the back, later on pain in chest and neck may appear. Complaints vary greatly between patients. Some patients have nothing more than a series of mild aches and pains coming and going over a period of months, never troubling them greatly. Others pass through a phase of active spondylitis when symptoms are more troublesome; they become generally unwell, lose weight and tire easily. Mobility may be reduced because of the incapacitating effect of pain and stiffness. The disease progresses with a series of exacerbations and remissions and spinal limitation and deformity increase with time. AS may lead to visible kyphosis, because patients automatically ease back pain by adopting a flexed or hunched-over position. AS rarely leads to hospitalization, and few patients die from it. Death is caused by unusual complications. The onset of AS usually occurs between the ages of 15 and 35 , and occurs more often in men than in women (van der Korst, 1980; Carette, Graham, Little, Rubenstein and Rosen, 1983; Calabro and Maltz, 1970).

The sample consists of 44 subjects with Crohn's disease, 44 AS patients and 44 matched - healthy persons, male as well as female. The subjects with Crohn's 
disease were asked to participate in our study through their specialist for internal diseases. They received a letter, containing a description of our study and a request to participate. When they agreed to participate they could return a reply form. We thus attained informed consent. All patients between 25 and 55 years of age $(n=76)$ were asked to participate, of whom 44 sent back the reply form $(58 \%)$. Non-respondents were asked to indicate the reason why they did not take part in the study. Only eight respondents answered this question. Most of them did not want to talk about the disease $(n=5)$. Another reason for non-response was the lack of time to participate because of workcircumstances $(n=3)$. Selective response might occur with regard to health status, network characteristics and control variables. It seems probable that the least severely ill as well as the most severely ill were most likely not to respond. However, we only have data with regard to gender and age of the non-respondents. We conducted non-response analyses with regard to gender and age. There appeared to be no significant differences: the average age of the respondents is 35.4 compared to 35.2 for non-respondents; $70 \%$ of the respondents are female compared to $65 \%$ for non-respondents. The non-response appeared to be non-selective with regard to gender and age: of the male Crohn patients asked to participate in the study $54 \%$ sent back the reply form compared to $61 \%$ of the female patients $\left(\mathrm{X}^{2}=.29, \mathrm{p}>.05\right)$. With regard to age we divided the respondents into $\leq 40$ and $>40$. The response percentages were 59 and 57 respectively.

Patients with Ankylosing Spondylitis were asked by their rheumatologist - during a consultation - to participate in the study. Like the Crohn patients, they received a letter containing a reply form. In returning this form to us, the patient agreed to participate in our study, and thus we obtained informed consent. Fifty-nine patients were asked to participate of whom 44 sent back the reply form (75\%). There are no data available about reasons of non-response. Furthermore, we have no data on the population at risk which makes it impossible to conduct any non-response analyses.

We confined the study to South Limburg and only two hospitals with regard to the homogeneity of the population.

All Crohn patients were obtained from the University Hospital of Maastricht; all AS patients were obtained from the 'De Wever" hospital in Heerlen. Both hospitals are situated in the south of the province of Limburg. They were chosen because of the specialization in Crohn's disease in Maastricht and in AS in Heerlen.

For every two patients one healthy control was taken into the study, matched with respect to social position. The number of healthy respondents was set at 45 to obtain three equally sized groups. Furthermore, because of the limited time period, it did not seem possible to include a matched healthy control for every patient. Originally we wanted to obtain healthy respondents by asking the patients in our study to name someone in their neighborhood who answered the inclusion criteria 
as far as they knew. It was expected that the number of 45 respondents would be reached this way. However, only 19 healthy respondents were obtained using this method. There are three explanations for this low number:

- the patient said he did not know anybody in the neighborhood who answered the criteria;

- the patient was afraid to burden healthy persons and therefore named no-one;

- the healthy person named by the patient was not willing to participate in our study.

Therefore, we turned to convenience sampling. We made a list of the characteristics the other 26 healthy respondents had to answer (with regard to social position) and asked colleagues and friends whether they knew persons that met this criteria. In this way, we obtained a number of 44 healthy respondents.
Crohn
AS
Heal thy

month
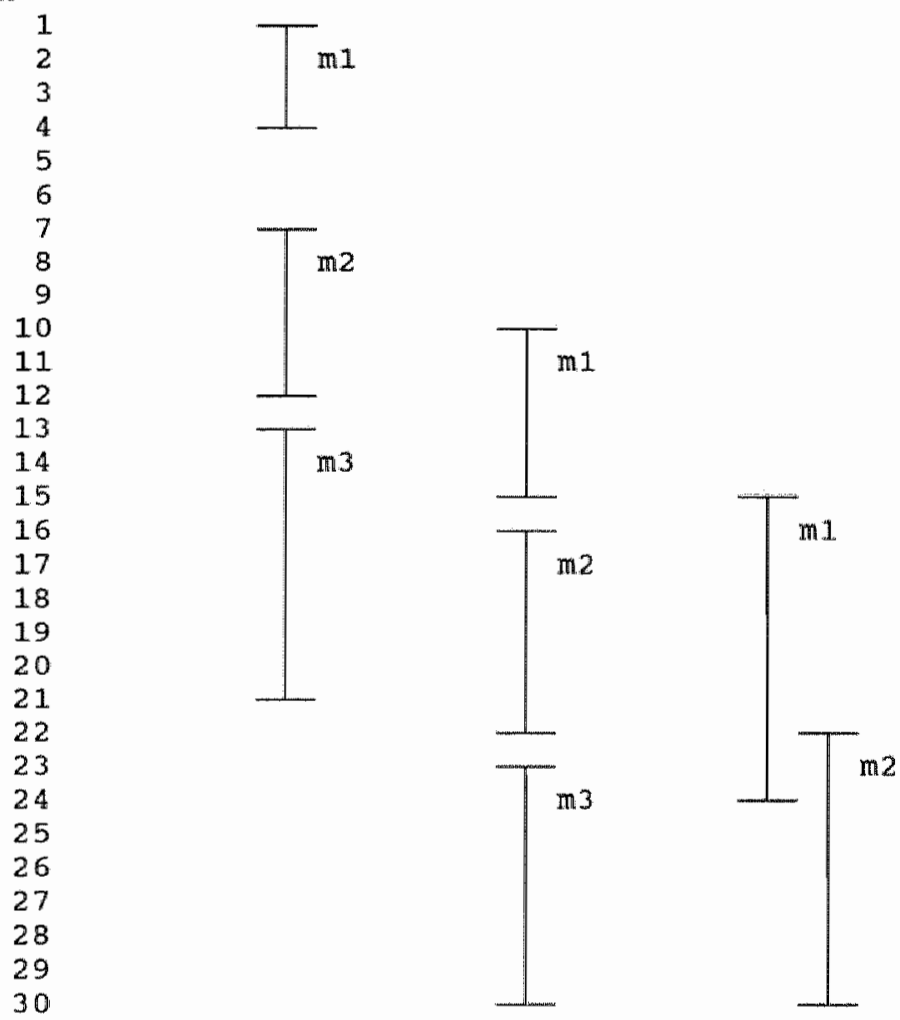

Figure 3.1 Interview time schedule 
As already stated, the study was limited to persons between 25 and 55 years of age. Another criterion used was that Crohn patients and AS patients with a disease other than Crohn and AS were excluded from the study.

There were three Crohn respondents excluded from the study. One respondent had a disease other than Crohn, one respondent was French and spoke poor Dutch and one respondent could not be reached.

The patients and the healthy respondents were interviewed three times and twice respectively with a period of half-a-year between every two measurements. Originally the intention was to interview the healthy participants three times as well. However, the interviews with the patients were more time-consuming than expected and led to a lack of time. Because the analyses with respect to Crothn patients revealed no significant differences between the scores on the variables at measurement 2 and measurement 3 , we decided to omit the third measurement with the healthy respondents. In anticipation of the analyses described in the following chapters, it should be noted that the second measurement of healthy respondents equates to the third measurement of the patients. Figure 3.1 presents the interview time schedule showing how the respondent groups were interviewed successively.

Table 3.1 shows the number of respondents for each group at each measurement time. There were a number of patients who no longer participated in the study at $\mathrm{m} 2$ and $\mathrm{m} 3$. The reasons for non-response of Crohn patients were: lack of time (3), do not want to be reminded of the disease any more (1). Reasons for nonresponse of AS patients: thought the questionnaire to be too personal (3), no longer interested (1), change of residence (1). The analyses in the following chapters have been conducted only for those respondents that participated in all three measurements.

The interviews were conducted by means of a structured questionnaire, which is discussed in the following section.

Table 3.1 Number of respondents at each measurement vime

\begin{tabular}{lllll}
\hline & $\mathrm{m} 1$ & $\mathrm{~m} 2$ & $\mathrm{~m} 3$ & $\mathrm{~m}$ all \\
\hline Crohn & $41^{2}$ & $37(90 \%)^{3}$ & $36(88 \%)$ & 36 \\
AS & 44 & $39(89 \%)$ & $39(89 \%)$ & 39 \\
Healthy & 44 & $44(100 \%)$ & & 44 \\
\hline
\end{tabular}

\footnotetext{
respondents participating in all three measurements

3 respondents were excluded from the study

"percentage of response with regard to $\mathrm{ml}$
} 


\subsection{Measurement instrument}

The concepts as presented in figure 2.1 were operationalized in a questionnaire, consisting of the following parts:

1. Personal network questionnaire

2. Health deviation related questionnaire

3. Sickness Impact Profile

4. Utrecht Coping Questionnaire

5. Questionnaire with regard to social position and life events

These questionnaires will be discussed in the following subsections.

\subsubsection{Personal network}

As stated in section 2.2, a person's network is defined as everyone the person knows or interacts with. Because we are interested in mapping a number of network characteristics with regard to all network members listed by the respondents, it seems impossible to take all the person's network members into study. We therefore limited the network to those persons the respondent frequently interacts with, from whom he gets support or whom he gives support. Structure and function of this part of the network are measured. There are several questionnaires available to measure personal networks, as, for instance, Bruhn and Philips (1984) indicate. We chose the questionnaire used in a study of the University of Limburg (RL) in co-operation with the Institute for Rehabilitation Research (IRV), because eventually the data from the RL/IRV study would be added to the data from our own study. The network characteristics are operationalized as follows:

\section{Size}

Those persons the respondent frequently interacts with, from whom he gets support or to whom he gives support. The respondent was asked to list these persons up to a maximum of 20 , in view of the data analysis. This inventarisation was done at each measurement, without using the list made at the preceding measurement(s).

\section{Composition}

Of each listed network member it is noted whether he/she is a parent (01), parentin-law (02), spouse (03), child (04), sibling (05), sister- or brother-in-law (06), child's spouse (07), grandparent (08), uncle/aunt (09), nephew/niece (10), friend (11), acquaintance (12), colleague (13), neighbor (14), fellow patient (15), professional (16). In the analyses these categories will be classified into kin, non- 
kin informal and formal network members.

\section{Content}

Content is operationalized in terms of emotional and instrumental support.

Emotional support is measured by asking the respondent to what extent he confides in his network member and to what extent he experiences that his network member confides in him. The score ranges from 1 (not at all) to 5 (very much).

Instrumental support was measured by asking the respondent to what extent he receives practical support from his network member and to what extent he gives practical support to his network member. Score ranges from 1 (not at all) to 5 (very much).

\section{Reciprocity}

Emotional reciprocity is measured by comparing the amount of emotional support received with the amount given.

Instrumental reciprocity is similarly measured, using the data on instrumental support received and given. ${ }^{2}$

In case of the chronic patients a number of questions were added to the existing questionnaire. These questions concerned their personal networks before the time the health deviation occurred, and the changes in the network that took place following the onset of the health deviation until the first measurement took place (described in Janssen and Philipsen, 1989).

As is the case with many other network questionnaires, there are no data yet available with regard to reliability and validity of the network questionnaire we used in our study.

\subsubsection{Health deviation related questionnaire}

This questionnaire consists of a number of questions in relation to the health status. In the first place it is noted whether the respondent is healthy, has Crohn's disease or AS. The patients are also asked about the age at which the onset of the health deviation occurred and its duration.

We aimed to measure the degree to which the disease is functionally disabling objectively as well as subjectively. In discussion with the medical specialists objective measurement of functional disability in the two patient categories appeared not possible, however, because the only objective data available were laboratory data indicating the severity of the inflammation, which is not

Janssen, Philipsen and Halfens (1990) describe emotional and instrumental reciprocity at the level of the individual network members. 
necessarily rellated to the level of functional disability. Other standard clinical judgments were not available in the files.

As subjective measures of functional disability a number of self-assessment questions and the Sickness Impact Profile (presented in section 3.2.3) are used.

Eight questions were asked to measure the respondent's subjective health:

- To what degree do you accept your health deviation?

- How serious do you think your health deviation is?

- How do you evaluate your physical functioning?

- To what degree does your health deviation hinder you in your daily activities?

- How do you evaluate your contacts with others?

- To what degree does your health deviation hinder you in your relationships with people you know well?

- To what degree does your health deviation hinder you in your relationships with people you know only slightly?

- How do you evaluate your health status?

All questions could be scored on a range from 1 to 5 . A low score means that the respondent assesses his health status as favorable; a high score means that the respondent assesses his health as unfavorable.

\subsubsection{Sickness Impact Profile}

The Sickness Impact Profile (SIP) was developed to provide a measure of perceived health status that is sensitive enough to detect changes or differences in health status that occur over time or between groups. The SIP measures the behavioral impacts of health deviation in terms of dysfunction. The SIP contains 136 statements about health-related dysfunction in 12 areas of activity, physical as well as psychosocial:

sleep and rest
eating
work
home management
recreation and pastimes
ambulation
mobility
body care and movement
social interaction
alertness behavior
emotional behavior
communication

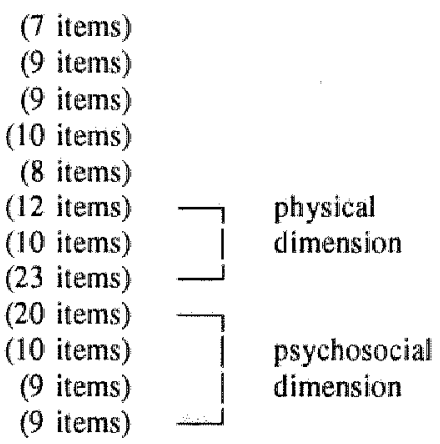

In completing the SIP, the subject is asked to endorse or check only those statements that he is sure describe him and are related to his health. Overall, 
category and dimension scores may be calculated, varying from 0 to $100 \%$. These calculations use pre-determined weights based on estimates of the relative severity of each dysfunction. A high score indicates a high level of health-related dysfunction; a score of 0 means that there is no health-related dysfunction at all (Bergner, Bobbitt, Carter and Gilson, 1981).

The test-retest reliability and internal consistency of the SIP were investigated using different interviewers, different forms, different administration procedures, and a variety of subjects who differed in type and severity of dysfunction. Overall, the test-retest reliability (one-day interval) of the SIP in terms of total and category scores was high $(r=.75$ to .92$)$. Reliability did not appear to be affected significantly by the variables examined, which suggests that the SIP is useful potentially for measuring dysfunction under a variety of administrative conditions and with a variety of subjects (Pollard, Bobbitt, Bergner et a1., 1976). Convergent and discriminant validity of the SIP were assessed using the Multitrait Multimethod technique and appeared to be appropriate (Bergner, Bobbitt, Pollard et al., 1976).

Similarly, de Witte, Jacobs, van der Horst et al. (1987) found that the Dutch version of the SIP seems to be a valuable instrument to measure the functional ability of a variety of patients.

\subsubsection{Utrecht Coping Questionnaire}

Coping is measured by the Utrecht Coping Questionnaire (UCL) (Schreurs, Tellegen and van de Willige, 1984). The classification of coping behavior by Westbrook (1979) and the stress model of van de Willige, Sorbi, Kluver et al. (1983) served as the basis of the development of the UCL. Approaches to measurement of coping are based on three perspectives, namely, coping as defense or ego processes, as a personality trait, and as a transactional process between the person and the environment. The UCL fits best the approach of coping as a personality trait. It is based on the assumption that individuals prefer certain ways of coping in general (Schreurs, Tellegen and van de Willige, 1984). The original scale consists of 47 items. We used a short 26 -item version. Factor analysis in a sample of 1226 healthy respondents and patients of several studies produced three factors, each consisting of five items:

1. action-directed coping (situation directed coping):

- making a direct intervention, when a problem occurs

- finding out all about the problem

- considering different solutions to the problem

- using a direct approach in order to solve the problem

- making several alternative plans for handling the problem

2. seeking social support (perception directed coping): 
- sharing one's worries with someone

- asking someone to help

- showing one's feelings

- seeking sympathy and comfort from somebody

- showing that there are things which are bothering you

3. awaiting/avoidance (strain reduction):

- looking for distraction

- directing one's thoughts towards other matters

- giving-in in order to avoid difficult situations

- resigning oneself to the situation

- trying to avoid difficult situations as much as possible

These three factors resemble the three factors of Pearlin and Schooler, presented in section 2.4.1 (placed in brackets).

Reliability and validity of the short version of the UCL are currently being tested in the sample of 1226 adults.

In our study, Cronbach's alphas for these three scales are .79, .67 and .61 respectively. We considered these high enough to make it acceptable to use the 3 factors in our analysis.

\subsubsection{Social position and life events}

As described in section 2.4.2, social position consists of gender, social class, age, marital status and family composition. Apart from age and gender, the operationalization of these concepts needs some clarification.

As stated in section 2.4.2.2, social class can be assessed in different ways. In the present study, social class is assessed using the occupation of the respondent or, in case of respondents without occupation, the occupation of the respondent's spouse. Following the "Classification of Occupation' (Westerlaak, Kropman and Collaris, 1975), occupations are classified by six criteria:

- manual or non-manual;

- education required;

- employee or self-employed;

- if employee: manager, yes/no;

- if employee: having subordinates, yes/no;

- if self-employed: the size of the company in terms of the number of emplloyees.

Thus, six categories of occupations could be distinguished:

1. unskilled laborers;

2. skilled laborers;

3. lower employees;

4. small tradesmen; 
5. intermediate employees;

6. higher occupations.

Marital status was categorized as:

never married, married, living together, widowed, divorced.

Family composition was operationalized according to Olson and McCubbin (1983): young couples without children, childbearing families and families with children in the preschool years, families with school-age children, families with adolescents in the home, launching families, empty nest families, families in retirement. It should be noted that, in view of the age limits set in this study, the latter type of families will probably not appear in our study.

Life events were operationalized by asking the respondent whether he or she experienced an event that he or she felt to be stressful during the half year period before the interview. The variable life events is thereby considered as a dichotomous variable: either an individual experienced such a stressful life event (possibly influencing the network) or he did not.

Table 3.2 gives an overview of the questionnaires used at each measurement time. Other research showed that nearly all healthy respondents without health complaints scored 0 on the SIP. Therefore, we decided not to administer any of the health status questionnaires to the healthy respondents (de Witte, Jacobs and Luttik, 1987).

Table 3.2 Overview of questionnaires used at each measurement time

\begin{tabular}{lccc}
\hline & $t 1$ & $t 2$ & $t 3$ \\
\hline personal network questionnaire & $x$ & $x$ & 0 \\
Health deviation related questionnaire & 0 & 0 & 0 \\
Sickness Impact Profile & 0 & 0 & 0 \\
Utrecht Coping Questionnaire & & - & 0 \\
social position & $x$ & $x$ & 0 \\
life events & $x$ & $x$ & \\
\hline
\end{tabular}

x questionnaire administered to patients as well as healthy respondents

o questionnaire administered to patients only

- questionnaire administered to healthy respondents only 
In this chapter we described the research sample, procedures and measurement instrument. In chapter 4 the data are described (mean, sd) using MANOVA procedures of repeated measurements. Chapter 5 presents t-tests and Pearson correlations with regard to the research hypotheses. Finally, the influence of coping, social position and life events on the relation between health status and personal network is determined by $\mathrm{AN}(\mathrm{C}) \mathrm{OVA}$ (chapter 6). It should be noted that the second measurement of healthy respondents is compared to the third measurement of the patients, because $\mathrm{m} 2$ of the healthy respondents took place at approximately the same time as $m 3$ of the patients. 


\section{Description of the data}

Most of the raw data collected with the help of the questionnaire described in chapter 3 had to be compiled in order to construct the ultimate variables used in the analyses. This chapter contains a description of the construction of the variables, along with some first results. Scores are presented of the groups at each measurement time and comparisons are made between groups and between measurements. MANOVA procedures of repeated measurements are conducted to find out whether there are time effects, group effects or interaction effects.

The chapter starts with a description of the three respondent groups. First, the social demographic characteristics according to social position (section 4.1) are described, followed by personal network and health status (sections 4.2 and 4.3 respectively). The chapter ends with data on coping and life events, described in sections 4.4 and 4.5 respectively. In section 4.6 the data is discussed with regard to the hypotheses.

Chapters 5 and 6 contain the analyses and results with regard to the hypotheses as formulated in chapter 2 .

\subsection{Social position}

The variables under social position were measured only at $t 1$, because most of them are not liable to changes. Changes were only expected with regard to marital status and family composition. When a respondent experienced such a change and found it stressful, this was scored by the variable life events.

\subsubsection{Gender}

As a result of the matching procedure the group of healthy respondents does not differ significantly from the total group of patients with respect to gender. When comparing the three groups, there proved to be a significant difference $\left(X^{2}=18.2\right.$; $p<.001$ ), as shown in table 4.1 , in that patients with Crohn's disease were mostly female, whereas in the AS group male patients predominated. 
Table 4.1 Number and percentage of male respondents

\begin{tabular}{|c|c|c|c|c|}
\hline & & $\begin{array}{l}\text { healthy } \\
(n=44)\end{array}$ & $\begin{array}{c}\text { AS } \\
(n=39)\end{array}$ & $\begin{array}{l}\text { Crohn } \\
(n=36)\end{array}$ \\
\hline male & $\begin{array}{l}\mathrm{n} \\
\%\end{array}$ & $\begin{array}{l}23 \\
52\end{array}$ & $\begin{array}{l}31 \\
79\end{array}$ & $\begin{array}{l}11 \\
30\end{array}$ \\
\hline
\end{tabular}

\subsubsection{Social class}

As stated in section 3.2.5, social class was assessed using the 'Classification of Occupation'. The scores are presented in table 4.2. The six categories have been reduced to three categories because of the number of empty cells.

The matching procedure described in chapter 3 did not succeed with regard to social class: healthy respondents had a higher social class compared to patients: $32 \%$ of the healthy respondents were intermediate employees or had higher occupations compared to $21 \%$ and $19 \%$ for AS and Crohn respectively $\left(\mathrm{X}^{2}=4.26\right.$, $\mathrm{p}<.05$ ).

Of the two groups of patients, Crohn patients had the higher social class; $38 \%$ of the AS patients were laborers compared to $30 \%$ of the Crohn patients.

When comparing the three groups using the Kruskal-Wallis test, the differences between them are not shown to be significant $\left(X^{2}=4.41 ; p=.08\right)$.

Table 4.2 Occupation of the respondents

\begin{tabular}{rrrrrrrr}
\hline & \multicolumn{2}{c}{ healthy } & \multicolumn{2}{c}{ AS } & \multicolumn{2}{c}{ Crohn } \\
& $\mathrm{n}$ & $\%$ & $\mathrm{n}$ & $\%$ & $\mathrm{n}$ & $\%$ \\
\hline (un)skilled laborers & 7 & 16 & 15 & 38 & 11 & 30 \\
lower empl/small trad. & 23 & 52 & 16 & 41 & 18 & 50 \\
intermed .empl/high oc. & 14 & 32 & 8 & 21 & 7 & 19 \\
total & 44 & 100 & 39 & 100 & 36 & 100 \\
\hline
\end{tabular}

\subsubsection{Age}

Mean age of healthy respondents $(n=44)$ was 35.7 years of age. The average age of Crohn $(n=36)$ and $A S(n=39)$ respondents, was 35.3 and 38.3 respectively. 
Using oneway between-subjects ANOVA we find no significant difference with respect to age $(F(2,116)=2.25 ; p=.11)$.

\subsubsection{Marital status}

Most respondents in each group were married or living together (see table 4.3). Comparing the three groups with regard to marital status, the differences are not significant $\left(X^{2}=6.2 ; p=.40\right)$.

Table 4.3 Marital status of the three respondent groups

\begin{tabular}{|c|c|c|c|c|c|c|c|}
\hline & \multicolumn{2}{|c|}{ healthy } & \multicolumn{2}{|c|}{ AS } & \multicolumn{2}{|c|}{ Crohn } \\
\hline & & $\mathrm{n}$ & $\%$ & $\mathrm{n}$ & $\%$ & $\mathrm{n}$ & $\%$ \\
\hline unmarried & & 5 & 11 & 4 & 10 & 7 & 19 \\
\hline married & & 33 & 75 & 33 & 85 & 27 & 75 \\
\hline living together & & 4 & 9 & 1 & 2 & 1 & 3 \\
\hline divorced & & 2 & 5 & 1 & 2 & 1 & 3 \\
\hline & total & 44 & 100 & 39 & 100 & 36 & 100 \\
\hline
\end{tabular}

\subsubsection{Family composition}

As stated in section 3.2 .5 family composition is operationalized according to Olson and McCubbin (1983). The categories were reduced to three: couples without children, families with children living at home, and families with children not

Table 4.4 Family composition per respondent group

\begin{tabular}{lrrrrrr}
\hline & \multicolumn{2}{c}{ healthy } & \multicolumn{2}{c}{ AS } & \multicolumn{2}{c}{ Crohn } \\
& $n$ & $\%$ & $\mathrm{n}$ & $\%$ & $\mathrm{n}$ & $\%$ \\
\hline couples without child & 10 & 23 & 6 & 15 & 9 & 25 \\
families with child at home & 26 & 59 & 23 & 59 & 19 & 53 \\
families with child not home & 3 & 7 & 5 & 13 & 1 & 3 \\
other & 5 & 11 & 5 & 13 & 7 & 19 \\
& 44 & 100 & 39 & 100 & 36 & 100 \\
\hline
\end{tabular}


living at home. The categories are presented in table 4.4 along with the frequencies of each respondent group.

The category 'other' is designed for those respondents who are unmarried and those who are divorced and who have no children. The Chi-squared analysis reveals no significant difference in family composition between the three groups $\left(X^{2}=4.63 ; p=.59\right)$.

\subsection{Personal network}

\subsubsection{Size}

Network size was determined from the number of network members listed by the respondent. As can be read in table 4.5 the average number of persons listed by the 44 healthy respondents is 11.3 and 10.6 at $t 1$ and $t 2$ respectively. AS patients $(n=39)$ list an average of $7.9,9.5$ and 9.9 at $t 1, t 2$ and $t 3$ respectivelly, compared to 10.1, 11.1 and 10.8 for patients with Crohn's disease $(n=36)$. The personal networks of AS patients appear to be smaller than those of healthy and Crohn respondents. The average network size of these latter groups is more or less equal.

Table 4.5 Mean number of relationships listed by healthy respondents and patients at 1,12 and t3

\begin{tabular}{lrrrrrrr}
\hline & \multicolumn{2}{c}{$\mathrm{t}$} & \multicolumn{2}{c}{$\mathrm{t} 2$} & \multicolumn{2}{c}{$\mathrm{t} 3$} \\
& $\mathrm{n}$ & mean & $\mathrm{sd}$ & mean & $\mathrm{sd}$ & mean & $\mathrm{sd}$ \\
\hline healthy & 44 & 11.3 & 5.0 & 10.6 & 4.5 & & \\
AS & 39 & 7.9 & 4.5 & 9.5 & 4.9 & 9.9 & 5.5 \\
Crohin & 36 & 10.1 & 5.3 & 11.1 & 6.0 & 10.8 & 5.3 \\
\hline
\end{tabular}

Repeated measurements MANOVA showed no significant difference in network size between the three groups. MANOVA revealed that AS patients' networks increase over time, whereas healthy and Crohn respondents' networks stay more or less the same size $(F(2,116)=2.98, p=.06)$.

Pearson correlations were computed for each respondent group between $11-t 2,12-13$ and $t 1-t 3$ to assess the stability of the data. The results are presented in Appendix Al. Stability is shown to range from acceptable to low ( $\mathrm{r}$ ranges from .35 to .80 ).

A check was conducted on whether the limitation of a maximum of 20 network members to be listed meant a serious limitation. When the number of respondents listing 20 network members is significantly larger than the number of respondents 
listing 19 network members we may assume that 20 is a serious limitation. Appendix B shows that at $t 1$ the number of respondents listing 20 network members $(n=5)$ is approximately equal to the number of respondents listing 19 network members $(n=4)$. The same goes for $12(n=6$ and $n=3$ respectively). At 3 the number of respondents listing 20 network members is larger $(n=10 ; 2$ healthy, 4 Crohn and 4 AS) compared to the number of respondents listing 19 network members $(n=2)$. The limitation of 20 network members does not seem to be a serious limitation at $t 1$ and $t 2$, whereas the difference in the number of respondents listing 20 compared to 19 network members at 33 might point to a serious limitation. However, the effect is more or less equally distributed over the three respondent groups.

\subsubsection{Composition}

As stated in chapters 2 and 3 , network size can be divided into the number of kin members (scores $0 \rrbracket$ to 10 as mentioned in section 3.2.1), the number of non-kin informal network members (scores 11 to 15 ) and the number of non-kin formal network members (score 16) listed by the respondent. The mean number of network members listed for each of these three groups is presented in table 4.6 , allong with percentages.

Table 4.6 Mean number and percentage of kin, non-kin informal and formal relationships

\begin{tabular}{|c|c|c|c|c|c|c|c|c|c|c|}
\hline & \multirow[b]{2}{*}{$n$} & \multicolumn{3}{|c|}{$\mathrm{tl}$} & \multicolumn{3}{|c|}{12} & \multicolumn{3}{|c|}{13} \\
\hline & & mean & 80 & $\%$ & mean & sd & 费 & mean & sd & $\%$ \\
\hline \multicolumn{11}{|l|}{ kin } \\
\hline healthy & 44 & 6.8 & 4.0 & 61 & 6.1 & 3.6 & 56 & & & \\
\hline AS & 39 & 5.5 & 3,2 & 75 & 6.1 & 3.7 & 66 & 6.6 & 4.4 & 68 \\
\hline Crohn & 36 & 7.7 & 4.6 & 77 & 7.6 & 4.9 & 70 & 7.7 & 4.3 & 73 \\
\hline \multicolumn{11}{|c|}{ now-kin informa } \\
\hline hesilithy & 44 & 4.0 & 3.2 & 36 & 4.3 & 3.0 & 42 & & & \\
\hline AS & 39 & 2.0 & 2.8 & 21 & 3.2 & 3.5 & 31 & 3.1 & 3.3 & 28 \\
\hline Crohn & 36 & 2.2 & 2.7 & 18 & 3.1 & 3.5 & 26 & 2.9 & 3.4 & 23 \\
\hline \multicolumn{11}{|c|}{ non-kin formal } \\
\hline haalthy & 44 & .0 & .0 & 0 & .0 & .0 & 0 & & & \\
\hline $\mathrm{AS}$ & 39 & .3 & .7 & 3 & .2 & .7 & 3 & .2 & .5 & 4 \\
\hline Crohn & 36 & .2 & .8 & 4 & .2 & .6 & 3 & .1 & .5 & 3 \\
\hline
\end{tabular}


Table 4.6 shows that the greatest part of the network of the three groups consists of kin members and that only a small number of formal relationships are listed by the respondents.

Repeated measurements MANOVA showed no group, time or interaction effects for the kin network. With regard to the non-kin informal network MANOVA revealed that healthy persons' networks hold more non-kin members compared to both AS and Crohn patients" networks $(F(2,116)=4.56, p<.05)$. There also appeared to be a time-effect: non-kin informal network size increases from $t 1$ to $\mathrm{t} 2 / \mathrm{t} 3(\mathrm{~F}(1,116)=8.67, \mathrm{p}<.01)$.

Again Pearson correlations were computed to assess stability. The results are presented in Appendix A2. Stability is high to moderate in all groups for each network category ( $\mathrm{r}$ ranges from .62 to .88), except for AS patients" kin relationships from $t 1$ to $\mathrm{t} 3(\mathrm{r}=.43)$. This analysis, however, does not answer the question whether the network members listed at $t 2 / \mathrm{t} 3$ are the same network members as listed at $\mathrm{t} 1$. Therefore, we computed the percentage of network members listed at $\mathrm{t} 2 / \mathrm{t} 3$ as well as at $\mathrm{t} 1$ (see Appendix A2). The results show that the kin network members listed are to a large degree the same at each measurement time, whereas stability of the non-kin informal network is much lower.

Table 4.7 Number of respondents listing kin, non-kin informal and non-kin formal network members, together with the mean number of network members listed

\begin{tabular}{|c|c|c|c|c|c|c|c|c|c|}
\hline & & t1 & & & 12 & & & 13 & \\
\hline & $\mathrm{n}$ & mean & $\mathrm{sd}$ & $n$ & mean & $s d$ & $n$ & mean & $\mathrm{sd}$ \\
\hline $\mathrm{kin}$ & & & & & & & & & \\
\hline healthy & 42 & 7.1 & 3.8 & 41 & 6.5 & 3.4 & & & \\
\hline $\mathrm{AS}$ & 39 & 5.5 & 3.2 & 39 & 6.1 & 3.7 & 39 & 6.6 & 4,4 \\
\hline Crohn & 34 & 8.1 & 4.3 & 34 & 8.0 & 4.7 & 34 & 8.1 & 4.0 \\
\hline non-kin & & & & & & & & & \\
\hline healthy & 41 & 4.3 & 3.1 & 39 & 4.8 & 2.7 & & & \\
\hline $\mathrm{AS}$ & 22 & 3.5 & 2.9 & 28 & 4.4 & 3.4 & 27 & 4.5 & 3.1 \\
\hline Crohn & 19 & 4.2 & 2.4 & 26 & 4.3 & 3.5 & 26 & 4.1 & 3.4 \\
\hline non-kin & & & & & & & & & \\
\hline healthy & 0 & - & - & 0 & - & - & & & \\
\hline AS & 6 & 1.8 & .8 & 3 & 2.3 & 1.2 & 6 & 1.3 & .5 \\
\hline Crohn & 2 & 3.5 & .7 & 4 & $\llbracket .5$ & 1.0 & 2 & 2.0 & 1.4 \\
\hline
\end{tabular}

Although the percentages in table 4.6 are used in the analyses described in chapters 5 and 6 , there is another interesting finding with regard to network 
composition we want to present, namely the number of respondents listing network members in each separate network category. Table 4.7 shows the number of respondents listing kin, non-kin informal and non-kin formal network members along with the mean number of network members listed. The data reveal that nearly all respondents, healthy respondents as well as patients, list kin network members. With regard to the non-kin network it appears that almost all healthy respondents $(91 \%$ ) list a non-kin informal member, whereas only about $66 \%$ of the patients list a non-kin informal network member $\left(X^{z}=17.44, p<.001\right.$ and $X^{2}=4.13, p<.05$ respectively), clearly illustrated by figure 4.1 .

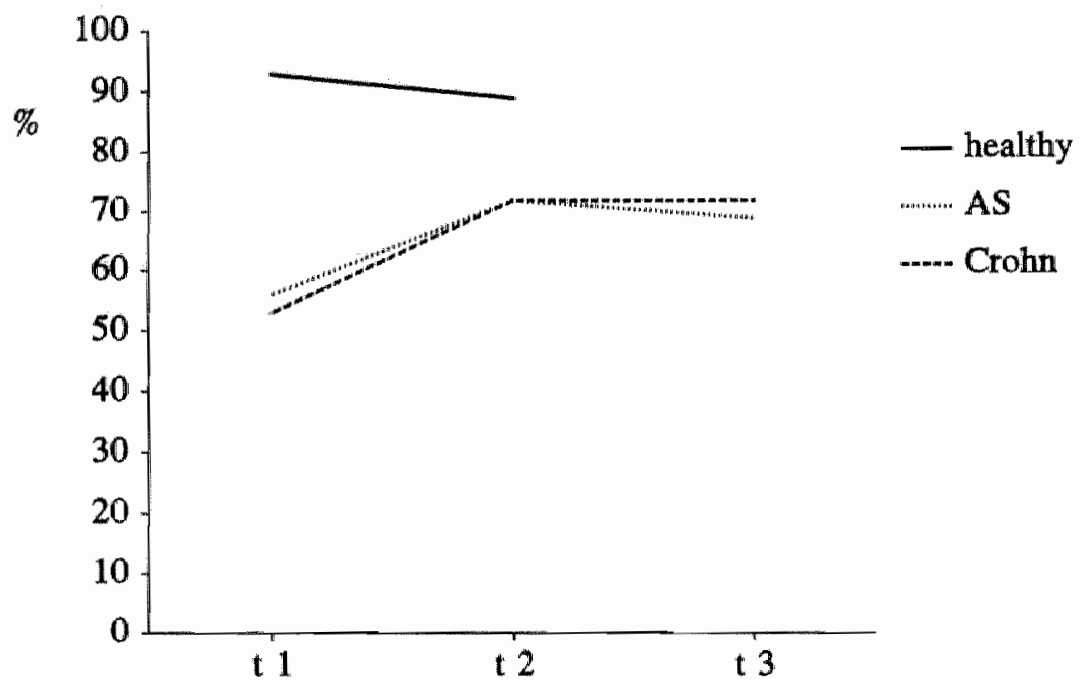

Figure 4.1 Percentage of respondents listing non-kin informal nework members

The data show that those patients who list non-kin informal network members list about the same number as healthy respondents do. Formal relationships are only listed by patients.

\subsubsection{Content}

As already stated in section 3.2.1, content is divided in emotional and instrumental support. For each of the three respondent groups the mean amount of instrumental and emotional support per network member, received and given, is computed at each measurement time. The results are also specified for the kin and the non-kin informal network. The results are presented in table 4.8 . There are no data in the 
Table 4.8 Emotional and ingmumenual suppont recented and given per nethork member

\begin{tabular}{|c|c|c|c|c|c|c|c|c|}
\hline & & \multirow[b]{2}{*}{$\mathrm{n}$} & \multicolumn{2}{|c|}{$\#$} & \multicolumn{2}{|c|}{2} & \multicolumn{2}{|c|}{3} \\
\hline & & & mean & sel & mean & sd & mexn & sd \\
\hline \multicolumn{9}{|c|}{ emotional support } \\
\hline \multicolumn{9}{|c|}{ rotal network } \\
\hline \multirow[t]{3}{*}{ received } & healthy & 44 & 3.7 & .7 & 3.7 & .5 & & \\
\hline & AS & 39 & 3.7 & $\mathbb{1 . 0}$ & 3.6 & .9 & 3.8 & .9 \\
\hline & Crohn & 35 & 3.9 & .7 & 3.8 & .7 & 3.7 & .8 \\
\hline \multirow[t]{3}{*}{ given } & healthy & 44 & 3.8 & .6 & 3.8 & .6 & & \\
\hline & AS & 39 & 3.8 & 1.0 & 3.9 & .8 & 3.8 & .9 \\
\hline & Crohn & 35 & 3.6 & .8 & 3.8 & .9 & 3.8 & .7 \\
\hline \multicolumn{9}{|c|}{ kin network } \\
\hline \multirow[t]{3}{*}{ received } & healthy & 41 & 3.8 & .8 & 3.8 & .8 & & \\
\hline & AS & 39 & 3.8 & 1.2 & 3.8 & 1.0 & 4.0 & 1.0 \\
\hline & Crohn & 34 & 4.0 & .8 & 3.9 & .6 & 3.8 & .9 \\
\hline \multirow[t]{3}{*}{ given } & heallthy & 41 & 3.9 & .6 & 3.9 & .7 & & \\
\hline & AS & 39 & 4.0 & 1.1 & 4.2 & .9 & 4.0 & $\leadsto$ \\
\hline & Crohn & 34 & 3.8 & .8 & 4.0 & .6 & 4.0 & .6 \\
\hline \multicolumn{9}{|c|}{ non-kin informal network } \\
\hline \multirow[t]{3}{*}{ reseived } & heallthy & 37 & 3.8 & .9 & 3.7 & .7 & & \\
\hline & AS & 17 & 3.5 & 1.3 & 3.5 & 1.0 & 3.7 & .9 \\
\hline & Crohn & 17 & 4.0 & 1.0 & 3.8 & 1.0 & 4.0 & .9 \\
\hline \multirow[t]{3}{*}{ given } & heallhy & 37 & 3.9 & .7 & 3.8 & .7 & & \\
\hline & AS & 17 & 3.5 & 1.0 & 3.9 & .8 & 4.0 & .6 \\
\hline & Crohn & 17 & 3.7 & .9 & 3.7 & 1.1 & 4.0 & .6 \\
\hline \multicolumn{9}{|c|}{ instrumental support } \\
\hline \multicolumn{9}{|c|}{ total network } \\
\hline \multirow[t]{3}{*}{ received } & healthy & 44 & 1.9 & .9 & 1.9 & 1.0 & & \\
\hline & AS & 39 & 2.2 & 1.11 & 1.9 & 1.1 & 1.6 & .8 \\
\hline & Crohn & 35 & 2.2 & .8 & 1.9 & 1.1 & $\mathbb{1} .7$ & 9 \\
\hline \multirow[t]{3}{*}{ given } & heallthy & 44 & 2.2 & 1. & 2.3 & 1.2 & & \\
\hline & $\mathrm{AS}$ & 39 & 2.6 & 1.0 & 2.4 & 1.3 & $\mathbb{1 1} .9$ & 1.1 \\
\hline & Crohn & 35 & 2.2 & .9 & 2. 1 & 1.1 & 11.6 & .9 \\
\hline \multicolumn{9}{|c|}{ kin network } \\
\hline \multirow[t]{3}{*}{ received } & hexilthy & 41 & 2.1 & 1.0 & 2.0 & 1.1 & & \\
\hline & AS & 39 & 2.3 & 1.2 & 2. 1 & 1.3 & 1.8 & 1.0 \\
\hline & Crohn & 33 & 2.4 & 1.0 & 2.0 & 1.1 & 1.9 & 1.1 \\
\hline \multirow[t]{3}{*}{ given } & healthy & 41 & 2.4 & 1.2 & 2.6 & 1.3 & & \\
\hline & AS & 39 & 2.8 & 1.1 & 2.7 & 1.5 & 2.1 & 1.2 \\
\hline & Crohn & 34 & 2.5 & 1.0 & 2.3 & 1.2 & 1.7 & 1.0 \\
\hline \multicolumn{9}{|c|}{ non-kin informal network } \\
\hline received & healthy & 37 & 1.7 & 1.1 & 1.6 & .9 & & \\
\hline & AS & 17 & 1.7 & 1.2 & 1.6 & 1.0 & 1.8 & 1.2 \\
\hline & Crohn & 17 & 1.6 & .8 & 1.5 & 1.0 & 1.4 & .9 \\
\hline given & healthy & 37 & 1.8 & 1.1 & 1.9 & 1.1 & & \\
\hline & AS & 17 & 2.1 & 1.0 & 2.1 & 1.4 & 1.5 & .8 \\
\hline & Crohn & 17 & 1.8 & .9 & 1.7 & 1.3 & 1.2 & .5 \\
\hline
\end{tabular}


table with regard to formal network members, because the number of formal network members listed is very small. Furthermore, content is only applicable for those respondents who list network members in the respective network categories (total, kin, non-kin informal). Those respondents, for instance, who do not list a non-kin informal member, are excluded from the analyses pertaining to support of the non-kin informal network.

The scores of the total network are computed by adding the amount of support received from (or given by) the network members and dividing the result by the number of network members listed. The scores of the kin network are computed by adding the amount of support received from (or given by) the kin network members and dividing the result by the number of kin relationships listed. The scores of the non-kin network are computed in the same way. Because the number of respondents is different in the respective analyses the total network scores are not just the mean of both partial network scores and must be treated as a separate measure.

With regard to emotional support, repeated measurements MANOVA reveals no differences between healthy respondents and patients. With regard to instrumental support MANOVA reveals a number of interaction effects. Whereas the amount of instrumental support received as well as given is stable in healthy respondents' networks, it decreases in the patients' networks. This development is found in both the kin and the non-kin informal part of the network, except for instrumental support received from non-kin informal members.

The stability of the content of the network was computed using Pearson correlations. These data can be found in Appendix A3. The data show a low to moderate stability for the overall network for each respondent group ( $\mathrm{r}$ ranges from .23 to .77). Dividing the network into categories reveals (Appendix A4) that the stability of the content of the kin network is moderate to low in all three groups. The same goes for the non-kin informal network of healthy respondents. However, the stability of the non-kin informal network of the two patient groups is shown to be very low.

\subsubsection{Reciprocity}

Emotional reciprocity is determined by dividing the total amount of emotional support given by the total amount of emotional support received. Instrumental reciprocity is computed similarly. The scores of each respondent group are presented in table 4.9. As in section 4.2 .3 the data only refer to those respondents who listed network members in the respective network categories.

MANOVA of repeated measurements shows a significant interaction effect for emotional reciprocity. Whereas healthy and Crohn respondents" emotional reciprocity scores increase over time, AS respondents' reciprocity score decreases 
Table 4.9 Mean reciprocity scores for each respondent group

\begin{tabular}{|c|c|c|c|c|c|c|c|}
\hline & \multirow[b]{2}{*}{$\mathrm{n}$} & \multicolumn{2}{|c|}{11} & \multicolumn{2}{|c|}{2} & \multicolumn{2}{|c|}{13} \\
\hline & & mean & sd & mean & sd & mean & sd \\
\hline \multicolumn{8}{|c|}{ emotional reciprocity } \\
\hline healthy & 44 & 1.0 & .2 & 1.1 & .2 & & \\
\hline$A S$ & 39 & 1.1 & .3 & 1.1 & .3 & 1.0 & .3 \\
\hline Crohn & 35 & 1.0 & .2 & 1.0 & .2 & 1.1 & .3 \\
\hline \multicolumn{8}{|c|}{ instrumental reciprocity } \\
\hline healthy & 44 & 1.2 & .5 & 1.3 & .5 & & \\
\hline AS & 39 & $\mathbb{1 . 4}$ & .9 & 1.4 & .8 & 1.2 & .5 \\
\hline Crohn & 35 & 1.2 & .7 & 1.3 & .7 & 11.0 & .4 \\
\hline
\end{tabular}

$(\mathrm{F}(2,115)=3.84, \mathrm{p}<.05)$.

MANOVA for the partial networks (table 4.10) reveals that emotional kin reciprocity increases over time in case of Crohn respondents, whereas in healthy respondents it remains constant and in AS respondents it decreases $(\mathrm{F}(2,111)=5.09, \mathrm{p}<.01)$. With regard to instrumental reciprocity in the kin network we find no significant effects.

With regard to the non-kin informal network we find that healthy respondents' instrumental reciprocity scores increase slightly over time whereas those of both groups of patients decrease $(F(2,71)=2.94, p=.06)$. There appear to be no effects for emotional non-kin informal reciprocity.

\subsubsection{Relation between the network variables}

In section 2.5 we described some relations found by other researchers between network measures, such as, for instance, between network size and supportiveness. In this section the relation between the network variables as assessed in the present study is described. Because of the large number of variables and taking into account the degree of their stability, overall measures for all variables were calculated by adding the scores of $t 1$ and $t 2$ for healthy respondents and the scores of $\mathrm{t} 1$ and $\mathrm{t} 3$ for patients respectively and dividing the result by 2 . Pearson correlations were computed between these overall measures. The data is in Appendix C.

The data shows that network size is positively related to the percentage of non-kin informal network members $(r=.16, p<.05)$. Size is negatively related to support measures ( $\mathrm{r}$ ranges between -.08 and -.22 for the total network, between -.06 and.,- 16 for kin and between .00 and -.15 for the non-kin network). 
Table 4.10 Mean reciprocity scores for each respondent group for the kin and non-kin nework

\begin{tabular}{|c|c|c|c|c|c|c|c|}
\hline & \multirow[b]{2}{*}{ nt } & \multicolumn{2}{|c|}{ t1 } & \multicolumn{2}{|c|}{12} & \multicolumn{2}{|c|}{0} \\
\hline & & mean & sd & mean & sd & mean & sd \\
\hline \multicolumn{8}{|c|}{ emotional reciprocity } \\
\hline \multicolumn{8}{|c|}{ kin nerwork } \\
\hline healthy & 41 & 1.1 & .2 & 1.1 & .3 & & \\
\hline AS & 39 & 1.1 & .4 & 1.1 & .2 & 1.0 & .2 \\
\hline Crohn & 34 & 1.0 & .2 & 1.0 & .1 & 1.1 & .3 \\
\hline \multicolumn{8}{|c|}{ non-kin informal network } \\
\hline healthy & 37 & 1.1 & .4 & 1.1 & .2 & & \\
\hline AS & 17 & 1.2 & .8 & 1.3 & .7 & 1.2 & .5 \\
\hline Crohn & 17 & 1.0 & .3 & 1.0 & .1 & 1.0 & .3 \\
\hline \multicolumn{8}{|c|}{ instrumental reciprocity } \\
\hline \multicolumn{8}{|c|}{ kin network } \\
\hline $\begin{array}{l}\text { hearthy } \\
\text { AS }\end{array}$ & 39 & 1.5 & 1.0 & 1.4 & .8 & 1.3 & .5 \\
\hline Crohn & 33 & 1.2 & .8 & 1.4 & .9 & 1.0 & .4 \\
\hline \multicolumn{8}{|c|}{ non-kin informal network } \\
\hline healthy & 37 & 1.2 & .6 & 1.3 & .6 & & \\
\hline AS & 17 & 1.5 & 1.1 & 1.4 & .9 & 1.0 & .6 \\
\hline Crohn & 17 & 1.3 & .7 & 1.2 & .4 & 1.0 & .3 \\
\hline
\end{tabular}

The percentage of non-kin informal network members is only related to the amount of instrumental support given by non-kin informal network members $(\mathrm{r}=.21, \mathrm{p}<.05)$.

With regard to support measures, we find a negative relation between emotional support received and emotional support given in the total network $(r=-.44$, $p<.001$ ). All other support measures are positively related. This applies to both the total and the kin and non-kin informal network. The correlations are, however, not high enough to construct a combined variable.

Emotional and instrumental reciprocity are positively related in the total and kin network $(r=.37, p<.001$ and $r=.28, p<.01$ respectively). In the non-kin informal network we found no relation between these variables.

The data with regard to the relation between support measures and reciprocity measures shows that the amount of emotional support received is negatively related to emotional network reciprocity. The amount of instrumental support received is negatively related to instrumental reciprocity. These findings apply to the total network $(r=-.32$ and $r=-.34$ for emotional and instrumental reciprocity respectively) as well as to the kin $(r=-.53$ and $r=-.35$ respectively) and non-kin informal $(r=-.67$ and $r=-.21$ respectively) network separately. 
Emotional and instrumental support given are positively related to emotional as well as instrumental reciprocity. This applies to the total and kin network. In the non-kin informal network a positive relation was found only between instrumental support given and instrumental reciprocity $(\mathrm{r}=.51, \mathrm{p}<.001)$.

These correlations between support and reciprocity measures seem obvious because of the way in which the reciprocity measures were constructed, namely by using the scores on the support measures.

Comparison of the total, kin and non-kin informal network reveals that both kin and non-kin support measures are highly positively correlated with total network support measures ( $\mathrm{r}$ ranges from .71 to $.93, \mathrm{p}<.001$ ), except for emotional support received. Therefore, in chapters 5 and 6 the analyses will be conducted only for the kin and non-kin support data, except for emotional support received. Kin and non-kin informal support measures are also related, but not strongly enough to combine these measures.

The same also applies to reciprocity measures. Total and kin network reciprocity are very strongly related $(r=.93$ and $r=.89, p<.001$ for emotional and instrumental reciprocity respectively). Correlations between total and non-kin informal reciprocity measures are lower $(r=.62$ and $r=.59, p<.001$ respectively) but still high enough to permit further analyses to be conducted only for the kin and non-kin informal network.

Emotional and instrumental reciprocity are positively related in the total $(r=.37$, $\mathrm{p}<.001)$ and $\mathrm{kin}(\mathrm{r}=.28, \mathrm{p}<.01)$ network. In the non-kin informal network we find no relation between the two measures.

\subsection{Health status}

As described in section 3.2 .2 health status is measured by a number of variables. The scores on the Sickness Impact Profile are used as a more or less objective measure of the respondent's dysfunctioning, physical as well as psychosocial. As a measure of subjective health we asked the respondents eight questions about the way they experience their functioning, again physical as well as psychosocial. The third measure taken into the analyses was duration of the health deviation, because of the relation between duration of the health deviation and personal network mentioned in section 2.1.

The following subsections contain a description of the three health status measures. As stated in chapter 3, health status is only measured for the patients. 


\subsubsection{Sickness Impact Profile}

In section 3.2.3 the two dimensions (physical - psychosocial) of the Sickness Impact Profile (SIP) are described. The scores of both groups of chronic patients are presented in table 4.11 .

The data shows that AS patients have a significantly higher percentage of physical dysfunctioning than Crohn patients $(\mathrm{F}(1,73)=24.70, \mathrm{p}<.001)$.

With regard to psychosocial functioning the functional level improves with time for both patient groups $(F(2,72)=3.49, p<.05)$.

Table 4,11 Physical and psychosocial SIP scores of the two groups of patients

\begin{tabular}{|c|c|c|c|c|c|c|c|}
\hline & \multirow[b]{2}{*}{$\mathrm{n}$} & \multicolumn{2}{|c|}{$\| 1$} & \multicolumn{2}{|c|}{$\mathrm{t} 2$} & \multicolumn{2}{|c|}{ t 3} \\
\hline & & mean & $\mathrm{sd}$ & mean & sd & mean & $s d$ \\
\hline \multicolumn{8}{|c|}{ Rhysical SIP score } \\
\hline AS & 39 & 10.4 & 8.3 & 10.7 & 9.4 & 9.4 & 7.9 \\
\hline Crohn & 36 & 3.3 & 3.7 & 2.4 & 4.0 & 3.0 & 5.6 \\
\hline \multicolumn{8}{|c|}{ psychiosocial SIP score } \\
\hline $\mathrm{AS}$ & 39 & 6.9 & 9.7 & 6.1 & 9.9 & 3.8 & 6.9 \\
\hline Crohn & 36 & 6.8 & 11.0 & 4.1 & 7.5 & 4.8 & 10.7 \\
\hline
\end{tabular}

The scores of each individual SIP scale are presented in table 4.12. From the table it can be concluded that there are two SIP scales - that are not part of the physical or psychosocial scale - on which the scores of AS and Crohn patients are significantly differently, namely the 'sleep and rest' scale and the 'homemanagement' scale. AS patients are more functionally disabled than Crohn patients. This difference can be explained by the nature of the disease, described in section 3.1, and therefore we conducted no separate analyses with regard to these two SIP scales in chapters 5 and 6.

With regard to stability of the SIP scores, the Pearson correlations, presented for $\mathrm{t} 1 \mathrm{t} 2,12-13$, and $t 1-\mathrm{t}$ for the psychosocial and the physical scale (Appendix D), show very high stability in the AS group ( $r$ ranges from .79 to 94 ). In case of Crohn patients, stability of the psychosocial scores is moderate ( $\mathrm{r} .50$ to .74), whereas the stability of the physical SIP scores is significantly lower ( $\mathrm{r} .19$ to .45).

Comparison of the data on the AS patients in our study with the data on the AS patients in the study by de Witte (de Witte, 1991) shows that both patient groups are comparable with regard to the physical as well as the psychosocial SIP scores. With regard to the group of Crohn patients no such comparable data is available from other studies. 
Table 4.12 Als $(n=39)$ and Crohn $(n=36)$ respondents' scores on the indivalual SPP scales

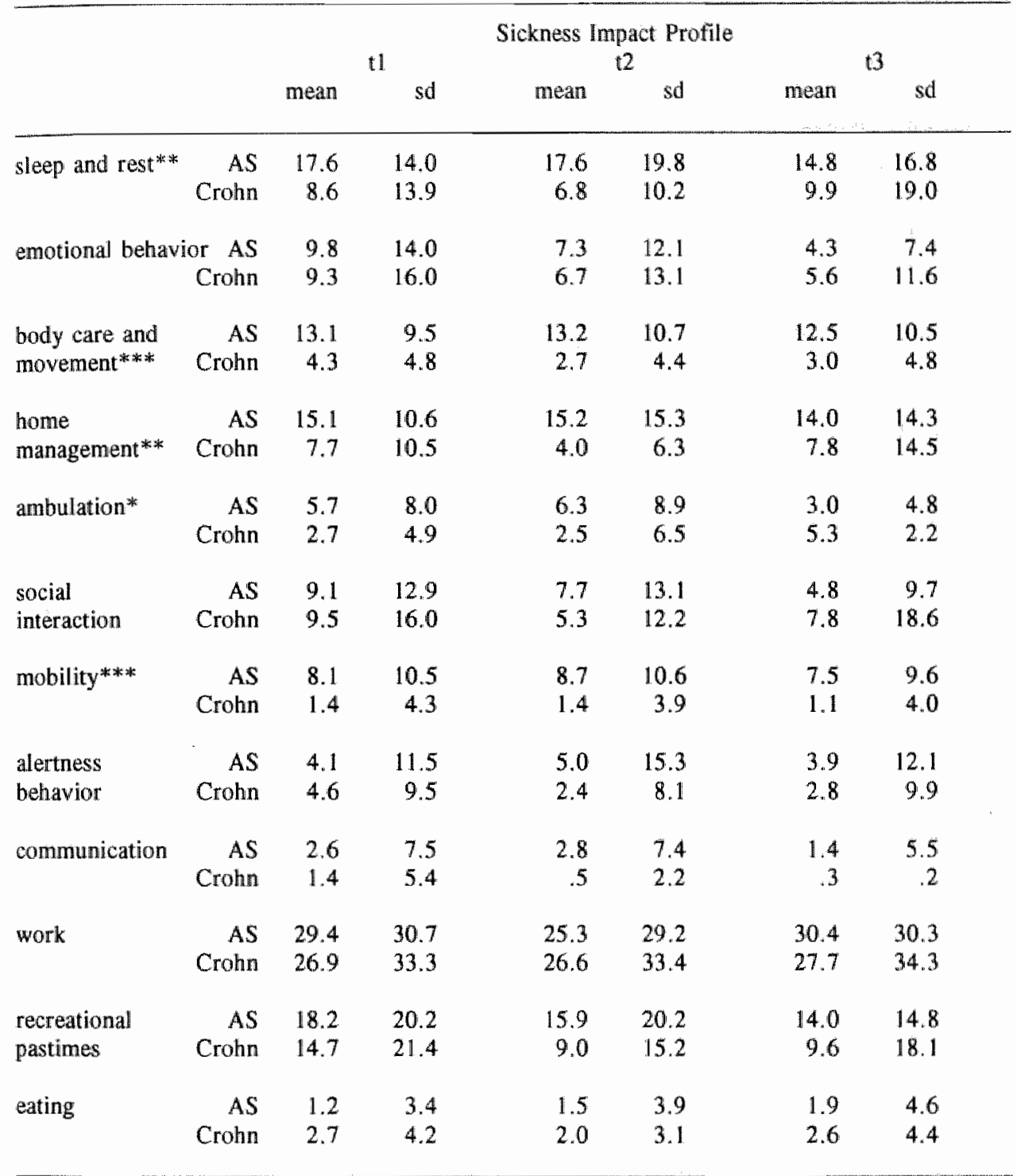

\footnotetext{
* AS respondents score higher than Crohn respondents $p<.05$ at $t 1$ and $t 2$

** AS respondents score higher than Crohn respondents $\mathrm{p}<.01$ at all measurement times

*** AS respondents score higher than Crohn respondents $\mathrm{p}<.001$ at all measurement times
} 


\subsubsection{Subjective health}

Eight questions are asked in order to measure the respondent's subjective health, namelly:

1. To what degree do you accept your health deviation?

2. How serious do you think your health deviation is?

3. How do you evaluate your physical functioning?

4. To what degree does your health deviation hinder you in your daily activities?

5. How do you evaluate your contacts with others?

6. To what degree does your health deviation hinder you in your relationships with people you know well?

7. To what degree does your health deviation hinder you in your relationships with people you know only slightly?

8. How do you evaluate your health status?

These questions were factor-analyzed with the help of a principal component analysis and there proved to be two reasonably stable factors: a physical and a psychosocial one. The physical dimension consists of the questions 2,3,4 and 8; the remaining questions form the psychosocial dimension. The internal consistency, measured with the help of Cronbach's alpha, is .74 and .65 respectively for the two scales at $t 1 ; .69$ and .67 at $t 2$; and .83 and .75 at $t 3$. As a consequence we computed a factor-score for both factors, presented in table 4.13. The higher the score the lower the experienced health status (range 4 to 20).

From the table it can be seen that Crohn patients give a better evaluation of their physical health status than AS patients do $(F(1,65)=5.78, p<.05)$. The groups do not differ with regard to psychosocial functioning.

Significant time-effects are found for the physical $(F(2,64)=40.42, p<.001)$ as well as the psychosocial dimension $(F(2,64)=24.67, p<.001)$. Whereas physical

Table 4.13 Physical and psychosocial factor-scores for AS and Croth

\begin{tabular}{|c|c|c|c|c|c|c|c|}
\hline & \multirow[b]{2}{*}{$\mathrm{n}$} & \multicolumn{2}{|c|}{$t$} & \multicolumn{2}{|c|}{$t_{2}$} & \multicolumn{2}{|c|}{13} \\
\hline & & mean & $s d$ & mean & $\mathrm{sd}$ & mean & $\mathrm{sd}$ \\
\hline \multicolumn{8}{|c|}{ physical sore } \\
\hline AS & 34 & 10.1 & 2.3 & 8.7 & 2.0 & 9.8 & 2.4 \\
\hline Crohn & 33 & 9.3 & 2.4 & 7.5 & 1.5 & 8.5 & 2.3 \\
\hline \multicolumn{8}{|c|}{ Dsychosocial score } \\
\hline $\mathrm{AS}$ & 34 & 5.4 & 1.3 & 6.0 & 1.3 & 6.3 & 1.3 \\
\hline Crohn & 33 & 5.8 & 2.0 & 6.1 & 2.1 & 6.8 & 2.3 \\
\hline
\end{tabular}


functioning improves from $t 1$ to $t 2$ and deteriorates from $t 2$ to $t 3$, psychosocial functioning deteriorates with time.

With regard to subjective health, Pearson correlations were also computed to assess stability (Appendix E). For both patient groups stability of both the physical and the psychosocial scores is revealed to be moderate to high ( $\mathrm{r}$ ranges from .42 to .86 ).

\subsubsection{Duration of the health deviation}

Table 4.14 presents the data with regard to duration of the health deviation. Duration of the health deviation is measured by the number of years the respondent has been diagnosed as having AS or Crohn's disease. Duration of the health deviation of AS patients ranges from 2 to 21 years, and that of Crohn patients ranges from .5 to 33 years. The mean duration is 9.3 years in case of AS respondents and 10.5 years in case of Crohn patients. The difference is not significant.

Table 4.14 Duration of the health deviation of AS and Crohn respondents

\begin{tabular}{lcc}
\hline & AS & $\begin{array}{c}\text { Crohn } \\
(\mathrm{n}=36)\end{array}$ \\
\hline$<2$ years & 2 & 5 \\
$2-10$ years & 24 & 17 \\
$>10$ years & 9 & 14 \\
\hline
\end{tabular}

\subsubsection{Relation between health status variables}

Similarly to the network measures, we computed the relations between the respective operationalizations of health status. First, the relation between the scores on the Sickness Impact Profile and the self-assessment scale by means of Pearson correlations is presented. The data are in table 4.15.

The table shows high Pearson correlations between the instruments used and between the physical and psychosocial dimensions. We also computed $z$-scores in order to determine Cronbach's alpha over the four scales for each measurement time. Alpha is $.82, .82$ and .83 for $t 1, t 2$ and t 3 respectively.

The same analyses were conducted as a check on the data of the separate patient groups. Similar results were found for AS as well as for Crohn patients.

Because of the high correlations together with high Cronbach's alphas, we 
conclude that it is hard to measure the respective dimensions of health status separately and therefore the $z$-scores of the four functional measures were combined into one score, by adding them together. This new variable is labeled "perceived disability level".

Table 4.15 Multiirait-multimethod matrix for the four measures of functional level in between brackets). All correlations are significant $p<.01$

\begin{tabular}{|c|c|c|c|c|}
\hline & & 1 & 2 & 3 \\
\hline 1. physical SIP & $\begin{array}{l}t 1 \\
12 \\
13\end{array}$ & & & \\
\hline 2. psychosocial SIP & $\begin{array}{l}11 \\
12 \\
43\end{array}$ & $\begin{array}{l}.37(75) \\
.58(75) \\
.53(75)\end{array}$ & & \\
\hline 3. physical self-ass. & $\begin{array}{l}\mathrm{t} 1 \\
\mathrm{t} \\
\mathrm{t}\end{array}$ & $\begin{array}{l}.61(72) \\
.62(71) \\
.69(74)\end{array}$ & $\begin{array}{l}.58(72) \\
.46(71) \\
.41(74)\end{array}$ & \\
\hline 4. psychosoc, self-ass. & $\begin{array}{l}t 1 \\
12 \\
13\end{array}$ & $\begin{array}{l}.30(72) \\
.33(71) \\
.33(74)\end{array}$ & $\begin{array}{l}.66(72) \\
.62(71) \\
.62(74)\end{array}$ & $\begin{array}{l}.72(71) \\
.63(70) \\
.60(73)\end{array}$ \\
\hline
\end{tabular}

A variable 'functional course' was also constructed as an indicator of changes in functional level over time. Functional course is computed using the z-scores of perceived disability level. The lowest score over the measurements was added to all scores, in order to get only positive $z$-scores. Then the change score $t 1-t 3$ was computed for these scores. The result is labeled 'functional course'.

After constructing these new variables we computed Pearson correlations with duration of the health deviation. Duration of the health deviation appeared not to be related to perceived disability level and functional course. Pearson correlations were $.07, .14$ and -.12 for perceived disability level at $t 1$, perceived disability level at $\mathbf{3}$ and functional course respectively.

Crohn and AS respondents were also compared with regard to functional course and perceived disability level. There appeared to be no significant differences between the two patient groups. 


\subsection{Coping}

As already stated in chapter 3 , coping was measured at $t 2$ and 13 for healthy respondents and patients respectivelly. Factor scores were computed for the three components of coping by weighting the variables according to their factor loading on each factor (Polit and Hungler, 1983). Factor loadings are enclosed in appendix F. Mean factor scores are presented in table 4.16.

Comparison of the groups using one-way ANOVA revealed that the groups did not differ significantly with regard to action-directed coping, whereas AS patients scored significantly lower on awaiting/avoidance and seeking social support compared to healthy $(p<.01)$ and Crohn $(p<.05)$ respondents.

Table 4.16 Mean factor scores for action-directed coping, seeking social support and awaiting/avoidance

\begin{tabular}{lrrrr}
\hline & & $\begin{array}{c}\text { healthy } \\
(\mathrm{n}=44)\end{array}$ & $\begin{array}{c}\text { AS } \\
(\mathrm{n}=39)\end{array}$ & $\begin{array}{c}\text { Crohn } \\
(\mathrm{n}=36)\end{array}$ \\
\hline \multirow{2}{*}{ action-directed coping } & mean & 11.0 & 11.1 & 10.2 \\
& $\mathrm{sd}$ & 1.9 & 1.8 & 2.5 \\
seeking social support & $\mathrm{mean}$ & 9.7 & 7.9 & 8.9 \\
& $\mathrm{sd}$ & 1.7 & 1.4 & 1.7 \\
awaiting/avoidance & mean & 5.7 & 4.6 & 5.5 \\
& $\mathrm{sd}$ & 1.7 & 1.2 & 1.5 \\
\hline
\end{tabular}

\subsection{Life events}

'Life events' was treated as a dichotomous variable: either an individual stated he experienced a life event or he did not. Table 4.17 presents the number of persons in each respondent group that experienced a life event.

Table 4.17 Number and percentage of respondents that experienced one or more life-events

\begin{tabular}{|c|c|c|c|c|c|c|c|c|}
\hline & \multicolumn{2}{|c|}{$\begin{array}{l}\text { healthy } \\
(n=44)\end{array}$} & \multicolumn{3}{|c|}{$\begin{array}{c}\text { AS } \\
(n=39)\end{array}$} & \multicolumn{3}{|c|}{$\begin{array}{l}\text { Crohn } \\
(n=36)\end{array}$} \\
\hline & 11 & 12 & $t 1$ & 12 & 13 & $\mathrm{tl}$ & 12 & $\mathrm{t} 3$ \\
\hline number & 12 & 15 & 17 & 6 & 8 & 15 & 12 & 15 \\
\hline$\%$ & 27 & 34 & 43 & 15 & 20 & 42 & 33 & 42 \\
\hline
\end{tabular}


Using the Chi-squared analysis no differences were revealed between the scores of the three groups at $t 1$ and $\mathfrak{B}\left(X^{2}=2.8, p=.24\right.$ and $X^{2}=4.0, p=.14$ respectively), and the scores of respondents with AS and those with Crohn at $12\left(X^{2}=2.4\right.$, $\mathrm{p}=.12$ ).

\subsection{Discussion}

In this chapter the data are described along with the results of some first, MANOVA, analyses.

\section{Social position}

We found that the matching procedure as described in chapter 3 led to a group of healthy respondents that were comparable to the patients with regard to social position, except for social class. Furthermore, we found that most Crohn patients were female, whereas in the AS group male patients predominated. We also compared the respondent groups with regard to personal network, health status, life events and coping.

\section{Personal network}

With regard to network size we found no differences between the respondent groups, except at 11 . At 11 AS patients' networks were smaller than both healthy and Crohn respondents' networks. As a consequence of the increase in network size from $\mathrm{t} l$ to $\mathrm{t} 3$ this difference disappears. The increase in size is opposite to our expectation that patients' networks will decrease over time, but, as the analyses described in chapters 5 and 6 will indicate, this probably has a methodological cause (see section 7.4).

With regard to composition, it was shown that the kin network is comparable for all three groups and is stable over time: this is in accordance with our expectations. We hypothesized that network changes following health deviation predominantly take place in the non-kin network. This was confirmed by the analyses, which show that nearly all healthy respondents list non-kin informal network members, whereas only approximately two-thirds of the patients list a non-kin informal network member. The percentage of non-kin informal network members, however, increases over time in all respondent groups. This is opposite to our expectations, but, as in case of size, the increase probably has a methodological cause.

Formal network members are only listed by patients, as we expected, although the number of patients listing a formal network member is low.

As we already expected, healthy respondents and patients predominantly differ with regard to the instrumental exchange in their relationships. We found no group, time or interaction effects with regard to emotional support and only a time 
effect for the kin network with regard to emotional reciprocity. Emotional reciprocity scores are stable over time for healthy respondents, whereas AS patients' scores decrease and Crohn patients' scores increase. The latter result is opposite to our expectations.

With regard to instrumental support, we found interaction effects. Instrumental support given to as well as received from network members is stable in healthy respondents" networks, whereas the amount given to kin and non-kin informal network members as well as the amount received from kin decreases over time in patients' networks. The decrease in the amount of support given to network members accords with our hypotheses, but the decrease in the amount received from kin is opposite to our hypotheses, because we expected that kin especially would be supportive in case of chronic health deviation. The data with regard to instrumental support act as an explanation of the results with regard to reciprocity: reciprocity is stable over time in the kin network and decreases over time in the patients' non-kin informal network.

\section{Health status}

Health status was only measured for the patients. The data show that AS patients have a significantly higher physical SIP score than Crohn patients. The data on subjective health show the same results.

Psychosocial functioning as measured by the SIP improves with time, whereas the self-assessment shows the opposite time effect. Self-assessment scores on physical functioning show an improvement from $t 1$ to $t 2$ followed by a deterioration from t 2 to 3 . These time effects are found in both patient groups.

Computation of Pearson correlations and Cronbach's alphas showed that the four measures of functioning could be combined to one variable labeled perceived disability level. Comparison of AS and Crohn patients no longer showed a significant difference with regard to functioning.

\section{Coping}

Analyses showed that AS patients score lower on awaiting/avoidance and seeking social support than healthy and Crohn respondents.

\section{Life events}

The number of life events experienced does not significantly differ between the three groups of respondents.

In chapter 5 the results with regard to the relation between health status and network will be discussed. The hypotheses are tested with the help of t-tesis and Pearson correlations. 


\section{Health status and personal network}

In this chapter the relationship between disease variables and network variables will be described regarding the hypotheses as formulated in section 2.6.

Section 5.1 contains the comparison of healthy persons" and patients' networks on the basis of hypothesis 1. In section 5.2 AS patients' networks are compared with Crohn patients' networks (hypothesis 2). The relation between duration of the health deviation and personal network (hypothesis 3) is described in section 5.3. Section 5.4 contains the relation between perceived disability level and network characteristics, on the basis of hypothesis 4 . In section 5.5 the longitudinal aspect of the study is described (hypothesis 5). Each section contains a description of the analyses used to test the hypothesis. The chapter ends with a discussion of the results (section 5.6).

The analyses described in chapter 4 showed that the second measurement of patients added no extra explanatory information. Most scores on the variables at 12 do not deviate from the scores at $\mathrm{t} l$ and $\mathrm{t} 3$. Furthermore, most relations between the scores of $\mathrm{t} 1$ and $\mathrm{t} 2$ do not deviate from the relations between the scores of $\mathrm{t} 1$ and $\mathbf{t} 3$. Therefore, we will only describe the data and results of the first and the third measurement time. When healthy respondents and patients are compared, the third measurement of the patients will be compared to the second measurement of the healthy respondents. Furthermore, section 4.2 .5 showed very high correlations between total and both kin and non-kin informal network measures ( $\mathrm{r}$ ranges from .71 to .93 for support measures and from .59 to .93 for reciprocity measures). Therefore, it has been decided to omit the description of the results with regard to the total network and only to discuss the results relating to the kin and the non-kin informal network.

Every section starts with a description of the results in relation to the hypotheses with regard to size and composition because the analyses concern the total respondent group $(n=119)$. Support and reciprocity are described last because the analyses are conducted on the data from only part of the respondents. 


\subsection{Comparing healthy respondents' and patients' networks}

In chapter 2 we argued that health deviation results in a disturbance of the dependency balance between the patient and his network members. The resulting imbalance will weaken some relationships and in the longer run some of these relations will fade away. Furthermore it was stated that relations with relatives are most likely to persist and that health care professionals will become part of the patient's network. In the following subsections the hypotheses deduced from this will be tested.

\subsubsection{Network size}

In the theoretical discussion in chapter 2 we hypothesized that, because of the imbalance in relationships, some network members will drop out of the patient's network. The hypothesis is:

Patients' networks are smaller than the personal networks of healthy persons.

To analyze this hypothesis, a one-tailed t-test was used to test the difference in size between healthy respondents and patients' networks. Table 5.1 shows the average network size at each measurement time.

Although the difference in network size is significant at $\mathrm{t} 1(\mathrm{~T}=2.41, \mathrm{p}<.01)$, this difference is no longer present at $\mathbf{t} 3$.

Table 5.1 Average nenwork size for healthy and patients (n. heathy $=44$ and patients $=7,5$ )

\begin{tabular}{lccccc}
\hline & \multicolumn{2}{c}{4} & \multicolumn{2}{c}{13} \\
& mean & $s d$ & mean & sd \\
\hline healthy & $11.3 * *$ & 5.0 & 10.6 & 4.5 \\
patients & 9.0 & 5.0 & 10.4 & 5.4 \\
\hline
\end{tabular}

** t-test shows that healthy respondents list larger networks $p<.01$

\subsubsection{Network composition}

This section tests the hypotheses that:

Patients' networks contain relatively fewer non-kin informal network members than the personal networks of healthy persons. 
and:

Patients" networks contain more formal network members than the personal networks of healthy persons.

To test the difference in relative amount of non-kin informal relationships we computed the percentages of non-kin informal network members in the respondents" networks. Than we conducted a t-test to see if this percentage was significantly larger in case of healthy respondents compared to the patients. Table 5.2 presents the data. Healthy persons' networks do indeed contain a significantly higher percentage of non-kin informal network members $(t 1: T=3.67, p<.01 ; t 3$ : $\mathrm{T}=3.03, \mathrm{p}<.01$ ), confirming the supposition that it is especially this part of the network that is affected by the health deviation.

Table 5.2 Percentage of non-kin informal network members in healthy respondents' and patients" networks (n:healthy $=44$ and patients $=75$ )

\begin{tabular}{|c|c|c|c|c|}
\hline & \multicolumn{2}{|c|}{$n$} & \multicolumn{2}{|c|}{ t3 } \\
\hline & mean & sd & mean & sd \\
\hline healthy & $36 * *$ & 24 & $42 * *$ & 29 \\
\hline patients & 20 & 23 & 27 & 24 \\
\hline
\end{tabular}

With regard to the difference in number of formal network members, section 4.2 .2 already indicated that the healthy persons' networks contained no formal network members. Moreover, only a small number of patients mentioned formal network members. Table 5.3 presents the number of patients who mentioned formal network members and the total number of formal network members listed.

Table 5.3 The number of patients who mentioned a formal network member together with the total number of formal network members listed $(n=75)$

\begin{tabular}{lrr}
\hline & $t 1$ & $t 3$ \\
\hline number of respondents & 8 & 8 \\
total $n$ of formal network members & 18 & 12 \\
\hline
\end{tabular}


In some cases the health deviation indeed led to formal network members becoming part of the network, although the number of patients who listed a formal network member is low. Although nearly all patients contact a formal caregiver at least once every half year most of them do not regard that person as part of their primary network.

\subsubsection{Support and network reciprocity}

The final hypothesis to test is whether the dependency balance is indeed changing following health deviation. Because our group of patients had already had the health deviation for a longer period, we tested this hypothesis by comparing the reciprocity within patients' and healthy persons' networks. The hypothesis is:

Table 5.4 Emotional ana instrumental support received and given per network member

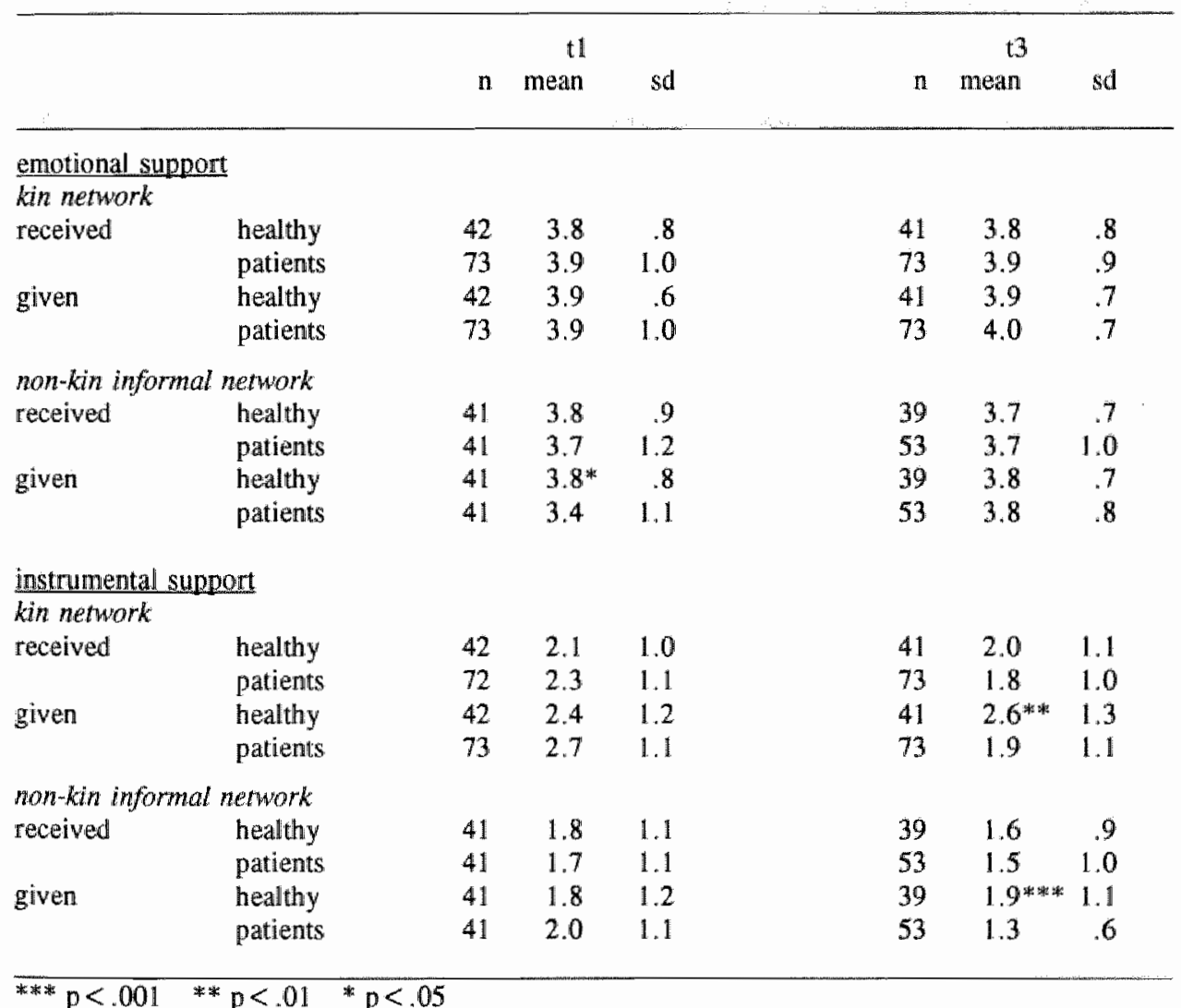


Patients" networks are less balanced than the personal networks of healthy persons, because patients give less and receive more support.

To test this hypothesis we first looked at the difference between healthy respondents and patients with regard to the average amount of support given as well as received per network member. The support data are in table 5.4.

With regard to emotional support, the only significant difference between healthy respondents and patients concerns the amount of emotional support given to nonkin informal network members at $t 1$. Healthy respondents give significantly more support to their non-kin informal network members than patients do $(T=1.94$, $\mathrm{p}<.05$ ).

With regard to instrumental support, at 13 we find a significant difference with regard to both the kin as well as the non-kin informal network. Whereas healthy respondents and patients receive about the same amount of support per network member, healthy give significantly more support to their kin $(T=2.52, p<.01)$ and non-kin informal $(T=3.61, p<.001)$ network members than patients do.

Table 5.5 shows the consequences with regard to kin and non-kin informal reciprocity. Emotional reciprocity scores are more or less equal for both healthy respondents and patients.

The results show that healthy respondents have higher instrumental reciprocity scores at $\mathrm{t} 3$ in the kin network $(T=1.95, \mathrm{p}<.05)$ as well as in the non-kin informal network $(T=2.07, p<.05)$ than patients. The hypothesis stated appears to hold for instrumental reciprocity.

Table 5.5 Average network reciprocity for healthy respondents and patients

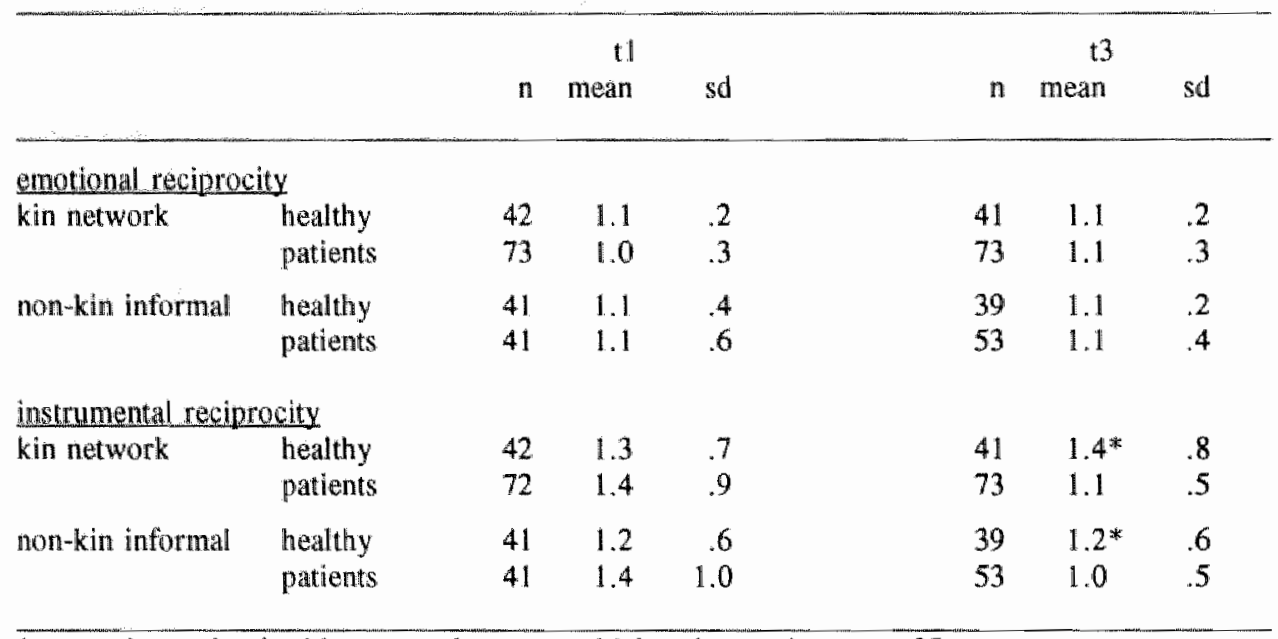

* $t$-test shows that healthy respondents score higher than patients $p<.05$ 
As we have already stated in chapter 2 , in case of physical health deviation it will be the instrumental aspect of the relationships that is affected most. It should be noted that the difference in reciprocity score is caused not so much by the patients receiving more support but by them giving less.

\subsection{Comparing AS and Crohn patients' networks}

In chapter 2 it was argued that the diagnosis may influence network characteristics. Chapter 3 described that the average AS patient is frequently or continuously troubled with backache and limitation of movements, whereas most Crohn patients experience no or little hindrance from their disease for years. The main hindrance lies in their need to take medication every day and the knowledge that at any moment a serious deterioration of the health deviation might occur. This led us to a number of hypotheses that will be discussed in the following subsections.

\subsubsection{Network size}

Because of the difference in disease characteristics it was liypothesized that:

$A S$ patients" networks are smaller than the personal networks of Crohn patients.

Table 4.5 shows the average network size at each measurement time for both respondent groups. Network size is 7.9 and 9.9 for $\mathrm{t} 1$ and $\mathrm{t} 3$ in case of AS patients and for Crohn patients 10.1 and 10.8 respectively. A one-tailed t-test was used to test the difference in network size between AS and Crohn patients. Although the average network of Crohn patients is larger at each assessment compared to that of AS patients, this difference is only significant at $t 1$ ( $T=-1.99$, $\mathrm{p}<.05$ ). Because of the increase in AS patients' network size following $\mathrm{t}$, the difference is no longer significant at $\mathbf{t} 3$.

\subsubsection{Network composition}

This section discusses two hypotheses with regard to network composition:

AS patients" networks contain relatively fewer non-kin informal network members than the personal networks of Crohn patients.

and: 
AS patients' networks contain more formal network members than the personal networks of Crohn patients.

As in section 5.1 .2 we computed the percentage of non-kin informal network members. A t-test was conducted to see if this percentage was significantly larger in case of Crohn patients compared to AS patients. Table 4.6 shows that the data do not support our expectations: AS patients' networks contain about the same percentage of non-kin informal network members as Crohn patients' networks at each measurement time (t1: 21 vs 18 and $\mathrm{t} 3: 28$ vs $23 \%$ ).

With regard to the second hypothesis, more AS than Crohn patients list a formal network member, as can be seen in table 5.6. The data point in the direction of our expectations. However, the number of patients listing a formal network member is very small in both patient groups.

Table 5.6 The number of patients who mentioned a formal network member together with the total number of formal network members listed

\begin{tabular}{lrrrrr} 
& \multicolumn{2}{c}{ AS $(\mathrm{n}=39)$} & \multicolumn{2}{c}{ Crohn(n=36) } \\
& $\mathrm{t} 1 \mathrm{t}$ & $\mathrm{t3}$ & $\mathrm{t1}$ & $\mathrm{t3}$ \\
\hline number of respondents & 6 & 6 & 2 & 2 \\
total $\mathrm{n}$ of formal members & 11 & 8 & 7 & 4 \\
\hline
\end{tabular}

\subsubsection{Support and network reciprocity}

The hypothesis to be tested was:

AS patients' networks are less balanced than the personal networks of Crohn patients, because AS patients give less and receive more support.

With regard to this hypothesis, we first studied the support data for AS and Crohn respondents (see table 5.7). Although Crohn patients receive more non-kin informal emotional support than AS patients (3.9 and 3.5 respectively per network member at $t 1$, and 3.7 and 3.6 at $\mathrm{B}$ ) this difference is not significant. With regard to instrumental support, no significant differences were detected either.

As in section 5.1.3, t-tests were conducted for the kin and non-kin informal metwork reciprocity, the results of which are shown in table 5.8 .

The data shown in table 5.8 reveals significant differences between both patient 
groups with regard to the kin network reciprocity at $\mathrm{t} 3$. Emotional reciprocity scores of Crohn patients are higher than reciprocity scores of AS patients, as we expected. With regard to instrumental support the opposite is the case (two-tailed t-test: $T=2.13, p<.05)$. This is in contradiction with our hypothesis. It may be that the gender difference between both patient groups might explain this finding.

Table 5.7 Emotional and instrumental support received and given per nerwork member

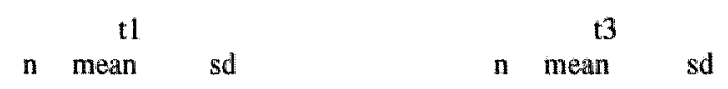

emotional support

kin network

$\begin{array}{llrrrrrrr}\text { received } & \text { AS } & 39 & 3.8 & 1.2 & 39 & 4.0 & 1.0 \\ & \text { Crohn } & 34 & 4.0 & .8 & 34 & 3.8 & .9 \\ \text { given } & \text { AS } & 39 & 4.0 & 1.1 & 39 & 4.0 & .9 \\ & \text { Crohn } & 34 & 3.8 & .8 & 34 & 4.0 & .6\end{array}$

non-kin informal network

$\begin{array}{llllllllr}\text { received } & \text { AS } & 22 & 3.5 & 1.3 & 27 & 3.6 & 1.0 \\ & \text { Crohn } & 19 & 3.9 & 1.2 & 26 & 3.7 & 1.0 \\ \text { given } & \text { AS } & 22 & 3.4 & 1.1 & 27 & 3.8 & .9 \\ & \text { Crohn } & 19 & 3.5 & 1.1 & 26 & 3.8 & .8\end{array}$

instrumental support

kin network

received AS

given

Crohn

39

$2.3 \quad 1.2$

$\begin{array}{lll}39 & 1.8 & 1.0\end{array}$

$\begin{array}{lll}33 & 2.4 & 1.0\end{array}$

$\begin{array}{lll}34 & 1.9 & 1.1\end{array}$

AS

39

$2.8 \quad 1.1$

$\begin{array}{lll}39 & 2.1 & 1.2\end{array}$

Crohn

$\begin{array}{lll}34 & 2.5 & \mathbb{1} .0\end{array}$

$\begin{array}{lll}34 & 1.7 & 1.0\end{array}$

non-kin informal network

received

AS

Crohn

22

$1.7 \quad 1.3$

$\begin{array}{lll}27 & 1.6 & 1.1\end{array}$

given

AS

19

$1.6 \quad .8$

$\begin{array}{lll}26 & 1.3 & .8\end{array}$

Crohn

22

$2.1 \quad 1.2$

$\begin{array}{lll}27 & 1.5 & .7\end{array}$

19

$1.7 \quad 9$

$\begin{array}{lll}26 & 1.2 & .4\end{array}$

\subsection{Duration of the health deviation and personal network}

In chapter 2 we argued that in case of long lasting health deviation those relationships based on balance reciprocity fade, because investments made by the patient's network member cannot be expected to be paid back within an acceptable time period. Duration of the health deviation is expected to be related to network size, composition, support and reciprocity. These relationships will be analyzed in 
the following subsections.

Table 5.8 Awerage network reciprocity for AS and Crohn respondents

\begin{tabular}{|c|c|c|c|c|c|c|c|}
\hline & & & $\mathrm{t} 1$ & & & $\mathrm{t} 3$ & \\
\hline & & $\mathrm{n}$ & mean & sd & $\mathbf{n}$ & mean & sd \\
\hline emotional recipro & cily & & & & & & \\
\hline kin network & AS & 39 & 1.1 & .4 & 39 & $1.0 *$ & .2 \\
\hline & Crohn & 34 & 1.0 & .2 & 34 & 1.1 & .3 \\
\hline non-kin informal & AS & 22 & 1.1 & .7 & 27 & 1.1 & .5 \\
\hline & Crohn & 19 & 1.0 & .3 & 26 & 1.1 & .3 \\
\hline instrumental recin & racity & & & & & & \\
\hline kin network & AS & 39 & 1.5 & 1.0 & 39 & 1.3 & .5 \\
\hline & Crolin & 33 & 1.2 & .8 & 34 & 1.0 & .4 \\
\hline non-kin informal & AS & 22 & 1.6 & 1.2 & 27 & 1.0 & .6 \\
\hline & Crohn & 19 & 1.2 & .7 & 26 & 1.0 & .3 \\
\hline
\end{tabular}

* $t$-test shows that Crohn patients score higher than AS patients $p<.05$

\subsubsection{Network size}

Because of the fading of certain relationships, we expect that:

The longer the health deviation exists (independent of diagnosis), the smaller the personal network.

Because of the stability of the network size (see chapter 4), an overall measure was calculated for this network variable (i.e. [size $t 1+$ size t3] / 2). We computed the Pearson correlation between duration of the health deviation and overall network size $(n=75)$. This correlation is significantly negative $(r=-.19$, $p=.05$ ) confirming the above hypothesis. The data on the separate measurements are in appendix $\mathrm{G}$.

\subsubsection{Network composition}

This section contains the analyses with regard to two hypotheses:

The longer the health deviation exists (independent of diagnosis), the relatively fewer non-kin informal network members there are. 
And:

The longer the health deviation exists (independent of diagnosis), the relatively more formal network members there are.

To test the first hypothesis Pearson correlations were computed between duration of the health deviation and percentage of non-kin informal network members. The overall percentage of non-kin is not significantly correlated to duration of the health deviation $(r=-.05, p>.05)$. This again may be explained by the fact that almost all patients had already had their health deviation for at least a few years. The data of the separate measurements are in appendix G.

With regard to the formal network, it has already been stated that there were only a small number of respondents who listed formal network members. Therefore, only the duration of the health deviation of those respondents who listed a formal network member was investigated. The mean duration of the health deviation of Crohn patients listing formal network members is 8.5 years. It appears that this is on average 2 years less than the mean duration of the health deviation of the total group of Crohn patients. This seems to be contrary to our hypothesis.

In the case of AS patients, those respondents who listed a professional had their health deviation on the average 0.5 years longer than the mean duration of the health deviation of the total group, but this is a very small difference.

\subsubsection{Support and network reciprocity}

With regard to network support and reciprocity we hypothesized that:

The longer the health deviation exists (independent of diagnosis), the less support the patient gives and the more he receives and thus the less balanced the network.

We first look at the Pearson correlations between duration of the health deviation and kin and non-kin informal emotional as well as instrumental support. The data are in table 5.9 .

According to our expectations, the correlations with regard to support received must be in a positive direction and the correlations with regard to support given in a negative one. The data in the table show that there are no significant correlations between duration of the health deviation and emotional support received and given in both the kin as well as in the non-kin informal network.

With regard to instrumental support, a positive relationship is found between duration of the health deviation and support received, as we expected. The correlation is, however, only significant for the kin network at $t . .(r=.19, p<.05)$. 
With regard to instrumental support given, only one significant correlation is found, that is between duration of the health deviation and support given to kin members at $\mathbf{3}$. The direction of the correlation is contrary to our hypothesis (twotailed test: $\mathrm{r}=.23, \mathrm{p}=.05$ ).

Table 5.9 Pearson correlations for duration of the health deviation and kin $(n=73)$ and nonkin informal $(n=42)$ support

duration of the health deviation

emotional support

kin network

receive

.15

non-kin informal network

give

$-.05$

$-.02$

receive

$-.07$

give

$-.04$

.04

instrumental support

kin network

receive

$.19^{*}$

.16

giwe

$-10$

.23

non-kin informal network

receive

give

.04

.20

$-.08$

.06

* $p<.05$

To test the hypothesis with respect to reciprocity, Pearson correlations were calculated between duration of the health deviation and the emotional and instrumental reciprocity scores for the kin and non-kin informal parts of the network as computed in section 4.2.4. Table 5.10 presents the Pearson correlations.

The data with regard to the kin network reciprocity show a significantly negative correlation between duration of the health deviation and both emotional and instrumental reciprocity at $\mathrm{t}$. The data indicate that the longer one has a health deviation, the lower the reciprocity score in the kin network. In other words, the patient gives less and receives more when he has a longer duration of the health deviation (see the data in table 5.9).

Table 5.10 shows that there is no significant correlation between duration of the health deviation and non-kin informal network reciprocity. The reciprocity between giving and receiving of support appears not to correlate significantly with duration of the health deviation. The explanation again may be that duration of the health deviation of the respondents has already lasted for such a period that the most unbalanced contacts have already faded away. 
Table 5.10 Pearson correlations for duration of the healh dewation and kin $(n=73)$ and monkin informal ( $n . " t=41, t 3=53$ ) network reciprocity

duration of the health dewiation

tI

emotional reciprocity

kin network

non-kin informal network

instrumental reciprocity

*** $\mathrm{p}<.01 * \mathrm{p}<.05$

\subsection{Perceived disability level and personal network}

In chapter 2 we argued that the more disabling a health deviation, the more the patient becomes dependent on other persons. This led us to hypothesis 4 which is discussed in the following subsections.

\subsubsection{Network size}

The higher the perceived disability level, the smaller the nerwork.

In order to test this hypothesis, we computed Pearson correlations between perceived disability level and network size. The results are presented in table 5.11.

Table 5.11 Pearson correlations between perceived disability level and network size $(n=67)$

$t^{\text {perceived disability level }}$

network size

$-.15$

$-.08$

A negative correlation here means that the higher the score on the functional measure (i.e. the higher the perceived disability level), the smaller the personal network. Thus, a negative correlation is in accordance with our hypothesis, as is 
shown in table 5.11 where perceived disability level is negatively correlated with network size. The correlations are not significant, but point in the direction of our hypothesis.

\subsubsection{Network composition}

Again there are two hypotheses which relate to network composition:

The higher the perceived disability level, the smaller the relative number of non-kin informal network members.

And:

The higher the perceived disability level, the higher the relative number of formal network members.

To test the first hypothesis, we computed the Pearson correlations between perceived disability level and percentage of non-kin informal network members as presented in table 5.12. Negative correlations point in the direction of our hypothesis. The table shows no significant correlations. Our hypothesis is not confirmed by the data.

Table 5.12 Pearson correlations between perceived disability level and percentage of non-kin informal network members $(n=66)$

perceived disability level

t.

t3

\% of non-kin network members

11

.00

With regard to the number of formal network members, we studied the z-scores of those respondents who listed formal network members. It appeared that at $\mathbb{t l}$ $(\mathrm{n}=7)$ the number of positive $\mathrm{z}$-scores was almost equal to the number of negative $z$-scores. At $\mathfrak{t} 3(n=7)$ there was only one positive $z$-score. These numbers indicate that formal network members are predominantly listed by respondents whose perceived disability level is relatively low. The data give no proof for the formulated hypothesis. They even seem to point in the opposite direction, but it should be noted that the number of patients listing formal network members was very small. 


\subsubsection{Support and network reciprocity}

The higher the perceived disability level, the less support given and the more support received and therefore the more unbalanced the network.

First, Pearson correlations were computed between perceived disability level and support measures. The results are shown in table 5.13.

With regard to emotional support, no correlation with perceived disability level is found. With regard to instrumental support we find positive correlations between kin and non-kin informal support received and perceived disability level at 13 $(r=.37, p<.01$ and $r=.59, p<.001$ respectively). This means that a higher perceived disability level is related to a higher amount of instrumental support received. This is in accordance with our hypothesis.

Table 5.13 Pearson correlations between perceived disability level and kin $(n=65)$ and non-kin informal $(n: t)=37, t 3=49)$ support

perceived disability level

t1

13

\begin{tabular}{|c|c|c|c|}
\hline \multicolumn{4}{|l|}{ emotional support } \\
\hline \multirow[t]{2}{*}{ kin network } & receive & -.16 & .02 \\
\hline & give & .16 & .09 \\
\hline \multirow{2}{*}{ non-kin informal network } & recelve & -.17 & -.04 \\
\hline & give & -.14 & .11 \\
\hline \multicolumn{4}{|l|}{ instrumental support } \\
\hline \multirow{2}{*}{ kin network. } & receive & .02 & $37^{2}$ \\
\hline & give & -.01 & .14 \\
\hline \multirow[t]{2}{*}{ non-kin informal network } & receive & -.04 & 59 皮 \\
\hline & give & .24 & 26 \\
\hline
\end{tabular}

Table 5.14 presents. Pearson correlations between perceived disability level and kin and non-kin informal network reciprocity.

We argued that a higher perceived disability level would be correlated to relationships in which the patient received more than he gave. In other words, a higher perceived disability level is expected to be related to a lower reciprocity score. The data with regard to emotional reciprocity show a positive correlation between kin reciprocity and perceived disability level at $t l(r=.40, p<.01)$. This is contrary to our expectations. Instrumental reciprocity is shown to be negatively related to perceived disability level at $\mathbf{t} 3$, be it only significantly so at 3 for the kin network $(r=-.22, p<.05)$. 
Table 5.14 Pearson correlations between perceved disability level and kin $(n=65)$ and non-kin informal $(n+1)=37,13=49)$ reciprocity

perceived disability level

11

t3

emotional reciprocity

kin network

.40

.15

non-kin informal network

$-.03$

instrumental reciprocity

kin network

non-kin informal network

$p<.05$

\subsection{Functional course and network changes}

As stated in chapters 1 and 2 , the purpose of the longitudinal part of the study is to map the changes in the patient's network that take place as a result of (changes in) the health deviation. For this purpose we formulated hypothesis 5 which will be discussed in the following subsections.

\subsubsection{Network size}

With regard to network size we hypothesized:

If the functional disability increases, the number of network members decreases.

The Pearson correlation between the change score $t 1-t 3$ for perceived disability level and network size shows that there is no correlation between functional course and changes in network size $(r=-.06)$. This means that no proof is found for the hypothesis stated.

\subsubsection{Network composition}

With regard to network composition, we are interested in the relative number of non-kin persons listed in the patients' networks. Two hypotheses were formulated:

If the functional disability increases, the relative amount of non-kin informal 
network members decreases.

If the functional disability increases, the number of formal network members increases.

To test the first hypothesis, we computed Pearson correlations between change in perceived disability level and change in the percentage of non-kin informal network members. No correlation was found between functional course and change in the percentage of non-kin informal network members $(\mathrm{r}=.02)$.

With regard to the second hypothesis, no statistical tests were conducted because of the small number of respondents listing a formal network member. We restricted the analysis to a study of the changes in the number of formal network members listed from $\mathrm{t} 1-\mathrm{t} 3$ in the functional group to which the respondent belongs. The data shows that respondents whose perceived disability level deteriorates more often show a decrease in the number of formal network members listed than an increase. The same applies to respondents whose perceived disability level improves over time. The data give no indication for confirmation or rejection of our hypothesis.

\subsubsection{Support and network reciprocity}

In this section we concentrate on the relation between changes in perceived disability level and changes in network support and reciprocity. The hypothesis is:

If the functional disability increases, the amount of support given decreases and the amount received increases and thus the imbalance in the patient's network increases.

We start by computing Pearson correlations between change score $t 1-t 3$ for the perceived disability level (=functional course) and the change scores $11-13$ for the support measures. According to the hypothesis, we expect positive correlations between functional disability and support received and negative correlations between functional disability and support given. The data are in table 5.15.

With regard to emotional support, the only higher correlation is found between functional course and support given to non-kin informal network members. The direction of the correlation is in accordance with our expectations but is not significant $(r=-.22, p=.10)$. 
Table 5.15 Pearson correlations betwen change score $11-13$ for perceived disability level and kin $(n=65)$ and non-kin informal $(n=34)$ support

functional course

t1 $1-13$

emotional support

$\begin{array}{llr}\text { Kin network } & \begin{array}{l}\text { receive } \\ \text { give }\end{array} & .01 \\ \text { non-kin informal network } & \begin{array}{l}.0 \\ \text { receive } \\ \text { give }\end{array} & .07 \\ \text { instrumental support } & & -22 \\ \text { kin network } & \begin{array}{l}\text { receive } \\ \text { give }\end{array} & .20^{*} \\ \text { non-kin informal network } & \text { receive } & -.31^{* * *} \\ & \text { give } & .20 \\ & \text { give } & -.05\end{array}$

* $p<.01 * p<.05$

With regard to instrumental support, the correlations are in the expected direction, but are only significant for the kin network. The data with regard to the kin network thus mean that when the perceived disability level increases from $t 1$ to $t 3$, the instrumental support received increases $(r=.20, p=.05)$ and the instrumental support given decreases $(r=-.31, p<.01)$. This finding is in accordance with the hypothesis stated and at the same time underlines the importance of kin in the deliverance of support in case of chronic health deviation.

Table 5.16 Pearson correlations berwen the change score $11-13$ for perceived disability level and kin $(n=65)$ and non-kin informal $(n=34)$ network reciprocity

functional course

t) $-1+3$

emotional reciprocity

kin network .14

non-kin informal network

$-.18$

instrumental reciprocity

kin network

$-.26^{*}$

non-kin informal network

$-.04$

${ }^{*} \mathrm{p}<.05$

In order to test the hypothesis with regard to reciprocity, Pearson correlations were computed between the change score $t 1-t 3$ for perceived disability level and 
the change scores for the kin and non-kin informal network reciprocity. The results are shown in table 5.16 , which reveals no significant correlations between change in perceived disability level and change in emotional network reciprocity. The data with regard to change in instrumental kin reciprocity are in agreement with the hypothesis. We find a negative correlation between change in perceived disability level and change in instrumental kin network reciprocity, as we expected $(\mathrm{r}=-.26, \mathrm{p}<.05)$.

There is no correlation between functional course and non-kin informal instrumental reciprocity $\mathrm{t} 1-\mathrm{t} \mathbf{3}$.

\subsection{Discussion}

This chapter produced a number of interesting results (see table 5.17). It is noted that most of these results are only found at either tl or $\mathrm{t} 3$. Because this is hard to explain using network theory, we assume that there is a methodological cause, such as information bias (see section 7.4).

We will now discuss the results for each network variable under study separately.

Table 5.17 Summary of the results described in chapter 5

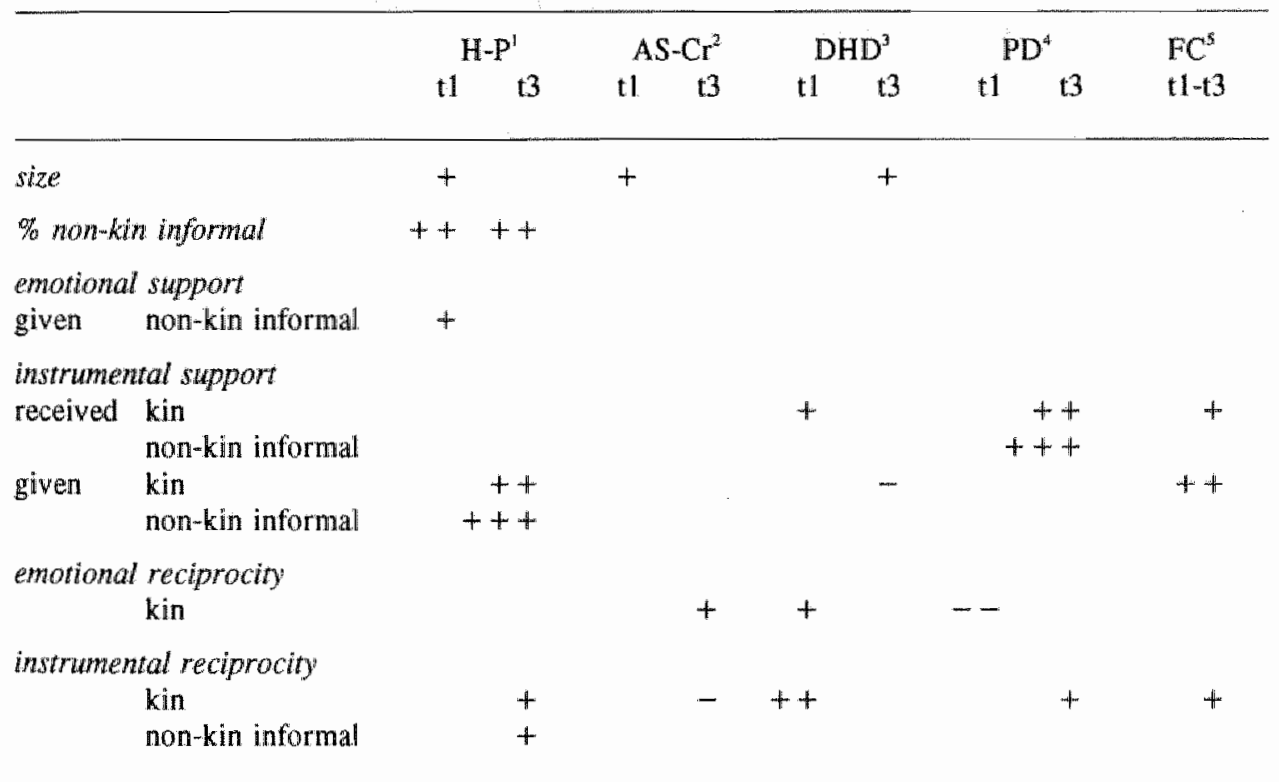

1 healthy-patient; $2 \mathrm{AS}-\mathrm{Crohn} ; 3$ duration of the health deviation; 4 perceived disability level; 5 functional course

+ significant correlation in expected direction; - significant correlation in opposite direction 


\subsubsection{Size}

With regard to size the analyses revealed that healthy respondents have larger networks than patients, as we hypothesized. However, this finding is valid only for 11 , because patients' networks increase from $t 1$ to $t 3$. This increase seems to be in contradiction with our hypothesis with regard to duration of the health deviation, stating that network size decreases when duration of the health deviation increases. This last hypothesis is affirmed (section 5.3.1) and therefore it must be assumed that the increase in size from $t 1$ to $B$ probably has a methodological cause. It might be that patients, more than healthy respondents, as a consequence of the interview are activated to think about their social relationships, thus leading them to list more network members at ( 12 and) $\mathrm{t} 3$, especially non-kin informal members. We also found that Crohn patients" networks are larger than AS patients' networks, again only at $\mathrm{tl}$. Although network size of both patient groups increases from $\mathrm{t} 1$ to $\mathrm{B}$, this increase is larger in case of AS patients, thus leading to the disappearance of the significant difference.

In contrast to our expectations, perceived disability level and functional course appeared to be not related to network size. It appears that it is not so much the degree of disability that is related to network size, but rather the fact that one is disabled. With regard to functional course, an explanation could be that the respondents" health deviation has already been present for such a time that network size has more or less stabilized. In other words: those contacts that were likely to disappear, have already faded. Only those network members remain who are able to deal with the health deterioration of the respondent.

\subsubsection{Composition}

With regard to composition, we have already noted in chapter 4 that a significantly larger number of healthy respondents listed non-kin informal network members compared to patients. In accordance with these findings t-tests described in section 5.1 .2 revealed that the percentage of non-kin informal network members in healthy respondents" networks is significantly higher at both 11 and $t 3$ than the percentage of non-kin informal network members in patients' networks.

It appeared that, contrary to our hypothesis, AS and Crohn patients list a comparable percentage of non-kin informal members in their networks. AS patients' percentage is even slightly higher, but this is probably due to the gender difference between the two patient groups (see section 2.4.2.1).

Although network size appeared to be negatively related to duration of the health deviation, the percentage of non-kin informal network members is not. Neither do we find relations between perceived disability level and functional course on the one hand and the percentage of non-kin informal members on the other. We refer 
to the explanation given in the last paragraph of section 5.6 .1 , concerning the degree of disability and duration of the health deviation.

With regard to formal network members we found that healthy respondents list no formal members, whereas 8 patients do. There are more AS than Crohn patients listing formal network members. However, because of the small number of respondents listing formal network members we are not able to confirm or reject any of our hypotheses with regard to the formal network.

\subsubsection{Support}

There are some very interesting results with regard to social support given to or received from network members. In the first place we found no significant difference between healthy respondents and patients or between the two separate patient groups with regard to emotional support. The only exception is the difference between healthy respondents and patients with regard to non-kin informal support given at $\mathrm{t} 1$, which shows that healthy persons give more support to non-kin informal network members than patients do. There also appear to be no relations between emotional support on the one hand and duration of the health deviation, perceived disability level and functional course on the other.

With regard to amount of instrumental support, we found that healthy respondents give significantly more than patients $(\mathrm{t} 3)$. There is no significant difference with regard to the amount of instrumental support received between healthy respondents and patients. There also appeared to be no differences between AS and Crohn patients with regard to instrumental support.

We found that duration of the health deviation is positively related to the amount of kin support received ( $t 1$ ) and given (t3). The first accords with our hypothesis, whereas the second is in contrast.

Furthermore, we found that a higher level of perceived disability is very important for receiving instrumental support of kin as well as non-kin informal network members. With regard to functional course it appeared that when functional disability increases the patient gives less to his kin members, whereas he receives more, indicating that especially kin network members are important in giving support.

Looking at these results concerning emotional and instrumental support, we may conclude that, as already suggested in section 2.1.1, it is especially the instrumental exchange in relations with network members that is affected by chronic somatic health deviation. 


\subsubsection{Reciprocity}

Most results with regard to reciprocity can be deduced from the support data. Thus we find that the instrumental reciprocity score - kin as well as non-kin informal - of healthy respondents is significantly higher than that of patients, supporting our hypothesis that patients receive more/give less than healthy respondents. With regard to the comparison between AS and Crohn patients we find that Crohn patients have higher emotional reciprocity scores than AS patients, as we expected. However, we also find that AS patients have higher instrumental kin reciprocity scores than Crohn patients. This contrasts with our hypothesis, but might be explained by the gender difference between both groups.

Duration of the health deviation is found to be related to emotional and instrumental kin reciprocity: the longer the health deviation exists, the lower the reciprocity score, as we expected. This also holds for perceived disability level and instrumental kin reciprocity. As for perceived disability level and emotional kin reciprocity we find a positive correlation, in contradiction with our hypothesis. At first we thought that this correlation could be explained by the fact that patients give more emotional support to compensate for their instrumental dependency. However, Pearson correlations between the change scores of emotional and instrumental support, falsify this explanation ( $\mathrm{r}$ ranges from -.09 to .10 ). We now suppose that a positive correlation shows that a person becomes important as emotional support giver by experiencing health problems.

The last result concerns the correlation between functional course and instrumental kin reciprocity. As already discussed in section 5.6.3, patients receive more support and give less to kin members. This leads to a decrease of the reciprocity score, in accordance with our hypothesis.

In chapter 6 the results will be discussed extensively, after analyzing the role of coping, social position and life events. 


\section{The effect of coping, social position and life events}

This chapter presents the necessary adjustments to the relation between health status and personal network characteristics as described in the preceding chapter with regard to the influence of coping, social position and life events.

We start with an analysis of the relations between these influencing variables and their relations with the independent and dependent variables (sections 6.1, 6.2 and 6.3 respectively). The relation between the respective operationalizations of health status and network characteristics was adjusted for those variables that show a significant relation with both the independent and the dependent variables. For those variables that are only related to the dependent variables, it was investigated whether they have an interaction with health status. Analysis of (co)variance was used to study the effect of coping, social position and life events. When a coping dimension is related to one of the network variables or to both health status and a network variable, it is taken into AN(C)OVA as a factor. Coping is never specified as a covariate because our interest lies in the possible interaction effects it has with health status. When social position or life events are related to the independent as well as the dependent variable, they are specified as a covariate, because we only want to control for these variables.

The analyses with regard to hypotheses 1 to 5 are described in sections 6.4 to 6.8 respectively. Section 6.9 contains a discussion of the results.

\subsection{Relation between coping, social position and life events}

Before relating the influencing variables to the independent and dependent variables, it is necessary to study the relationships that hold between them. In an overview of their mutual relations, appendix $H$ indicates that male respondents score higher on action-directed coping $(r=-.41, p<.001)$ and lower on seeking social support $(r=.21, p<.05)$ than female respondents.

With regard to social class, we find that the higher the social class a respondent occupies the higher he scores on action-directed coping $(r=.34, p<.001)$ and seeking social support $(r=.20, p<.05)$. Respondents in a higher social class are also less likely to mention experiencing life events compared to respondents in the 
lower social classes $(r=-.23, p<.05)$.

With respect to age, it is apparent that the older a person is, the lower the score on seeking social support $(r=-.21, p<.05)$.

Seeking social support is also related to both other coping dimensions: the higher the score on seeking social support, the higher the scores on action-directed coping $(\mathrm{r}=.19, \mathrm{p}<.05)$ and awaiting/avoidance $(\mathrm{r}=.36, \mathrm{p}<.001)$.

Attention must be paid to these relations between influencing variables insofar as these variables appear together in the same analyses.

\subsection{Relation between influencing variables and health status}

Table 6.1 gives an overview of influencing variables that are related to the respective measures of health status.

In chapter 4 attention had already been drawn to the differences between the three respondent groups with regard to coping, social position and life events. It appeared that AS and Crohn respondents differed with regard to gender and two dimensions of coping: seeking social support and awaiting/avoidance.

Table 6.1 Overview of significant relations between the respective measures of health status and influencing variables

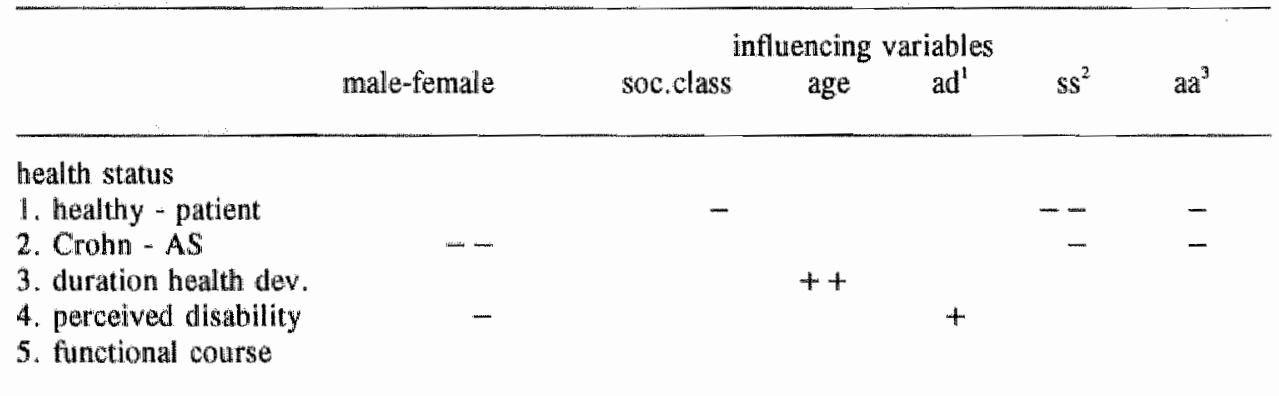

1 action-directed coping; 2 seeking social support; 3 awaiting/avoidance

- negative relation $p<.05 \quad--$ negative relation $p<.01$

+ positive relation $p<.05 \quad++$ positive relation $p<.01$

Chapter 4 compared healthy respondents to both groups of patients separately. Hypothesis I entails a comparison between healthy respondents and the total group of patients. The results show that healthy persons and patients differ with regard to social class $\left(X^{2}=4.26, p<.05\right)$, and the two coping dimensions seeking social support $(T=4.13, p<.01)$ and awaiting/avoidance $(T=2.28, p<.05)$ : healthy respondents have a higher social class and score higher on seeking social support and awaiting/avoidance. The data are given in appendix I. Appendix I also 
contains the data on the relation between influencing variables and duration of the health deviation, perceived disability level and functional course. It appears that duration of the health deviation is only correlated with age $(r=.49, p<.01)$. Perceived disability level correlates with gender $(T=2.11, p<.05$ at $t 1$ and $\mathrm{T}=2.22, \mathrm{p}<.05$ at $\mathrm{t} 3)$ and action-directed coping $(\mathrm{r}=.22, \mathrm{p}=.06$ at $\mathrm{tl}$ and $\mathrm{r}=.27$, $\mathrm{p}<.05$ at $\mathrm{t} 3$ ). It appears that male respondents' perceived disability level is higher at all measurement times than female respondents' perceived disability level. Furthermore, a higher score on action-directed coping is related to a higher perceived level of disability.

Not one of the influencing variables in the study is related to changes in perceived disability level (=functional course).

\subsection{Relation between influencing variables and network}

This section reports the investigation of the relation between coping, social position and life events and the personal network variables. We conducted the analyses for the total group of respondents, healthy as well as patients. Since hypothesis 5 concerns the patients only, the analyses in this instance were conducted for the patients only. An overview of the data is in appendix $J$.

Table 6.2 presents an overview of significant relations between the network characteristics and the influencing variables for the total respondent group and the change scores of the patients.

Network size is related to seeking social support: the higher the score on the coping dimension, the larger the network $(r=.22, p<.01)$.

The percentage of non-kin informal network members is related to gender, family composition, action-directed coping and seeking social support. Male respondents list a higher percentage of non-kin informal network members than female respondents $(T=2.12, p<.05)$; respondents with no children living at home list a higher percentage of non-kin informal network members compared to respondents with children living at home (35 vs $24 \%, \mathrm{~T}=2.41, \mathrm{p}<.05)$. Furthermore, a higher score on action-directed coping and on seeking social support is related to a higher percentage of non-kin informal network members (action-directed coping: $r=.19$, $p<.05$ and seeking social support: $r=.25, p<.01$ ).

We find that the amount of emotional support received per kin network member is positively related to age: the higher the age, the higher the amount of kin support received $(r=.23, p<.05)$. Non-kin informal emotional support received is negatively related to action-directed coping: a higher score on action-directed coping is related to a smaller amount of non-kin informal emotional support received $(r=-.25, p<.05)$. 
Table 6.2 Overvew of signficant relations benween nework characteristics and influencing wariables. $n$ size and compostion $=119(75)$, kin support and reciprocity $=114(73)$, not-kin informal support and reciprocity $=74(37)$. Between brackets is the number of patients.

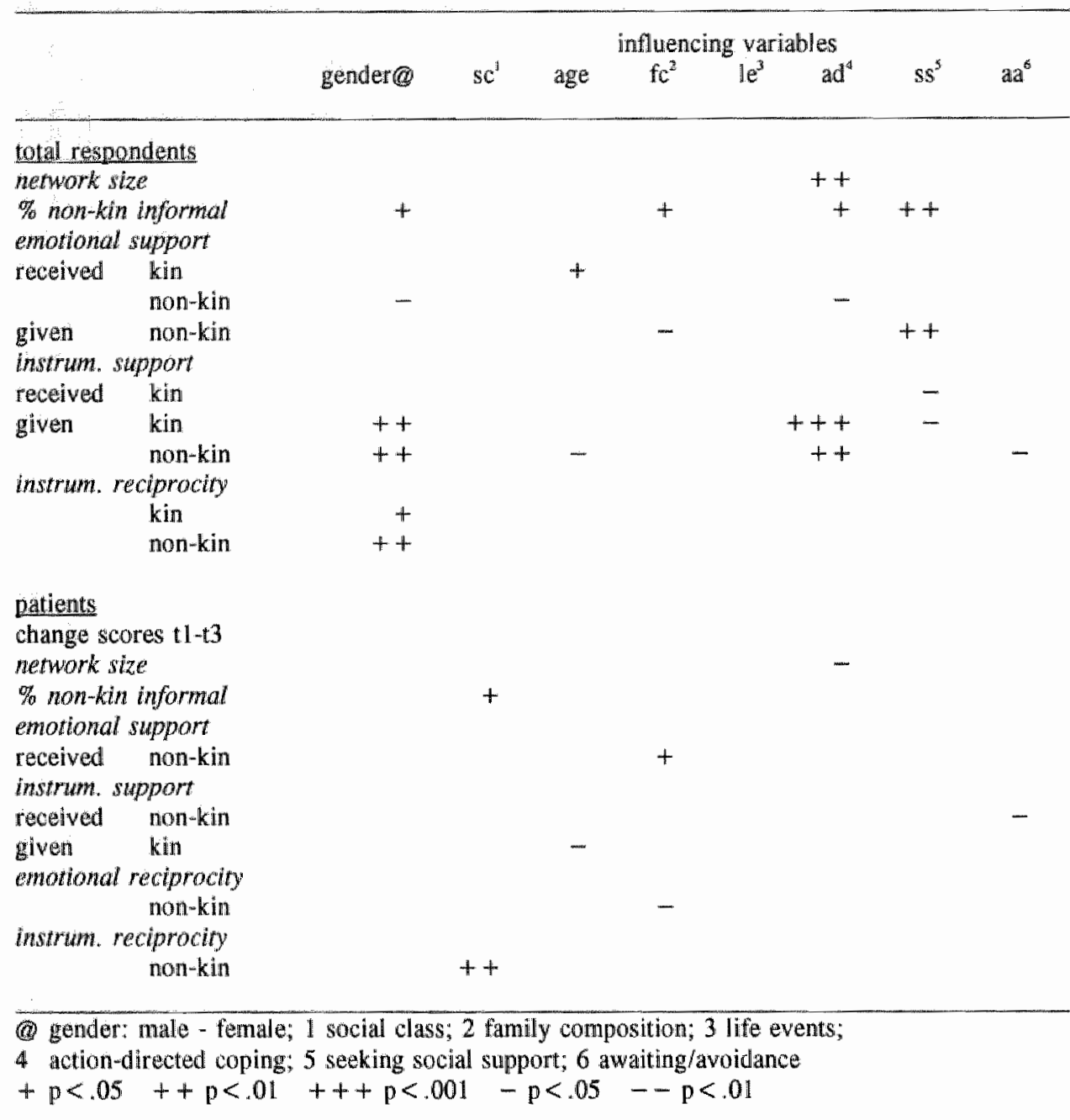

It also appears that female respondents receive more non-kin informal emotional support than male respondents $(T=-2.26, \mathrm{p}<.05)$.

With regard to emotional support given, relations hold between support given by non-kin informal network members and both family composition and seeking social support. Respondents having children at home give more emotional support to their non-kin informal network members than respondents without children at 
home $(T=-2.01, \mathrm{p}<.05)$ and a higher score on seeking social support is related to a higher amount of emotional support given to non-kin informal network members $(\mathrm{r}=.35, \mathrm{p}<.01)$.

Concerning instrumental support, a higher score on seeking social support is related to a lower amount of kin support received $(r=-.22, p<.05)$. Furthermore, male respondents give more kin $(T=3.21, p<.01)$ as well as non-kin informal $(T=3.29, \mathrm{p}<.01)$ instrumental support than female respondents. Instrumental support given to kin is related to the coping dimensions action-directed coping and seeking social support: a higher score on action-directed coping is related to a higher amount of instrumental support given to kin network members $(r=.32$, $\mathrm{p}<.001$ ), whereas a higher score on seeking social support is related to a lower amount of instrumental support given to kin $(r=-.19, p<.05)$.

Instrumental support given to non-kin informal network members is related to age, action-directed coping and awaiting/avoidance. Higher age and a higher score on awaiting/avoidance are both related to a smaller amount of instrumental support given to non-kin informal network members $(r=-.25, p<.05$ and $r=-.27, p<.05$ respectively), whereas a higher score on action-directed coping is related to a higher amount given $(r=31, p<.01)$.

Emotional reciprocity is related to none of the influencing variables studied, whereas instrumental reciprocity is only related to gender. Male respondents appear to have higher kin as well as non-kin informal instrumental reciprocity scores compared to female respondents $(F=2.42, p<.05$ and $F=3.45, p<.01$ respectively).

For the patients we studied the relations between the influencing variables and change scores $\mathrm{t} 1-\mathrm{t} 3$ of the network variables. With regard to coping, a relation can be found between action-directed coping and changes in network size from $t \rrbracket$ to $t 3$ $(\mathrm{r}=-.20, \mathrm{p}<.05)$. A higher score on action-directed coping is correlated to a lower change score. This means that the higher the respondent scores on actiondirected coping, the larger the increase in network size. Social class is related to changes in the percentage of non-kin informal network members $(F=4.51$, $\mathrm{p}<.05$ ). Respondents in the higher social class show an increase in the percentage of non-kin informal network members from $t 1$ to $t 3$. Respondents in the average social class show no changes, whereas the respondents in the low social class show a decrease in the percentage of non-kin members.

Changes in emotional support are only related to family composition. It appears that for respondents without children at home the non-kin informal emotional support received decreases from $t 1$ to 3 , whereas it increases for respondents having children at home $(T=2.39, \mathrm{p}<.05)$.

Changes in instrumental support are related to both age and awaiting/avoidance. Higher age appears to be related to an increase in instrumental support given to kin network members from $\mathrm{t} 1$ to $\mathrm{t} 3(\mathrm{r}=-.19, \mathrm{p}<.05)$ and the higher the score on awaiting/avoidance, the larger the increase in instrumental support received from 
non-kin informal network members $(r=-.27, \mathrm{p}<.05)$.

Changes in emotional reciprocity are only related to family composition. Respondents without children at home show an increase of the emotional non-kin informal reciprocity score from $\mathrm{tl}$ to $\mathrm{t} 3$ compared to a decrease in case of respondents having a child at home $(\mathrm{T}=-2.07, \mathrm{p}<.05)$.

Changes in instrumental reciprocity are related to social class: respondents in the average and higher social class show stable non-kin informal reciprocity scores, whereas instrumental reciprocity in the non-kin informal network decreases from t1 to $\mathrm{t} 3$ for respondents in the low social class $(T=5.69, p<.01)$.

In the subsequent sections the relations between the different measures of health status and network measures are studied taking into account those influencing variables that are significantly related to the dependent variable or to both the independent and dependent variable.

Each subsection starts with a description of the influencing variables that are relevant to the relation between health status and the network characteristic under study. Attention is only paid to those relations between health status and network characteristics that, in chapter 5 , appeared to be significant.

Those relations that, in chapter 5, appeared not to be significant are only described when ANOVA reveals an interaction effect between one of the influencing variables and health status.

\subsection{Comparing healthy respondents' and patients' networks}

In section 5.1 it was reported that healthy respondents and patients differ significantly with regard to network size (t1), percentage of non-kin network members $(t 1,13)$, emotional support given to non-kín informal network members (t1), instrumental support given to kin as well as non-kin informal network mernbers (t3) and instrumental kin and non-kin informal reciprocity (t3). This section focuses on the question whether there are interaction effects between health status and the influencing variables found (section 6.3) to be related to the network characteristics. The variables related to the network measures differ per network characteristic and will be discussed in the following subsections. The coping dimensions and age are dichotomized in order to define them as factors in ANOVA by using the frequency distributions of the respective variables. 


\subsubsection{Network size}

Using the data of sections 6.2 and 6.3 we constructed a model with regard to network size, an example of which is shown in figure 6.1. Similar models can be drawn for the other relations under study as described in the following subsections.

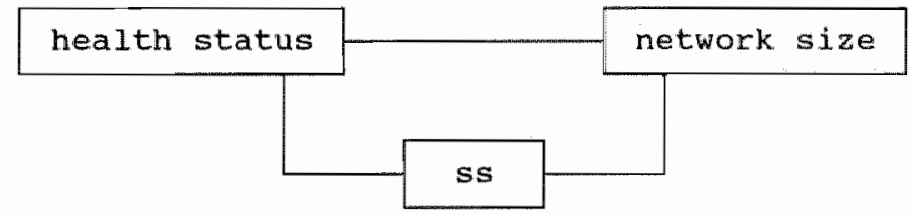

Figure 6.1 Model concerning health status and network size

Here, we are interested whether health status has a direct or an interaction effect with regard to network size. Therefore, we conducted ANOVA with seeking social support specified as a factor. The results are shown in table 6.3.

Besides of the main effects for health status at $t 1$ and seeking social support at $t 3$, table 6.3 shows a significant interaction effect of health status and seeking social support with regard to network size at $t l$ and $t 3$.

Table $6.3 \quad F$-values for network size by health status and seeking social support $(n=118)$

\begin{tabular}{|c|c|c|}
\hline & \multicolumn{2}{|c|}{ network size } \\
\hline & $t 1$ & 13 \\
\hline 1 health status & $4.57 *$ & .56 \\
\hline 2 seeking social support & .95 & $8.56^{\text {th }}$ \\
\hline $1 \times 2$ & $23.37^{\text {*aks }}$ & 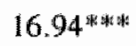 \\
\hline
\end{tabular}

Figure 6.2 shows that healthy respondents scoring low on seeking social support have significantly larger networks than patients scoring low (14.57 vs 7.54 at tl and 12.14 vs 8.43 at $\mathrm{t} 3$ ). Patients scoring high on seeking social support have larger networks than healthy respondents scoring high (11.54 vs 9.70 at tl and 13.75 vs 9.80 at $\mathbf{B}$ ). The strategy to seek social support appears to have an important effect on changes in network size following health deviation. 


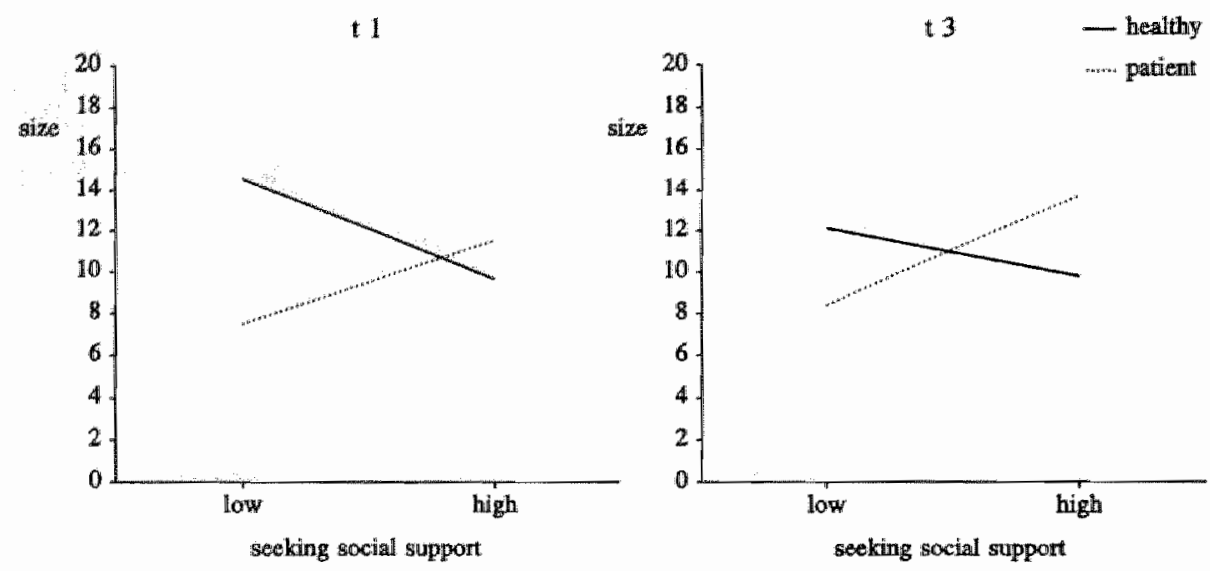

Figure 6.2 Relationship between average network size and seeking social support according to health status

\subsubsection{Network composition}

This section is restricted to the percentage of non-kin informal network members, for the number of formal network members listed by the respondents is far too small to perform further analyses regarding the formal network.

In section 5.1.2 it was found that the percentage of non-kin informal network members is significantly larger in the case of healthy respondents compared to patients at both $\mathrm{t} 1$ and $\mathrm{t} 3$. Based on the results of sections 6.2 and 6.3 , we conducted ANOVA with seeking social support, action-directed coping, gender and family composition specified as factors. The results are in table 6.4.

The table shows a large main effect of health status on percentage of non-kin network members at both assessments $(F=11.62, p<.001$ and $F=8.29, p<.01$ at 1.1 and 13 respectively), as well as main effects for gender $(F=4.69, p<.05$ and $F=4.82, p<.05$ at $t 1$ and $t 3$ respectively) and family composition $(F=9.78$, $p<.01$ at 13 ). There appear to be no interaction effects.

\subsubsection{Network support and reciprocity}

Section 5.1.3 revealed significant differences between healthy persons and patients with regard to emotional support given to non-kin informal network members (t1), instrumental support given to kin and non-kin informal network members ( $\mathrm{t} 3$ ) and instrumental kin as well as non-kin informal reciprocity ( $\mathrm{B}$ ). Sections 6.2 and 6.3 
Table 6.4 F-walues for the percentage of non-kin network wembers by health status, seeking social support, action-directed coping. gender and family composition $(n=119)$

\begin{tabular}{|c|c|c|}
\hline & \multicolumn{2}{|c|}{ \% of non-kin informal network members } \\
\hline 1 health status & $11.62 * * *$ & $8.29 *$ \\
\hline 2 seeking social support & 3.15 & 3.44 \\
\hline 3 action-directed coping & .05 & .61 \\
\hline 4 gender & $4.69^{*}$ & $4.82 *$ \\
\hline 5 family composition & 3.63 & $9.78 *$ \\
\hline $1 \times 2$ & .18 & 1.98 \\
\hline $1 \times 3$ & .03 & 1.23 \\
\hline $1 \times 4$ & .34 & .09 \\
\hline $1 \times 5$ & 3.17 & .11 \\
\hline
\end{tabular}

**** $\mathrm{p}<.001 * * \mathrm{p}<.01 * \mathrm{p}<.05$

indicate that there are no covariates. Therefore, for each of the relations found we only tested whether there are interaction effects, using ANOVA.

Emotional support given to non-kin informal network members appeared to be related to both seeking social support and family composition. ANOVA with these two variables specified as factors revealed no interaction effects. The results are presented in table 6.5 .

Table $6.5 \quad$ F-values for emotional support given to non-kin informal network members by health status, seeking social support and family composition at $11(n=81)$

1. health status

2 seeking social support

3 family composition

$1 \times 2$

$1 \times 3$

$\mathrm{p}<.05$
2.36*

1.57

.86

.10

.21

Instrumental support given to kin appeared to be related to seeking social support, action-directed coping and gender. Table 6.6 shows the results. ANOVA reveals that there are only main effects. There appears to be no interaction between the variables. 
Table 6.6 F-values for instrumental support given to kin by health status, action-directed coping. seeking social support and gender $(n=113)$

instrumental kin support given $\mathrm{t}$

1 health status

2 action-directed coping

$11.37^{\text {皮前 }}$

3 seeking social support

$3.18 *$

4 gendar

$4.64^{*}$

$1 \times 2$

7.22 * *

$1 \times 3$

.32

$1 \times 4$

.02

.01

**** $p<.001 * * * 0<<01 * 0.05$

Sections 6.2 and 6.3 revealed that instrumental support given to non-kin informal network members is related to action-directed coping, awaiting/avoidance, age and gender. Table 6.7 shows that there are no interaction effects.

Table 6.7 F-values for instrumental support given to non-kin informal nenwork members by health status, action-directed coping, awaitinglavoidance, age and gender $(n=91)$

instrumental non-kin support given $\mathbf{t} 3$

1 health status

$15.58 * * *$

2 action-directed coping

1.65

3 swaiting/alvoidance

$6.22 *$

4 agge

$10.30^{* * *}$

5 gender

$7.05^{*}$

$1 \times 2$

.02

$1 \times 3$

.34

$1 \times 4$

3.19

$1 \times 5$

.91

**** $p<.001$ **i* $p<.01 * p<.05$

After analyzing the support data we studied network reciprocity. We only found differences between healthy respondents and patients with regard to instrumental reciprocity. Kin as well as non-kin informal reciprocity appeared to be related to gender. Table 6.8 shows the ANOVA results. 
Table 6.8 F-values for instrumental kin and non-kin ivformal reciprocity at is by healh status and gender $(n=114$ and 92 respectively)

\begin{tabular}{lcc}
\hline & kin reciprocity & non-kin reciprocity \\
\hline 1 health status & $4.41^{*}$ & $4.78^{*}$ \\
2 gender & $5.04^{*}$ & 2.04 \\
$1 \times 2$ & .09 & 1.51 \\
\hline $\mathrm{p}<.05$ & &
\end{tabular}

$* p<.05$

As was the case with support measures, only main effects can be found. Health status and gender show no interaction.

We also conducted ANOVA for those support and reciprocity measures that appeared to be not significantly different between healthy respondents and patients. ANOVA revealled no suppressing variables.

\subsubsection{Summary}

The results of the ANOVA analyses reveal that there is an interaction between health status and the coping dimension seeking social support. It appeared that healthy respondents and patients scoring high on seeking social support list approximately the same number of network members. Healthy respondents scoring low on seeking social support list larger networks, whereas patients list smaller networks. Therefore, the strategy to seek social support seems very important in maintaining one's social relationships in case of health deviation.

With regard to the other network variables no interaction effects were found. The differences concerning the percentage of non-kin informal network members and support and reciprocity measures that appeared to be different between healthy respondents and patients (see sections 5.1.2 and 5.1.3) appear to be main effects; health status is not interacting with any of the other variables that are related to the network measures. In other words, healthy respondents have a higher percentage of non-kin informal network members than patients, give more emotional support to non-kin informal network members, give more instrumentall support to kin as well as non-kin informal network members and have higher kin and non-kin informal instrumental reciprocity scores.

Furthermore, there appeared to be no suppressing variables with regard to the relations found to be not significant in chapter 5 . 


\subsection{Comparing AS and Crohn patients' networks}

In section 5.2 AS and Crohn patients were found to differ significantly only with regard to network size (t1), emotional and instrumental kin reciprocity (t3). This section investigates whether there are interaction effects between health status and the influencing variables found to be related to network characteristics (section $6.3)$, using ANOVA procedures. Furthermore, we investigated whether there are suppressing variables with regard to the relations found to be not significant in section 5.2. The following subsections present the results.

\subsubsection{Network size}

In chapter 5 we only found a difference between AS and Crohn respondents with regard to size at $\mathrm{t1}$. Section 6.3 showed that size is also related to the coping dimension seeking social support. Therefore, we conducted an ANOVA with seeking social support defined as a factor. The results of the ANOVA show no interaction for health status and seeking social support $(F=.02$ and 2.34 for $t 1$ and $B$ respectively, $p>.05$ ).

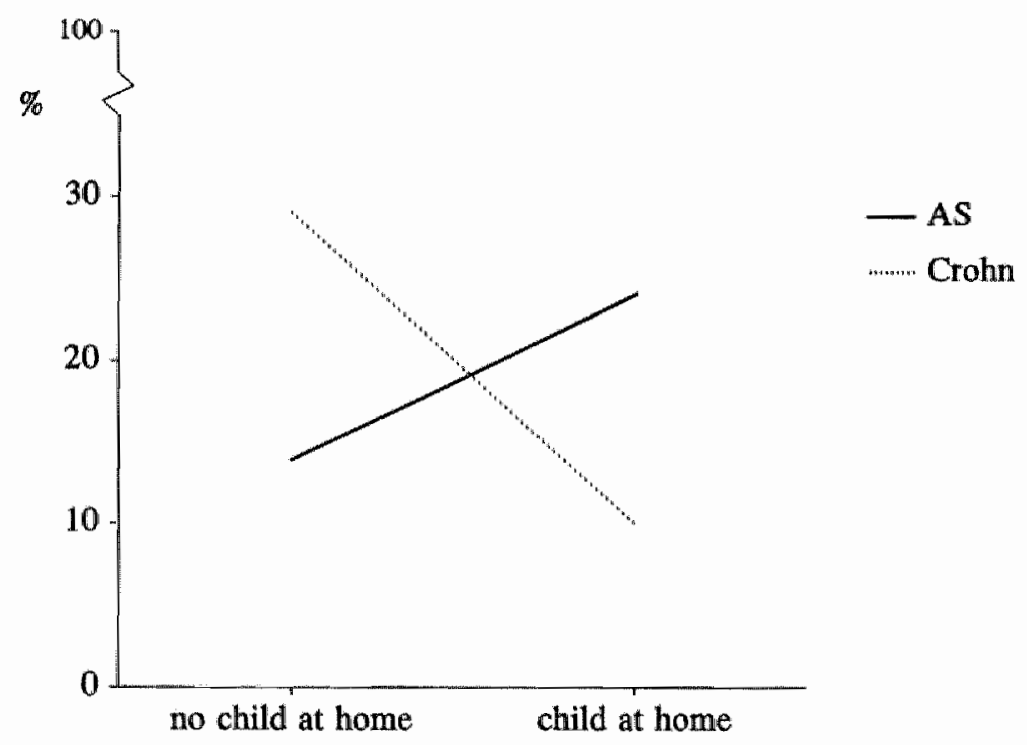

Figure 6.3 Relationship between the percentage of non-kin informal network members and family composition at il according to health starus 


\subsubsection{Network composition}

Section 5.2 showed no differences between AS and Crohn patients with regard to the percentage of non-kin informal network members. Therefore, we only looked for the presence of suppressing variables. AN(C)OVA was conducted with seeking social support, action-directed coping and family composition as factors and gender specified as a covariate. The analysis revealed an interaction between health status and family composition at $\mathrm{tl}(\mathrm{F}=5.86, \mathrm{p}<.05)$. In the group without children living at home AS patients' networks consist of $14 \%$ non-kin informal network members compared to $29 \%$ for Crohn patients. In the group having children at home AS have $24 \%$ non-kin informal network members compared to $10 \%$ for Crohn respondents (see figure 6.3).

\subsubsection{Network support and reciprocity}

With regard to support we found no differences between AS and Crohn respondents. Therefore, we only conducted $A N(C) O V A$ analyses to check the relations for suppressing variables.

A significant effect was only found for instrumental support given to kin network members. At $\mathrm{t} 1$ there appears to be an interaction effect between health status and action-directed coping $(F=5.78, p<.05)$. Figure 6.4 shows that in the group scoring low on action-directed coping AS patients give a higher amount of instrumental support to their kin network members compared to Crohn patients (2.91 vs 2.10$)$, whereas in the group scoring high on action-directed coping the opposite is the case $(2.81 \mathrm{vs} 3.08)$.

With regard to emotional reciprocity section 5.2 showed a significant difference only for the kin network at $\mathbf{B}$ : Crohn patients having a significantly higher reciprocity score than AS patients. Because not one of the influencing variables defined in this study appeared to be related to emotional kin nor non-kin informal reciprocity, no further analyses were conducted with regard to these variables.

Instrumental kin as well as non-kin informal reciprocity appeared to be related to gender. Because gender is also related to health status, it is specified in $\mathrm{AN}(\mathrm{C}) \mathrm{OVA}$ as a covariate. After adjusting for gender, the significant difference between AS and Crohn patients with regard to instrumental kin reciprocity at $\mathrm{t} 3$ disappears $(F=.05, p>.05)$. With regard to instrumental non-kin informal reciprocity gender does not act as a suppressing variable. 


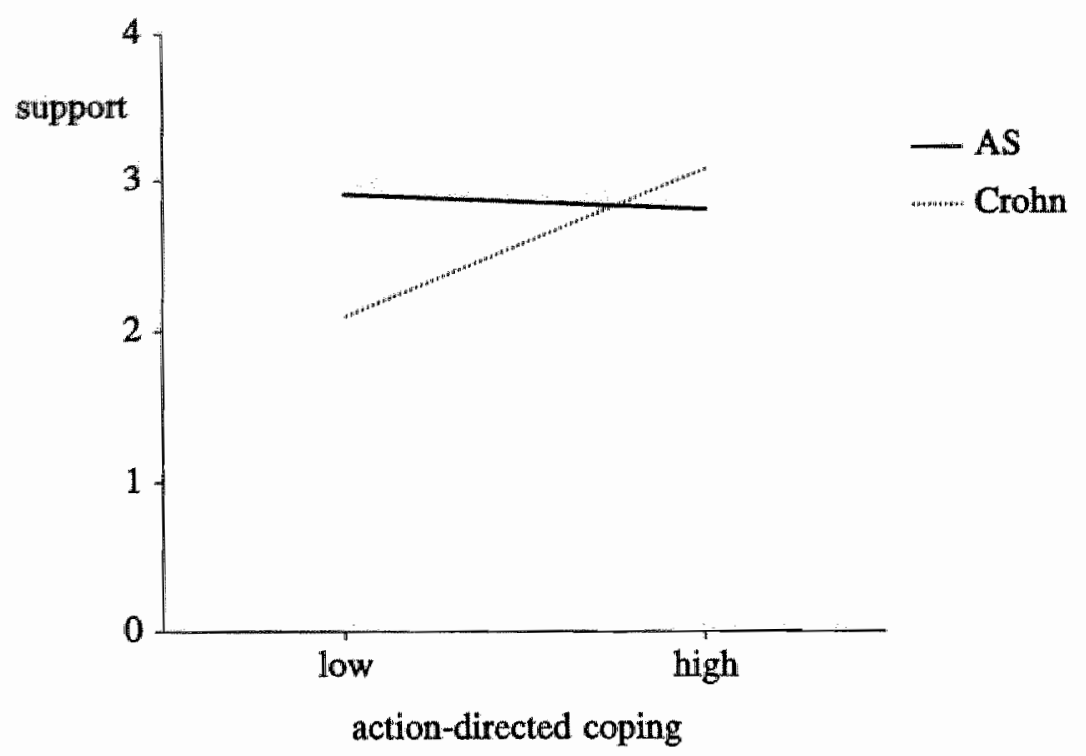

Figure 6.4 Relationship between average amount of instrumental support given to kin network members and action-directed coping at tI according to health status

\subsubsection{Summary}

The differences between AS and Crohn respondents with regard to size and emotional kin reciprocity ( $\mathrm{t} 3$ ) prove to be main effects. AS patients have smaller networks and lower emotional kin reciprocity scores than Crohn patients. The third difference found in section 5.2 with regard to instrumental kin reciprocity (13) disappeared after adjusting for gender.

AN(C)OVA conducted for the relations not found to be significant in section 5.2 revealed an interaction between health status and family composition with regard to the percentage of non-kin informal network members at $t 1$. It appeared that in the group having no children at home Crohn patients list a significantly higher percentage of non-kin informal network members than AS patients, whereas in the group having children at home the opposite is the case.

Similarly, we found an interaction for health status and action-directed coping at $\mathrm{tl}$, showing that in the group scoring low on action-directed coping AS patients give more instrumental support to kin network members than Crohn patients, whereas in the group scoring high on action-directed coping the opposite is the case.

However, not one of the main or interaction effects appears at both $t 1$ and $t 3$. This will be discussed in greater detail in chapter 7 . 


\subsection{Duration of the health deviation and personal network}

ANOVA was also performed with regard to duration of the health deviation. Chapter 5 revealed significant relations between duration of the health deviation and network size ( $\mathrm{B})$, instrumental support received from (t1) as well as given to (t3) kin network members, emotional and instrumental kin reciprocity (t1).

ANOVA was conducted to determine whether there are interaction effects for duration of the health deviation and any of the other variables related to these network measures (see section 6.3). For this purpose duration of the health deviation was dichotomized using the frequency distribution.

\subsubsection{Network size}

ANOVA was conducted with regard to network size specifying seeking social support as a factor. Both duration of the health deviation and seeking social support appear to have only a main effect on size. There is no interaction between duration of the health deviation and seeking social support $(\mathrm{t} 1: \mathrm{F}=.00, \mathrm{p}>.05 ; 13$ : $\mathrm{F}=.05, \mathrm{p}>.05$ ).

\subsubsection{Network composition}

Section 5.3 revealed no significant relation between duration of the health deviation and the percentage of non-kin informal network members. Therefore, we checked only for the presence of suppressing variables. Section 6.3 showed that seeking social support, action-directed coping, family composition and gender are related to the percentage of non-kin informal network members. Not one of these variables is related to duration of the health deviation. Therefore, they were all specified as factors in ANOVA. The analyses revealed no interaction between duration of the health deviation and these variables.

\subsubsection{Network support and reciprocity}

Section 5.3.3 revealed significant relations between duration of the health deviation and instrumental kin support received ( $\mathrm{t} 1)$ as well as given ( 3 ), emotional and instrumental reciprocity (t1). Sections 6.2 and 6.3 show that there are no covariates. Therefore, we only tested whether there were interaction effects, using ANOVA.

Instrumental support received from kin network members appeared to be related to 
seeking social support. ANOVA with seeking social support specified as a factor revealed no interaction between seeking social support and duration of the health deviation $(F=1.06, p>.05)$.

Instrumental support given to kin network members appeared to be related to seeking social support, action-directed coping and gender. Table 6.9 shows the results of the ANOVA with these variables specified as factors. The table shows that all variables in the analysis only have main effects. There are no interaction effects.

Table 0.9 Fualues for instrumental support given to kin network members by duration of the health dewiation, seeking social support, action-directed coping and gender at $t^{3}$ $(n=72)$

instrumental kin support given $\mathfrak{t 3}$

$\begin{array}{lc}1 \text { duration health deviation } & 4.95^{*} \\ 2 \text { seeking social support } & 6.27^{*} \\ 3 \text { action-directed coping } & 3.29^{*} \\ 4 \text { gender } & 4.15^{*} \\ 1 \times 2 & .05 \\ 1 \times 3 & .25 \\ 1 \times 4 & .54\end{array}$

$* p<.05$

With regard to reciprocity, significant relations were found between duration of the health deviation and both kin emotional as well as instrumental reciprocity. Emotional kin reciprocity is not related to one of the influencing variables and therefore we conducted no further analyses.

Instrumental kin reciprocity is related to gender. ANOVA was conducted with gender specified as a factor. There appears to be an interaction between duration of the health deviation and gender $(F=4.35, p<.05)$. Figure 6.5 shows this effect. Figure 6.5 shows that male respondents in the low duration of the health deviation group have significantly higher instrumental reciprocity scores $(2.07)$ than male respondents in the high duration of the health deviation group (1.10). It appears that male respondents in the low duration of the health deviation group give much more support to their network members than they receive, whereas in the high duration of the health deviation group, the amount of kin support given is almost equal to the amount of support received.

In case of female respondents duration of the health deviation has no effect: in both the low (1.15) and the high (1.05) duration of the health deviation groups, female respondents seem to have almost equal instrumental reciprocity scores. 


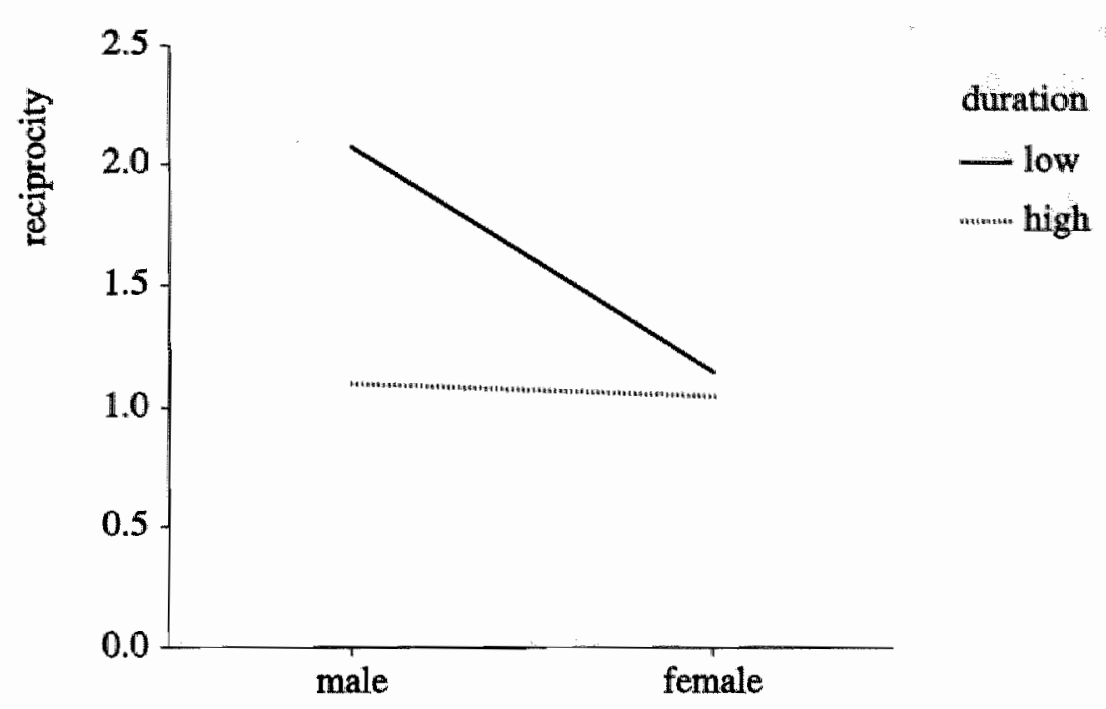

Figure 6.5 Relationship between average instrumental kin reciprocity and gender at 11 according to duration of the health deviation

ANOVA was also conducted for those support and reciprocity measures that appeared to be not significantly related to duration of the health deviation. ANOVA revealed no suppressing variables.

\subsubsection{Summary}

ANOVA revealed that the relations between duration of the health deviation and network measures as found in section 5.3 are main effects, except for the one with regard to instrumental kin reciprocity. Thus, a longer duration of the health deviation is related to a smaller network ( $t 3)$, a higher amount of instrumental kin support received ( $\mathrm{t} 1$ ) as well as given ( $\mathrm{t} 3$ ) and a lower emotional kin reciprocity score (ti). With regard to instrumental kin reciprocity, the reciprocity score is found to be negatively related only to duration of the health deviation in the male respondent group ( $t 1)$. In the female respondent group the instrumental kin reciprocity score appears to be almost the same for respondents in both the low and the high duration of the health deviation group.

There appeared to be no suppressing variables with regard to the relations found to be not significant in chapter 5 . 


\subsection{Perceived disability level and personal network}

In case of perceived disability level, section 5.4 only revealed relations with instrumental support received from kin as well as non-kin informal network members ( $\mathrm{B}$ ), and emotional (t1) as well as instrumental kin reciprocity ( $\mathrm{B}$ ). AN(C)OVA was used to study whether there are interaction effects between perceived disability level and the influencing variables found to be related to these network measures (see section 6.3). For this purpose, perceived disability level is divided into three levels - low, average, high - using the frequency distribution.

\subsubsection{Network size}

Network size appeared to be significantly related to the coping dimension seeking social support (see section 6.3). ANOVA was conducted with this coping dimension specified as a factor. There appears to be no interaction between perceived disability level and seeking social support $(\mathrm{t} l: \mathrm{F}=1.00, \mathrm{p}>.05 ; \mathrm{t} 3$ : $\mathrm{F}=.16, \mathrm{p}>.05$ ). Perceived disability level appears to have neither a main nor an interaction effect with regard to network size.

\subsubsection{Network composition}

The percentage of non-kin informal network members appeared to be related to seeking social support, action-directed coping, familly composition and gender.

Table 6.10 F-values for percentage of non-kin informal network members by perceived disability level. seeking social support, action-directed coping and family composition with gender $(n . t 1=70, t 3=72)$

\% of non-kin informal network members

t1

13

1 perceived disability level

2.48

.76

2 seeking social support

1.77

$9.71^{\text {*2* }}$

3 action-directed coping

.24

.20

4 family composition

.48

$4.31 *$

$1 \times 2$

1.71

.76

$1 \times 3$

.10

.39

$1 \times 4$

$4.74 *$

$3.22 *$

*** $p<.001 * p<.05$ 
Gender is also related to perceived disability level. Therefore, we conducted ANCOVA with seeking social support, action-directed coping and family composition specified as factors and gender specified as a covariate. The results are in table 6.10. The table shows main effects for seeking social support $(F=9.71, p<.001)$ and family composition $(F=4.31, p<.05)$ at 3 and an interaction between perceived disability level and family composition at $t 1$ $(F=4.74, p<.05)$ as well as at $\mathrm{t} 3(\mathrm{~F}=3.22, \mathrm{p}<.05)$. Figure 6.6 shows this interaction effect.
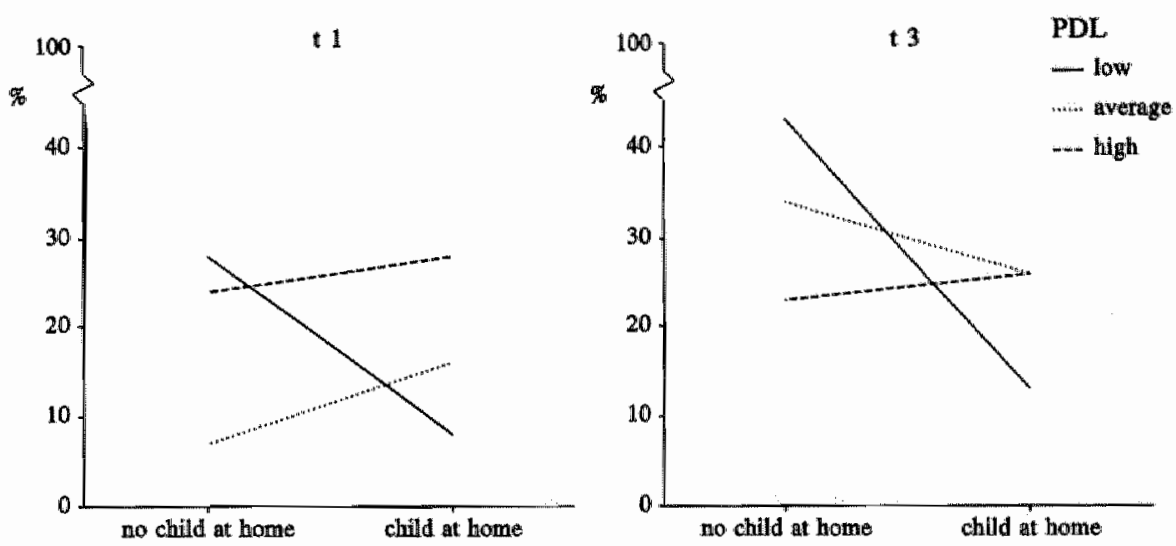

Figure 6.6 Relationship between percentage of non-kin informal network members and family composition according to perceived disability level (PDL)

Figure 6.6 shows that respondents having a child at home list a higher percentage of non-kin informal network members when the perceived disability level is high (28 and $26 \%$ at $\mathrm{tl}$ and $\mathrm{t} 3$ respectively) compared to respondents in the low ( 8 and $13 \%)$ and average (16 and $26 \%$ ) perceived disability level group.

Respondents without children at home show the opposite effect: when the perceived disability level is low, the percentage of non-kin informal network members is higher ( 28 and $43 \%$ at $t 1$ and 3 respectively) compared to the high ( 24 and $23 \%$ ) and average ( 7 and $34 \%$ ) perceived disability level group.

\subsubsection{Network support and reciprocity}

Section 5.4.3 showed relations between perceived disability level and instrumental kin and non-kin informal support received (t3), and emotional (t1) as well as instrumental kin reciprocity $(\mathrm{t} 3)$. 
Instrumental support received from kin is related to seeking social support (see section 6.3). This variable is defined in ANOVA as a factor and showed no interaction with perceived disability level $(F=.19$ and .17 at $t 1$ and $\mathrm{t} 3$ respectively).

Instrumental non-kin informal support received is not related to one of the influencing variables and therefore no further analyses were conducted. The same also applies to emotional kin reciprocity.

Instrumental kin reciprocity appeared to be related to gender (see section 6.3). Section 6.2 shows that gender is also related to perceived disability level. Therefore, AN(C)OVA was conducted with gender specified as a covariate. Adjusting the relations for gender does not reveal a main effect for perceived disability level at $\mathrm{t} l(\mathrm{~F}=.68, \mathrm{p}>.05)$, but the main effect at $\mathrm{t} 3$ remains present $(\mathrm{F}=3.13, \mathrm{p}<.05)$.

We also conducted AN(C)OVA analyses for those relations that were found to be not significant in section 5.4. We found no suppressing variables.

\subsubsection{Summary}

The relations found in section 5.4 were tested using ANOVA. Those relations with regard to instrumental support received from kin and instrumental kin reciprocity appeared to be main effects: a higher perceived disability level is related to a higher amount of instrumental support received from kin network members and a lower kin instrumental reciprocity. Because both instrumental support received from non-kin informal network members as well as emotional kin reciprocity are not related to any of the influencing variables under study, no ANOVA was conducted and the results of section 5.4 remain unaltered: a higher perceived disability level is related to a higher amount of non-kin informal instrumental support received and a higher emotional kin reciprocity score.

ANOVA procedures were also conducted for the relations of section 5.4 that were found not to be significant. Thus, an interaction effect was found between perceived disability level and family composition with regard to the percentage of non-kin informal network members. It appears that, for respondents without children at home, a higher perceived disability level is related to a lower percentage of non-kin informal network members, whereas, for respondents having children at home, a higher perceived disability level is related to a higher percentage of non-kin informal network members. 


\subsection{Functional course and network changes}

Section 5.5 revealed significant relations between instrumental support received from as well as given to kin network members and functionall course. As a result, functional course is also related to kin instrumental reciprocity.

In order to conduct ANOVA, functional course was divided into three classes positive, average, negative - using the frequency distribution.

\subsubsection{Network size}

Section 6.3 revealed that changes in network size are related to action-directed coping. ANOVA with this variable specified as a factor showed no interaction with functional course $(F=.06, p>.05)$. Therefore, we find that functional course has no main or interaction effect with regard to network size.

\subsubsection{Network composition}

Changes in network composition appeared to be related to social class (see section 6.3). ANOVA was conducted with social class defined as a factor. The analysis showed no interaction effect for functional course and social class with regard to changes in the percentage of non-kin informal network members $(F=.55, p>.05)$. Functional course thus appears not to have a main or interaction effect with regard to network composition.

\subsubsection{Network support and reciprocity}

Changes in the amount of instrumental support received from kin network members appeared not to be related to any of the influencing variables (see section 6.3). The same applies to changes in instrumental kin reciprocity. Therefore, no ANOVA analyses were conducted with regard to these variables and the results of chapter 5 remain unchanged.

Changes in instrumental support given to kin appeared to be related to age. ANOVA was conducted with age specified as a factor. Both functional course and age appear to have a main effect towards changes in instrumental kin support given only. ANOVA revealed no interaction effect $(F=1.08, p>.05)$.

ANOVA procedures conducted for the relations not found to be significant in section 5.5 revealed an interaction effect between functional course and awaiting/avoidance with regard to changes in instrumental support received from 
non-kin informal network members $(F=3.84, p<.05)$. This interaction effect is shown in figure 6.7 .

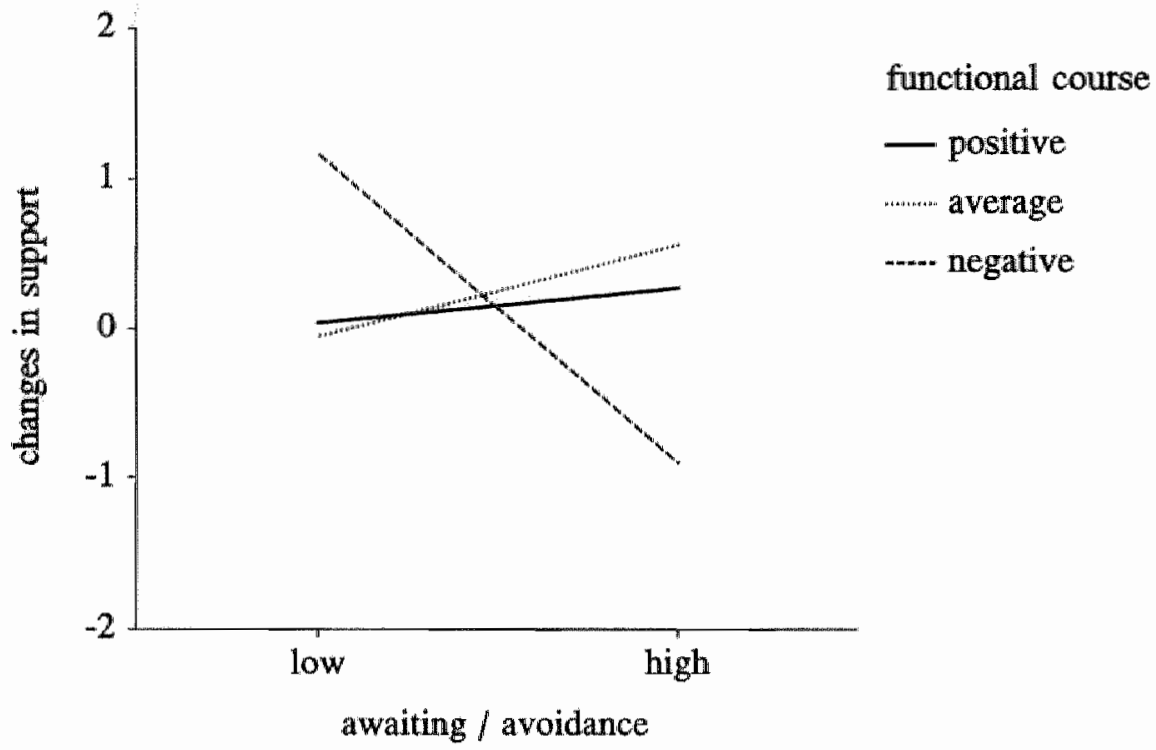

Figure 6.7 Relationship between changes in instrumental support received from non-kin informal network members and awaiting/awoidance according to functional course

Figure 6.7 shows that respondents having a relatively positive functional course receive less instrumental support at $t 3$ than at $t 1$. This is stronger in the group scoring high on awaiting/avoidance than in the group scoring low on awaiting/avoidance (change score $.28 \mathrm{vs} .04$ ). The respondents who have an average functional course and who score high on awaiting/avoidance receive less support at $\mathrm{t} 3$ than at $11(.57)$, whereas those having an average functional course and scoring low on awaiting/avoidance receive almost the same amount of support at $t 1$ and $3(-.05)$. The respondents whose functional course is relatively negative and who score low on awaiting/avoidance receive less instrumental support at $\mathfrak{t} 3$ than at $t 1(1.17)$; respondents whose functional course is relatively negative and who score high on awaiting/avoidance receive more instrumental support at $\mathrm{t} 3$ than at $\mathrm{tl}(-90)$. 


\subsubsection{Summary}

The relations found in section 5.5 all prove to be main effects; ANOVA reveals no interaction effects. This means that when the perceived disability level increases from $t 1$ to 3 , the instrumental support received from kin increases whereas that given to kin decreases, and consequently the instrumental kin reciprocity score decreases.

Conducting ANOVA for the relations not found to be significant in section 5.5 revealed an interaction effect. It appears that respondents having a relatively positive functional course receive less instrumental support at $t 3$ than at $t 1$. This is stronger in the group scoring high on awaiting/avoidance than in the group which scores low. The respondents who have an average functional course and who score high on awaiting/avoidance receive less support at $\mathbf{t}$ than at $t 1$, whereas those having an average functional course and scoring low on awaiting/avoidance receive almost the same amount of support at $t 3$ as at $t 1$. The respondents whose functional course is relatively negative and who score low on awaiting/avoidance receive less instrumental support at $\mathrm{t} 3$ than at $\mathrm{t}$; respondents whose functional course is relatively negative and who score high on awaiting/avoidance receive more instrumental support at $\mathrm{t} 3$ than at $\mathrm{t} 1$.

\subsection{Discussion}

In chapter 6 the influence of coping, social position and life events with regard to the relation between health status and network measures was studied. Table 6.11 shows the main and interaction effects found. These will be discussed for each network variable under study separately in the following subsections.

\subsubsection{Size}

Section 6.4.1 shows the importance of seeking social support with regard to network size. This coping dimension has a significant interaction effect with health status. Patients who score high on seeking social support have somewhat larger networks than healthy respondents scoring high on seeking social support, whereas patients scoring low on seeking social support have significantly smaller networks than healthy respondents scoring low on seeking social support. It appears that the strategy to seek social support is important in maintaining and even widening one"s personal network in case of health deviation.

It was also found that the difference between AS and Crohn patients with regard to size at $t 1$ and the relation between duration of the health deviation and size at $t 3$ appear to be main effects. The same can be said for seeking social support, 
although this effect is much stronger than the effect of health status and is present at both $\mathrm{t} 1(\mathrm{p}<.01)$ and $\mathrm{t} 3(\mathrm{p}<.001)$.

The problem of the effects of health status being only present at $t 1$ or at $t 3$ is also found with regard to the other network measures. In chapter 7 attention will be paid to this problem.

Table 6.II Summary of the results described in chapter 6

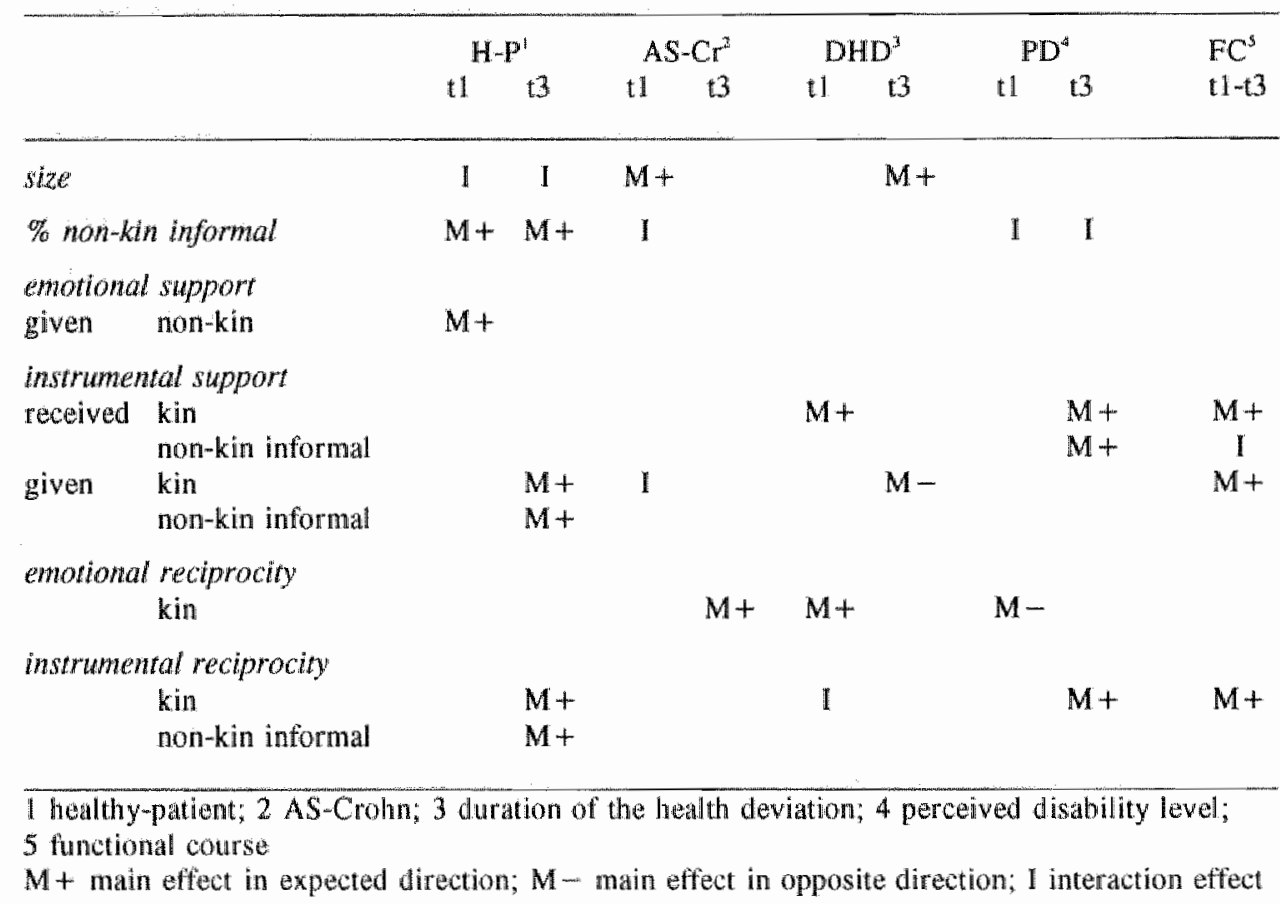

\subsubsection{Composition}

With regard to composition, chapter 6 revealed that the difference between healthy respondents and patients is a main effect, not influenced by coping, social position or life events. Healthy respondents list a higher percentage of non-kin informal network members compared to patients. There is also a main effect of gender: male respondents list more non-kin informal network members compared to female respondents.

Furthermore, there appears to be an interaction between perceived disability level and family composition. Roughly speaking, it appeared that, in patients without children at home, the higher the perceived disability level, the lower the 
percentage of non-kin informal network members, whereas in patients having children at home, the opposite is the case. The explanation might be that for people without children non-kin informal contacts are relatively important, for instance in going out together. When the perceived disability level is higher, the patient is no longer able to take part in all activities he used to do, so a number of contacts with persons he shares these activities with will fade. When patients have children at home, much time is spent together with them and they are relatively important to the respondent. However, when the perceived disability level is high, other people become more important, for instance friends and neighbors in delivering support.

At $t 1$ we also found an interaction with regard to having AS or Crohn's disease and family composition: in the group without children at home Crohn patients have, as we expected, a higher percentage of non-kin informal network members than AS patients. In the group having children at home, however, the opposite was found. Gender was taken into AN(C)OVA as a covariate, but the interaction remained significant.

\subsubsection{Support}

With regard to emotional support, chapter 6 reveals no effects other than the one already described in chapter 5 , namely the difference between healthy persons and patients with regard to emotional support given to non-kin informal network members: healthy respondents give more support than patients, as we expected.

With regard to instrumental support, chapter 6 reveals that the relations found in chapter 5 are all main effects. Besides, sections 6.5 and 6.8 revealed interaction effects for health status with coping. Section 6.5 .3 revealed that in the group scoring low on action-directed coping AS patients give a higher amount of instrumental support to kin than Crohn patients, whereas in the group scoring high on action-directed coping the opposite was found.

Furthermore, functional course appears to interact with awaiting/avoidance: respondents whose functional level improves or stays unchanged from $t 1$ to $t 3$ and who score low on awaiting/avoidance show an almost equal amount of instrumental support from non-kin informal network members, whereas respondents whose functional level deteriorates show a decrease in instrumental non-kin informal support received. Respondents whose functional level improves or remains unchanged from tl to $\mathrm{t} 3$ and who score high on awaiting/avoidance show a decrease in instrumental support received from non-kin informal network members, whereas respondents whose functional level decreases and who score high on awaiting/avoidance show an increase. The hypothesis we formulated with regard to functional course seems to hold only for those respondents scoring high on awaiting/avoidance. 
Although most of the results are only found either at $t \mid$ or at $t 3$, the data indicate that it is especially the instrumental exchange that is affected by chronic somatic health deviation. Furthermore, except for instrumental support given to kin, all relations point in the hypothesized direction.

\subsubsection{Reciprocity}

The relations found in chapter 5 with regard to emotional reciprocity are all shown to be main effects, because emotional reciprocity is not related to any of the influencing variables. Thus, it may be sufficient to state that Crohn patients have higher emotional reciprocity scores at 3 than AS patients, that a longer duration of the health deviation is related to a lower emotional reciprocity score (t1), and that a higher perceived disability level is related to a higher emotional kin reciprocity score (t1). As with the other network measures, significant relations are only found at either $\mathbf{t l}$ or $\mathbf{t} 3$. Again we refer to the discussion in chapter 7 . The same applies to instrumental reciprocity. For instrumental reciprocity chapter 6 showed that the difference between AS and Crohn patients with regard to kin instrumental reciprocity disappeared after adjusting for gender.

Furthermore, we found an interaction between duration of the health deviation and gender with regard to kin instrumental reciprocity. In the male respondent group our hypothesis holds: respondents with a lower duration of the health deviation have higher reciprocity scores than respondents with a higher duration of the health deviation. In the female respondent group no difference was found between respondents having a low or having a high duration of the health deviation. All other relations found in chapter 5 were shown to be main effects in accordance with our hypotheses: healthy respondents have higher instrumental kin as well as non-kin informal reciprocity scores than patients, and both a higher perceived disability level and a more negative functional course are related to lower instrumental kin reciprocity scores.

Chapter 6 again showed the difference in significant relations found at $\mathrm{tl}$ and $\mathrm{t} 3$. The only relations found at both measurement times are the difference between healthy respondents and patients with regard to size and composition and the relation between perceived disability level and network composition. In chapter 7 this phenomenon will come under discussion.

Chapter 7 will also review the results in the light of our hypotheses and the findings of other researchers as described in chapter 2 . 


\section{Summary, conclusion and discussion}

This final chapter starts with a summary of the aim, design and results of the study in section 7.1. In section 7.2 and 7.3 the results will be discussed with respect to the theoretical perspectives as described in chapter 2. Furthermore, in sections $7.4,7.5$ and 7.6 some methodological considerations, practical implications and recommendations for further research are made.

\subsection{Summary}

The development of a chronic - disabling - health deviation causes many changes in the individual and affects his relationship with his environment. The aim of this study was to map the changes in the personal networks of chronic somatic patients by comparing a group of healthy respondents and two patient groups (chapter 1). The theoretical framework of the study was described in chapter 2. Theoretical perspectives about exchange, interaction and role are applied to network changes following health deviation. It is argued that more serious health deviation results in temporary or permanent loss of physical, psychological and/or social function. Several roles, tasks and responsibilities can no longer be performed by the patient, and have to be taken over by other persons. This results in a disturbance in the existing dependency balance and the more serious the health deviation, the greater the chance that the role-relations will be affected.

According to exchange theory, the imbalance in the dependency balance will weaken some relationships and in the longer run some of these relations will fade away. Those relations in which posilive concern is strong are most likely to persist. Adams (1967) states that positive concern is frequently strongest in relations with members of one's own family. Apart from changing or disappearing relationships, there also will be new relationships, as the patient becomes more dependent on other persons. In the case of permanent health deviation health care professionals like physicians and nurses will take over some roles, tasks and/or responsibilities for the patient. These health care professionals become part of the patient's network.

In the light of the theories used, network variables selected for study were size, 
composition, emotional as well as instrumental support and reciprocity. Health status was defined in terms of impairment, disability and handicap.

Chapter 2 also devoted attention to variables possibly influencing the relation between health status and personal network. Coping, social position and life events other than the onset of health deviation are included in the research model. Furthermore, an overview was given of what is currently known about the relation between health deviation and personal network with regard to network changes following health deviation. The chapter concluded with a number of hypotheses which will be discussed in section 7.2 along with the results of the study.

Chapter 3 described the research design and instruments. The networks of patients having Crohn's disease or Ankylosing Spondylitis (AS) were selected for study. Patients were asked to participate in the study through their medical specialists. Their networks were compared to those of healthy persons. The patients and healthy respondents were interviewed three and two times respectively with a period of half a year between each measurement. A totall of 36 Crohn patients, 39 AS patients and 44 healthy respondents participated in all measurements.

Chapter 4 presents a description of the respondent groups with regard to the variables under study together with some preliminary analyses. AS patients' networks appear to be smaller than both healthy and Crohn respondents' networks. With regard to composition, nearly all healthy respondents listed non-kin informal network members, whereas only approximately two-thirds of the patients listed non-kin informal network members. Formal network members were only listed by patients, although the number of patients listing formal network members is small. The results also show that the predominant difference between healthy respondents and patients is in the instrumental exchange in their relationships.

In chapter 5 the data are analyzed with regard to the hypotheses formulated in chapter 2. It appeared that patients" network size is smaller than that of healthy respondents. Diagnosis seems to be important: AS patients" networks are smaller than Crohn patients" networks. The percentage of non-kin informal network members is smaller for patients than for healthy respondents; there is no difference between AS and Crohn patients. Duration of the health deviation appeared to be negatively related to network size. Furthermore, chapter 5 showed that it is notably the instrumental exchange in the kin network that is affected by health status. This is expressed most clearly in the instrumental kin reciprocity score which is related to all five operationalizations of health status.

Chapter 6 focuses on the effect of coping, social position and life events with regard to the relation between health status and personal network. It appears that the strategy to seek social support is important in maintaining one's network when one has a chronic health deviation. Furthermore, it showed that family composition plays an important role with regard to the percentage of non-kin informal network members: if they do not have children living at home, Crohn patients have a higher percentage of non-kin informal network members than AS 
patients, and a higher perceived disability level is related to a lower percentage of non-kin informal network members. In the group having children at home the opposite is found.

In section 7.2 the results are discussed in the light of the hypotheses formulated in chapter 2.

\subsection{Evaluation of the study}

This section describes the results of the study with regard to the hypotheses as formulated in section 2.6. Attention is also paid to the relative strength of health status compared to the other variables in the study with regard to the network measures. Finally, the results are interpreted with respect to the research model as presented in figure 2.1 .

\subsubsection{Comparing healthy persons' and patients' networks}

The first hypothesis concerns the comparison of healthy persons' and patients' networks: patients' networks are smaller than healthy respondents' networks, contain relatively fewer non-kin informal and more formal network members and are less balanced, because patients give less and receive more support.

\section{Size}

The results showed that this hypothesis is affirmed with regard to size and composition, although size appeared to interact with the coping strategy seeking sacial support. Only for those respondents who score low on seeking social support does the hypothesis hold. Those patients scoring high on seeking social support list even larger networks than healthy respondents scoring high on social support. It appears that patients who are able, for instance, to seek sympathy and comfort and show their feelings are also able to maintain their personal network and even widen it. This concords with Dunkel-Schetter, Folkman and Lazarus' (1987) findings that people who cope by seeking social support report more sources of support. By seeking social support the individual provides cues to his network members regarding his needs and desires for support and the results indicate that the individual's network members are responsive to these cues.

\section{Composition}

Both health status and seeking social support have a significant effect with regard to composition, but there is no interaction: healthy respondents list a higher percentage of non-kin informal network members compared to patients, 
independent of the score on seeking social support. Formal network members appeared to be listed only by patients, as we expected. Only a few patients, however, list a formal network member, which is in accordance with Tilden's (1985) suggestion that the mutual give-and-take in noncontractual interactions comes more to mind when people think of social support than the contractual interaction with professional care providers.

\section{Support and reciprocity}

We found no differences between healthy respondents and patients for the emotional aspect of the relationship, except for emotional support given to non-kin informal network members, which is lower for patients than for healthy respondents. The effect with regard to emotional support given is found only at $t 1$. Probably as a result of the increase in size from $t 1$ to $t 3$ the relation is no longer present at $\mathbf{t}$ (change score size - change score support $\mathrm{r}=.38, \mathrm{p}<.01$ ).

With regard to instrumental support we found no difference in the amount received from kin as well as non-kin informal network members for healthy respondents and patients. They only differ with regard to instrumental support given to kin as well as non-kin informal network members at $\mathbf{t} 3$, in that healthy respondents give more than patients. This also results in higher kin as well as non-kin informal reciprocity scores for healthy respondents compared to patients at $\mathbf{t} 3$. This difference in the results at $\mathrm{t} 1$ and $\mathrm{t} 3$ cannot be explained by the increase in network size from $t \mathrm{t}$ to $\mathrm{t} 3$. Therefore, we presume a methodological cause, discussed in section 7.4 .

As we have already stated in chapter 2, the results indicate that in cases of chronic somatic health deviation it is especially the instrumental exchange that is affected.

\subsubsection{Comparing AS and Crohn patients' networks}

Owr second hypothesis addresses the question of the effect the nature of the disease has on network changes. This was the reason for taking two different patient groups into the study: one group having Ankylosing Spondylitis (AS) and one group having Crohn's disease. AS patients are frequently or continuously troubled with backache and limitation of movements, whereas most Crohn patients experience no or little hindrance from their disease for years. Their main hindrance consists in the need to take medication every day and the knowledge that at any moment a serious deterioration of the disease might occur. This led us to hypothesize that Crohn patients have larger networks, containing relatively more non-kin informal and fewer formal network members than AS patients" networks, as well as a lower amount of support received and a higher amount given, leading to higher reciprocity scores. 


\section{Size}

At tl Crohn patients' networks are indeed larger than AS patients' networks. The increase in, especially AS, patients' network size from 11 to 13 , however, led to the disappearance of this effect (see section 7.4).

\section{Composition}

The hypothesis appears to hold for AS and Crohn respondents without children at home. In the group having children living at home the opposite was found. Adjustment for gender gave the same result. The explanation might be that AS patients' mobility is significantly lower than Crohn patients' mobility and as a result AS patients are more home-bound than Crohn patients. Having children at home then becomes important because these children act as a means through which the patient can contact other people, for instance the parents of his children's friends.

The relation was found at $t l$ only. At $t 3$ this relation is no longer present, probably as a result of the increase in AS patients' network size, which is positively related to an increase in the percentage of non-kin informal network members $(r=.43, \mathrm{p}<.001)$.

\section{Support}

We only found an interaction effect between health status and action-directed coping with regard to instrumental support given to kin: in the group scoring low on action-directed coping AS patients give a higher amount of instrumental support to kin than Crohn patients, whereas in the group scoring high on action-directed coping the opposite is found, as in accordance with our hypothesis. We have no idea what the explanation of this finding might be.

\section{Reciprocity}

We found that the emotional kin reciprocity score is higher at $\mathfrak{B}$ for Crohn patients compared to AS patients, as we expected.

With regard to other support and reciprocity measures we found no relations. Therefore, we may conclude that AS and Crohn patients differ with regard to size and composition, but scarcely with regard to support and reciprocity. This means that the network size of AS patients is affected more compared to that of Crolin patients and that the percentage of non-kin informal network members is different for the groups depending on whether or not there are children living at home. However, those network members that remain are more or less comparable for AS and Crohn patients with regard to support and reciprocity. 


\subsubsection{Duration of the health deviation and personal network}

Besides the nature of the disease we also expected duration of the health deviation to be an influence in that a longer duration of the health deviation is related to a smaller network, a lower percentage of non-kin informal network members, a higher amount of support received, a lower amount of support given and lower reciprocity scores.

\section{Size}

Duration of the health deviation indeed appeared to be negatively related to network size, albeit only at $\mathrm{B}$. This indicates that following $\mathrm{t} 1$ network changes take place leading to the relation found at $t 3$. Because most patients have already had the health deviation for a considerable time, however, it is not likely that such changes would take place within the one-year period of our study. Therefore, it seems a methodological explanation must be put forward (see section 7.4).

\section{Composition}

No relation was found with regard to network composition. The explanation might be that almost all the patients in our study have had a health deviation for a long time and most of those contacts that were liable to vanish already have.

\section{Support and reciprocity}

Furthermore, we found no relation between emotional support and duration of the health deviation. Emotional support seems to remain unchanged following health deviation, although at $t 1$ we do find a relation between emotional kin reciprocity and duration of the health deviation in the expected direction: the longer one has a health deviation, the lower the reciprocity score.

With regard to instrumental support and reciprocity relations were found only in the kin network. The explanation might again lie in the already lengthy duration of the respondents" health deviation and those non-kin informal contacts that were liable to change have already changed. With regard to the kin network patients were found to receive more instrumental support, as expected, but also give more support, in contrast to our hypothesis, when duration of the health deviation was longer. The explanation might be the patients' need for reciprocation (e.g. Wentowski, 1981). When the patient receives more support, he will try to find a way to reciprocate in order to maintain his self-respect. Both findings are present at one measurement moment only.

An interaction was found between instrumental kin reciprocity and gender. Among males respondents with a shorter duration of the health deviation have higher reciprocity scores than those whose health deviation has lasted longer, as we expected. In the female respondent group we found no difference between respondents having a short or a long duration of the health deviation. The 
explanation might be that the presence of instrumental support is greater in men's relationships than it is in women's relationships.

\subsubsection{Perceived disability level and personal network}

It has been argued that another important variable in studying network changes following health deviation is the disability level, in that the more disabling the health deviation, the greater the effect on the person's network. We therefore hypothesized that when the perceived disability level is higher, the patient's network will be smaller, the percentage of non-kin informal network members lower, the amount of support received larger and that given smaller, and the reciprocity scores lower.

\section{Size}

The results showed no relation with regard to network size. The explanation may again be the duration of the health deviation. The longer duration of the health deviation probably resulted in the loss of those contacts that were liable to change. This applies to almost all respondents and as a consequence we no longer find any effect of perceived disability level.

\section{Composition}

With regard to the percentage of non-kin informal network members the perceived disability level has an effect in combination with family composition. It appeared that, in patients not having children at home, the higher perceived disability level is related to a lower percentage of non-kin informal network members, whereas for patients having children at home we found the opposite. This finding may be explained by the importance of the nuclear family. To respondents not having children at home relationships with non-kin informal network members are relatively important, but these contacts are probably largely based on sharing free time activities. When the respondent becomes physically disabled, part of these activities can no longer be done, and the persons with whom the patient shared these activilies look for other persons to do them with. As a result the relationship with the patient fades. When having children at home the nuclear family is important to the respondent. However, functional disability cannot be handled by the family members alone (see Litwak and Szelenyi, 1969) and people outside the family must be called upon for help. As a result these persons, for example friends and neighbors, become more important in the patient's network. As already stated before, having children at home increases the opportunity to contact other people such as parents of the children's friends. 


\section{Support and reciprocity}

As we also found with the other health status variables, emotional support is not significantly affected by somatic health deviation. The emotional reciprocity score even increases with the perceived disability level, perhaps indicating that the health deviation makes the patient important as an emotional support giver.

With instrumental support we find that the amount given does not correlate with the perceived disability level, whereas the amount received is higher when the perceived disability level is higher. This applies to the kin as well as the non-kin informal network, indicating that the respondent is able to maintain his role as a support giver, but becomes more dependent on others for receiving instrumental support. This leads to lower reciprocity scores in the kin network only. In the non-kin informal network instrumental reciprocity is more or less maintained, which indicates that kin members are more important in delivering support, either because they are more willing to give support without getting a comparable amount in return or because the patient is more willing to accept more support from kin network members (see chapter 2).

\subsubsection{Functional course and network changes}

The final hypothesis, and probably the most interesting because it is longitudinal, concerns the relation between functional course and network changes. It was hypothesized that when the functional level decreases, network size will decrease as will the percentage of non-kin informal network members and the amount of support given to network members, whereas the amount of support received increases accompanied by a decrease in the reciprocity scores.

\section{Size and composition}

With regard to size and the percentage of non-kin informal network members we found no relations with functional course. Once again we point to the fact that almost all respondents have endured their health deviation for a considerable time and therefore big changes in size and composition no longer take place.

\section{Support and reciprocity}

As we could also deduce from the results with regard to the other hypotheses, emotional support and reciprocity too do not change over the one-year period of our study, whereas in the kin network the amount of instrumental support received increases and the amount of support given decreases, leading to a lower reciprocity score, as we expected.

In the non-kin network no effect was found for instrumental support given and reciprocity. There only was an interaction found between functional course and awaiting/avoidance with regard to instrumental support received. In the group 
scoring high on awaiting/avoidance, the hypothesis that patients would receive more support when their disability level increased appears to hold, whereas in the group scoring low on awaiting/avoidance the opposite applies. The explanation might be that patients who score high on awaiting/avoidance, who resign themselves to the situation, show their disability more clearly to their network members, thus giving them a cue that they need support. In cases where patients score low on awaiting/avoidance, it is less clear to their network members that they are disabled and therefore need support.

Once again this finding gives an indication of the importance of relatives in giving support to patients.

\subsubsection{The relative strength of the relation between health status and personal network}

The relative strength of the relation between health status and network variables was determined by comparing it to the strength of the relation between influencing variables and network variables. It appeared that health status is a relatively important variable with regard to size, composition and a number of support and reciprocity measures.

With regard to network size, seeking social support appeared to be the only influencing variable other than health status and the strength of the relation is comparable to that of the health status measures.

In relation to the percentage of non-kin informal network members, the only health status measure that was shown to be important was the existence of a health deviation (healthy person - patient), while gender, familly composition, actiondirected coping and seeking social support appeared also to be related to the percentage of non-kin informal network members. The relation between the health status measure and the percentage of non-kin informal network members is, however, much stronger than that between any of the influencing variables and the percentage of non-kin informal members.

With regard to emotional support, a relation was only apparent between the existence of a health deviation and non-kin emotional support given. Analysis of the relation between this network variable and the influencing variables revealed that seeking social support has a stronger relation to non-kin informal support given and family composition is just as important as the health status measure.

With regard to instrumental support, we found that duration of the health deviation, perceived disability level and functional course as well as seeking social support are related to the amount of support received from kin. Perceived disability level appeared to have the strongest relation, whereas the other variables are equally strongly related. Instrumental support received from non-kin informal network members was only related to perceived disability level. The most 
important variable related to instrumental support given to both kin and non-kin informal network members appeared to be the existence of a health deviation. Action-directed coping and gender also showed a strong relation, albeit less strong than the health status measure. The same goes for functional course with respect to instrumental support given to kin. Furthermore, seeking social support appeared to be related to instrumental kin support given, while both age and awaiting/avoiding were related to non-kin instrumental support given, but the strength of these relations is weaker than both the existence of a health deviation and functional course.

With regard to emotional reciprocity relations were only found with health status measures. The influencing variables appeared to be unrelated.

With respect to instrumental kin reciprocity, all health status measures appeared to be related as well as gender. The strongest relation was found for duration of the health deviation, all other relations being equally strong. Non-kin informal instrumental reciprocity is related to the existence of a health deviation and gender. The latter relation is the strongest.

In summary, we may conclude that, in a comparison of the strength of the relations of the influencing variables and health status variables with regard to personal network measures, health status appears to be the most important variable, except for emotional support given to non-kin informal network members and non-kin informal instrumental reciprocity. Here, seeking social support and gender respectively appear to be the most important variables.

\subsubsection{Conclusion}

In this section we return to the research model as presented in figure 2.1 . The relevance of the variables in the study is discussed with respect to network changes following health deviation.

\section{Health status}

As we have already concluded in the preceding subsection, all health status variables appear to be important with regard to one or more of the network variables. The most important measure appeared to be the existence of a health deviation (healthy person - patient). This variable is related to size, composition, support as well as reciprocity. Furthermore, functional course appeared to be related only to network function.

\section{Coping}

Coping was included in the study because other studies indicated that it influences the amount of support or number of network members providing the support an individual receives in experiencing life-strains. Three dimensions of coping were 
distinguished in our study: seeking social support, action-directed coping and awaiting/avoidance. Seeking social support appears to be very important with respect to network size. In interaction with existence of a health deviation (healthy person - patient), it influences the number of network members listed by the respondent. Our findings indicate that the strategy to seek social support is important in maintaining one's network following health deviation.

Action-directed coping and awaiting/avoidance both have an interaction effect with regard to support. Action-directed coping interacts with diagnosis (AS - Crohn) with regard to the amount of instrumental support given to kin: in the group scoring low on action-directed coping AS patients give a higher amount of instrumental support to kin than Crohn patients, whereas in the group scoring high on action-directed coping the opposite was found. Awaiting/avoiding interacts with functional course with regard to the amount of instrumental support received from non-kin informal network members: in the group scoring high on awaiting/avoiding patients receive more support when their disability level increases, whereas in the group scoring low on awaiting/avoidance the opposite holds.

\section{Social position}

On the basis of a literature search, gender, social class, age, marital status and family composition were included in the study.

With regard to gender we found an interaction with duration of the health deviation concerning instrumental kin reciprocity. Male respondents with a lower duration of the health deviation appeared to have higher reciprocity scores than male respondents having a higher duration of the health deviation. In the female respondent group no difference was found between respondents having a low or a high duration of the health deviation.

Social class was included in the study because a number of studies indicated a relation between social class and the amount of emotional as well as instrumental support received. In our study, however, no relation was found between social class and any of the network variables.

With regard to age we found relations with emotional support received from kin and instrumental support given to non-kin informal network members. This, however, did not affect the relation between health status and these network variables.

We have no data on the effect of marital status on the relation between health status and personal network. More than $75 \%$ of the respondents in every group were either married or living together and therefore marital status was omitted from the analyses.

The last variable under social position, family composition, appeared to be important to the percentage of non-kin informal network members. In the group without children living at home AS patients appeared to have a lower percentage 
of non-kin informal network members than Crohn patients, and a higher perceived disability level is related to a lower percentage of non-kin informal network members. In the group having children at home the opposite was found.

\section{Life events other than the onset of health deviation}

There are severall life events other than health deviation that (may) lead to network changes; hence, we took life events into account. There appeared to be no relation between experiencing life events and network characteristics.

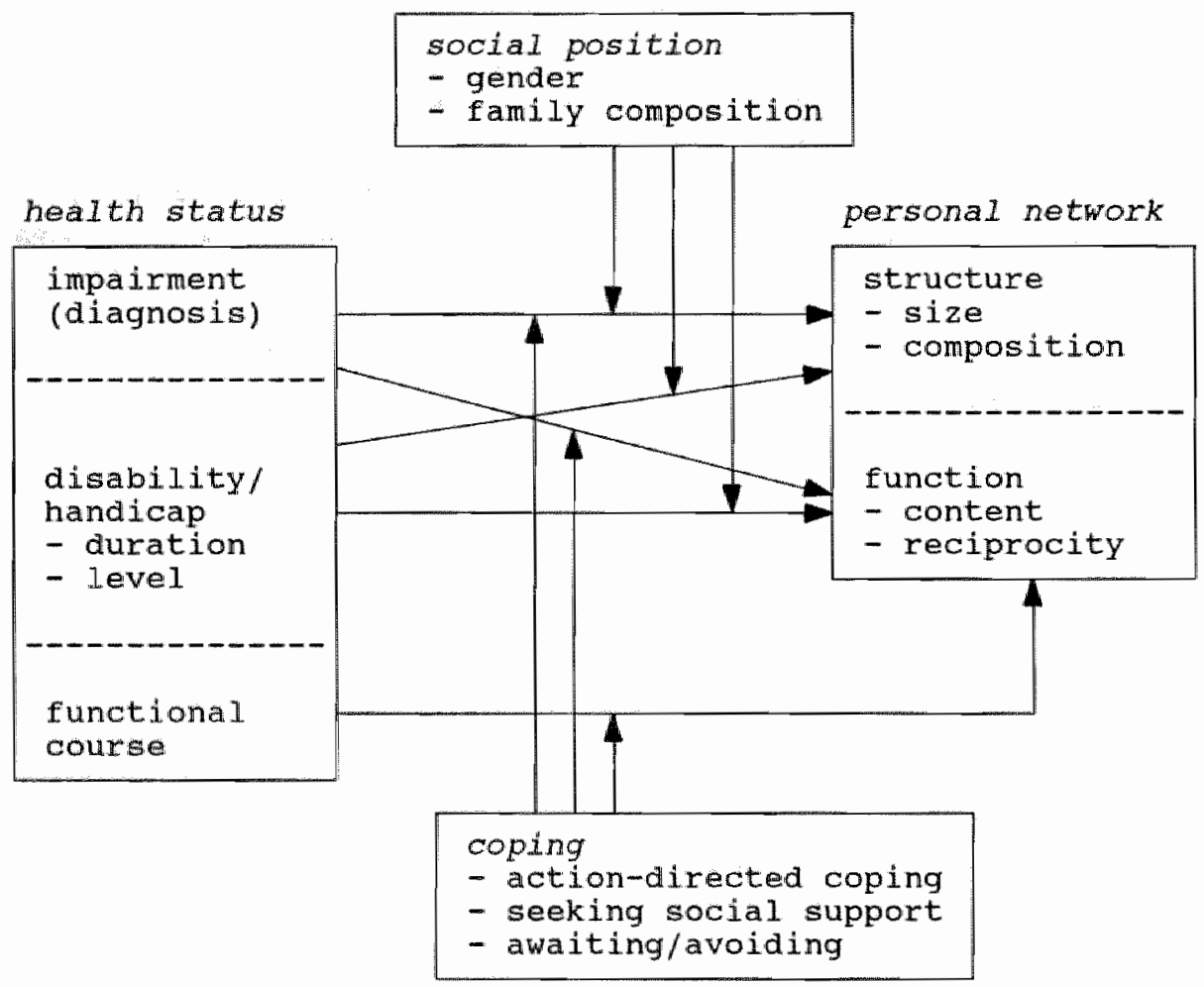

Figure 7.1 Revised research model

In figure 7.1 we summarize the results of our study in the shape of a revised operational research model. The model represents the overall conclusions and therefore we do not distinguish between the several operationalizations of health status and personal network. The arrows in the model represent a kind of 
functional loop rather than causal relationships, because it is clear (chapter 1) that network characteristics in their turn influence health status.

Most results were, however, only found at either $t 1$ or 3 . In this respect, we refer to the methodological discussion in section 7.4 , but first we will discuss the utility of the theories applied to the relation between health status and personal network.

\subsection{Theoretical considerations}

In this section we discuss the utility of exchange, interaction and role theory witl respect to health status and personal network.

From the exchange point of view we expected a decrease in reciprocity between patients and their network members: the patient gives less, whereas he receives more. In cases of chronic somatic health deviation it was stated that this lack of reciprocity would apply especially to instrumental exchange. Because of the lack of reciprocity network size could be expected to decrease. The results of our study show that it is indeed the instrumental exchange that is negatively influenced by health deviation. With regard to size, however, it appeared that the influence of health status on network size is dependent on whether or not the patient is able to seek social support: network size is only smaller for those patients who score low on seeking social support. Furthermore, we expected that the longer the duration of the health deviation, the smaller the network size, because the period during which the equilibrium of the dependency balance is disturbed is longer and the expectation that the delivered care will ever be repaid disappears. However, we only found a relation between duration of the health deviation and network size at B. Because nearly all patients have had their health deviation for a considerable time already, it is understandably not likely that network size would decrease following $\mathrm{t} \mathrm{l}$, as this result indicates. Therefore, it seems that a methodological explanation must be put forward, and as such our expectations towards the relation between duration of the health deviation and network size are not adequately tested. We also expected a higher level of perceived disability as well as a more negative functional course to be related to a smaller network, because the disturbance of the dependency balance is probably more serious. We find no proof of these hypotheses. The longer duration of the health deviation probably resulted in the loss of those contacts that were liable to change, and because this applies to almost all patients we no longer find any effect of perceived disability level and functional course. With respect to the content of the relationship, the data on duration of the health deviation, perceived disability level and functional course again indicate that in case of somatic health deviation the instrumental exchange is influenced, whereas the emotional exchange is not significantly affected.

On the basis of interaction theory we made a distinction between kin and non-kin 
informal network members with regard to the effects of health deviation on the personal network. It was argued that kin relationships would be less vulnerable to the lack of reciproeity than non-kin informal relationships and as a consequence the decrease in network size would especially concern the non-kin network members. The results show that this indeed appears to be true, because the percentage of non-kin informal network members is significantly smaller in the patients ${ }^{3}$ networks than in the healthy respondents' networks. Furthermore, the data on perceived disability level show the importance of family composition with regard to network composition: in the group of patients not having children living at home, the higher perceived disability level is related to a lower percentage of non-kin informal network members, whereas for patients having children at home the opposite is found. Because of the longer duration of the health deviation of nearly all patients, we found no effect of duration of the health deviation and functional course towards network composition.

Role theory was applied to health status and personal network to predict the position of formal network members, especially health care providers, in the patients" networks. It turned out, however, that although all patients mention contacts with health care providers, formal network members are only listed in the personal network by a small number of patients. The conclusion seems to be that the professional enters the social network, but is not viewed as part of the personal network. Because of the small number of patients listing formal network members it was not possible to conduct advanced statistical analyses with regard to the relation of duration of the health deviation, perceived disability level and functional course with the number of formal network members listed. Inspection of the data reveals no confirmation of the hypotheses that a longer duration of the health deviation, a higher perceived disability level and a more negative functional course are related to a larger number of formal network members listed by the patient.

To summarize the results, we found that, because of the longer duration of the health deviation, it is hard to draw any conclusions with regard to the effect of duration of the health deviation, perceived disabiltity level and functional course with regard to the network measures. With regard to the comparison between healthy respondents and patients, the ideas generated by exchange and interaction theory appear to be confirmed by the results of our study, whereas this is not the case with regard to role theory. Furthermore, because only a small number of patients listed formal network members, it was not possible to test the effect of duration of the health deviation, perceived disability level and functional course with regard to the number of formal network members listed. 


\subsection{Methodological considerations}

In this section we pay attention to the research sample, procedures, measurement instrument and data analysis. With regard to each of these aspects a number of considerations can be made as described in the following subsections.

\subsubsection{Sample}

As described in section 3.1, we had originally planned to take three patient groups into the study: AS, Crohn and CVA. As a consequence of a number of problems in obtaining the CVA patients the study was, however, limited to AS and Crohn patients only. We regret this limitation because the onset and course of CVA are different compared to the onset and course of AS and Crohn: AS and Crohn develop slowly and are characterized by a progressive course, whereas CVA occurs from one moment to another and usually the patient improves with time. Because of these differences the effects of CVA on the patients' network might be very different and inclusion of CVA in our study might have provided us with some very valuable extra information.

Another consideration with regard to the sample concerns the criteria set for participation in the study. Only age limits were set with regard to participation in our study and no attention was paid to the duration of the patients' health deviation. The data showed that most patients who participated in our study have endured a prolonged health deviation, probably related to a more or less stable network. Herein probably lies the explanation for the fact that relations with regard to size and composition other than the difference between healthy respondents and patients are not found (at both measurements). Because of the longer duration of the health deviation most changes in the network caused by the health deviation may already have taken place. This indicates that duration of the health deviation has to be added as at criterion for participation in the study.

\subsubsection{Procedure}

With regard to the procedure used in the study we want to consider the time period we set between the measurements and the research design.

With regard to the longer duration of the health deviation the time period of half a year between the interviews is probably not long enough to observe any changes in the personal network. A half-year period will probably suffice when a disease has recently been diagnosed, but will be too short when health deviation has been present for years already, because most changes in the network will already have taken place. 
Another important issue in this section concerns the research design used. The study revealed an unexpected difference in the results found at $t 1$ and $t 3$, which cannot be explained by selection, for the results are based on the data of only those respondents who participated at all moments. We therefore think this difference is caused by information bias, caused in turn by the design. Patients were asked for cooperation by their specialists and as such knew that they were selected as patients. Healthy respondents were also aware that they were selected because they were healthy. Patients and healthy respondents knew that the study concerned the personal relationships of chronic patients compared to those of healthy individuals. This may have resulted in different reactions between healthy respondents and patients following $\mathbb{1 1}$. Because patients were more involved in the study, they would have felt it concerned them directly. Therefore, more than healthy respondents, they may have been led to think about their social relationships and as such answer the interview questions in a different way at 12 and $\mathbf{t} 3$. This leads us to the measurement instrument used in the study.

\subsubsection{Measurement instrument}

In this section we pay attention to the personal network questionnaire used in the study. As stated in section 7.4 .2 patients were probably led to think about their personal network following $\mathrm{t} 1$ which in turn led them to answer differently at $\mathrm{t} 2$ and $\mathbf{3}$. This effect might be reinforced by the way network characteristics are measured. Size, for instance, is measured by asking the respondent to list the names of those persons he frequently interacts with, from whom he gets support and to whom he gives support. The advantage is that only a single question is required to generate a list of names. However, because the criteria employed are quite general, they may be applied differently at subsequent moments. Therefore, it might be useful to use a more specific measure to determine network size. The same applies with respect to the measurement of both emotional and instrumental support. Van Sonderen's (1990) dissertation on measuring social support may act as a basis for developing a more specific questionnaire.

Remarks should also be made about the operationalization of life events other than the onset of health deviation. Our study revealed no effects with regard to life events. We thus might conclude that life events could be omitted from future research. However, it should be noted that we dichotomized this variable into whether the respondent did or did not experience a life event. By doing this we did not pay attention to the difference between life events experienced as positive and life events experienced as negative. As a result the possible effect of life events with respect to network variables might disappear, because the effects of positive and negative life events might be opposite and thus eliminate each other. We therefore recommendate the use of a life event scale such as that described by 
Holmes and Rahe (1967).

\subsubsection{Data analysis}

In this section we discuss the personal network questionnaire used in this study in more depth, especially its stabillity. Furthermore, attention is paid to the large number of relations analyzed and consequently the increased probability of finding significant correlations by chance.

With regard to the personal network questionnaire, Appendix A showed that stability is moderate to low. This is important as far as it concerns the stability of the data in the group of healthy respondents, because we assumed that personal network characteristics are more or less stable in this group. Pearson correlations, however, do not exceed .73 and most correlations are even considerably lower, especially those concerning support received and given. This confirms what is said in section 7.4.3 about the questionnaire being a weak instrument, reducing the chance to find significant relations. The low stability probably also caused the unexpected fluctuations in the scores on the network variables.

On the other hand, the large number of tests conducted $(n=126)$ increased the probability of finding relations by chance. With regard to this, we want to note that the number of significant relations found in the expected direction $(n=20)$ is considerably higher than the number of significant relations that could be found on the basis of chance $(0.05 * 126=6.3)$, although this kind of statistical reasoning is not without flaws. Because of the relatedness of the tests, we think it is valid to assume that most relations found are not based on chance.

\subsection{Practical implications}

Although this study was not primarily designed to draw practical implications, the results led us to formulate a number of comments with regard to practice. Most important in that respect would seem to be the importance of seeking social support in maintaining one's network size and as such the supportiveness from one's network. As we have already stated in the introductory chapter, social support plays an important rolle in the course of health deviation, only recently affirmed again with regard to functional course by de Witte (1991). Therefore, we think that professional health care providers, such as physicians, nurses and physiotherapists, ought to be alert to the way their patients cope. In cases where they find patients unable to seek social support, they might encourage them to seek sympathy and comfort, for instance, to show their feelings or to ask someone to help. This is most likely to be successful when the health deviation has recently been diagnosed, because the patients' communication patterns are probably still 
more open (e.g. Maxwell, 1982). In case of AS patients this could become part of the rehabilitation training they usually get shortly after the disease has been diagnosed.

When it proves to be hard for the patient to alter his coping behavior, the health care provider plays an important role in training network members in supporting the patient.

\subsection{Recommendations with regard to further research}

Most important with regard to further research is to prevent the occurrence of the measurement effect following $\mathrm{tl}$. In our opinion there is only one way to achieve this, namely, as alreadly suggested in chapter 1, conducting a cohort study in which a sample of healthy persons is selected and studied at regular intervals with regard to their health status and personal network. This seems to be the only way in which network changes related to health status can be properly mapped, without for instance the appearance of information bias. This demands, however, a large research population as well as a long time period over which repeated measurements take place. Population size as well as the time period can be kept within manageable bounds by selecting groups of healthy persons who are known to have a higher risk of developing health deviations. Another option would be to study newly diagnosed patients. The problem would then be, however, that most patients have already had health complaints for some period affecting the personal network before the diagnosis is determined. For that reason again a group of healthy controls would have to be taken into the study, again resulting in the risk of information bias.

With regard to the importance of coping in maintaining one's network following health deviation, we recommend developing intervention programs concerning the suggestions in section 7.5, with special attention to the evaluation of the effect of these interventions.

In this respect we welcome the policy of the Dutch Government which pays special attention to the position of chronic patients in Dutch society, recorded in a memorandum on chronic patient policy (1990-1991). In the light of this Government policy, we also once again stress the importance of a cohort study in which the health status and personal networks of initially healthy persons are recorded over a longer period of time, using more specific questionnaires with regard to personal network and life events other than the onset of health deviation. 


\section{Samenvatting, conclusie en discussie}

Dit hoofdstuk begint met een samenvatting van het doel van het onderzoek, de onderzoeksopzet en de resultaten in paragraaf 8.1. In de paragrafen 8.2 en 8.3 worden de resultaten besproken in relatie tot de theoretische uitgangspunten zoals die in hoofdstuk 2 beschreven zijn. De paragrafen $8.4,8.5$ en 8.6 ten slotte bevatten respectievelijk enkele methodologische opmerkingen, praktische aanbevelingen en aanbevelingen voor verder onderzoek.

\subsection{Samenvatting}

Het ontwikkelen van een chronische, invaliderende afwijking van gezondheid veroorzaakt veel veranderingen in het individu en beïnvloedt zijn relatie tot zijn omgeving. Het doel van dit onderzoek was het vastleggen van de veranderingen in de persoonlijke netwerken van patiënten met een chronische lichamelijke afwijking van gezondheid, door middel van het vergelijken van gezonde respondenten en twee groepen patiënten (hoofdstuk 1).

Het theoretisch raamwerk van het onderzoek werd beschreven in hoofdstuk 2 . Theoretische uitgangspunten met betrekking tot ruil, interactie en rol zijn toegepast op veranderingen in het netwerk als gevolg van afwijkingen van gezondheid. We redeneerden dat een enigszins ernstige afwijking van gezondheid zal leiden tol tijdelijk of blijvend lichamelijk, psychologisch en/of sociaal functieverlies. Verscheidene rollen, taken en verantwoordelijkheden kunnen niet langer door de patiënt worden vervuld en moeten worden overgenomen door anderen. Dit heeft een verstoring tot gevolg van de bestaande afhankelijkheidsbalans en naarmate de afwijking van gezondheid ernstiger is, wordt de kans groter dat de rolrelaties worden beïnvloed.

Volgens de ruiltheorie zal deze onevenwichtigheid in de afhankelijkheidsbalans sommige relaties doen verzwakken en op langere termijn zullen verscheidene wegvallen. De relaties waarbij positieve betrokkenheid sterk is, hebben de meeste kans te blijven bestaan. Adams (1967) merkt op dat deze positieve betrokkenheid vaak het sterkst is in relaties met leden van de eigen familie. Naast veranderende en wegvallende relaties zullen er ook nieuwe ontstaan zodra de patient 
afhankelijker wordt van anderen. In het geval van een blijvende afwijking van gezondheid zullen professionele werkers in de gezondheidszorg, onder anderen artsen en verpleegkundigen, sommige rollen, taken en/of verantwoordelijkheden van de patiënt overnemen en deel gaan uitmaken van het netwerk van de patiënt. Met het oog op de gebruikte theorieën werden netwerkgrootte, samenstelling, emotionele en instrumentele steun en wederkerigheid in het onderzoek opgenomen. Gezondheidstoestand is gedefinieerd in termen van stoornis, beperking en handicap.

In hoofdlstuk 2 werd ook aandacht besteed aan de variabelen die mogelijk de relatie tussen gezondheidstoestand en persoonlijk netwerk beïnvloeden. Coping, sociale positie en levensgebeurtenissen anders dan het ontstaan van een afwijking van gezondheid zijn opgenomen in het onderzoeksmodel. Ook werd er een overzicht gegeven van wat er op dit moment bekend is over de relatie tussen afwijking van gezondheid en persoonlijk netwerk met betrekking tot veranderingen in het netwerk als gevolg van een afwijking van gezondheid. Het hoofdstuk werd afgesloten met een aantal hypothesen dat in paragraaf 8.2 wordt besproken tesamen met de resultaten van het onderzoek.

In hoofdstuk 3 werden de onderzoeksopzet en het meetinstrument beschreven. De netwerken van patiënten met de ziekte van Crohn en patiënten met Spondylitis Ankylopoetica (AS) werden ter bestudering geselecteerd. De patiënten werden door hun specialist benaderd met het verzoek deel te nemen aan het onderzoek. De netwerken van de patiënten werden vergeleken met die van gezonden. De patiënten en gezonden werden respectievelijk drie en twee keer geïnterviewd met tussen twee metingen een tijdvak van een half jaar. In totaal namen 36 Crohnpatiënten, 39 AS-patiënten en 44 gezonden deel aan alle metingen.

Hoofdstuk 4 bevat de beschrijving van de respondentengroepen met betrekking tot de bestucleerde variabelen evenals het enige eerste analyses inhoudt. Het blijkt dat de netwerken van AS-patiënten kleiner zijn dan die van zowel gezonden als Crohnpatiënten. Met betrekking tot de samenstelling van het netwerk bleek dat bijna alle gezonden relaties met niet-familieleden uit de categorie van vrienden, kennissen, buren en collega's - in het vervolg van dit hoofdstuk kortweg met informele netwerkleden aangeduid - noemen, terwijl slechts ongeveer tweederde van de patiënten dit soort netwerkleden noemt. Formele netwerkleden werden slechts genoemd door patiënten, hoewel het aantal patiënten dlat formele netwerkleden noemt, klein is. De resultaten tonen ook dat gezonde respondenten en patiënten overwegend verschillen wat betreft de instrumentele ruil in hun relaties.

In hoofdstuk 5 worden de data geanalyseerd met betrekking tot de hypothesen zoals geformuleerd in hoofdstuk 2 . Het bleek dat de netwerkgrootte van patiënten kleiner is dan die van gezonden. De diagnose blijkt daarbij belangrijk: de netwerken van AS-patiënten zijn kleiner dan die van Crohnpatiënten. Het percentage informele netwerkleden is kleiner bij patiënten dan bij gezonden; er is 
hierbij geen verschil tussen AS- en Crohnpatiënten. Duur van de afwijking van gezondheid bleek negatief samen te hangen met netwerkgrootte. Verder toonde hoofdstuk 5 dat het vooral de instrumentele ruil in het familienetwerk is die wordt beïnvloed door gezondheidstoestand. Dit komt het duidelijkst tot uitdrukking in de score met betrekking tot instrumentele wederkerigheid die samenhangt met alle vijf de operationalisaties van gezondheidstoestand.

In hoofdstuk 6 wordt aandacht besteed aan het effect van coping, sociale positie en levensgebeurtenissen op de relatie tussen gezondheidstoestand en persoonlijk netwerk. Blijkbaar is de geneigdheid om sociale steun te zoeken belangrijk voor het in stand houden van het netwerk wanneer de afwijking van gezondheid chronisch is. Voorts blijkt de belangrijke rol van gezinssamenstelling met betrekking tot het percentage informele netwerkleden: in de groep zonder thuiswonende kinderen hebben Crohnpatiënten een hoger percentage informele netwerkleden dan AS-patiënten, en een hogere mate van ervaren dysfunctioneren is gerelateerd aan een lager percentage informele netwerkleden. In de groep met thuiswonende kinderen vinden wij het tegendeel.

In paragraaf 8.2 worden de resultaten besproken in het licht van de in hoofdstuk 2 geformuleerde hypothesen.

\subsection{Evaluatie van het onderzoek}

In deze paragraaf beschrijven we de onderzoeksresultaten met betrekking tot de in paragraaf 2.6 geformuleerde hypothesen. Ook wordt aandacht besteed aan de relatieve sterkte van gezondheidstoestand vergeleken bij de andere variabelen in het onderzoek met betrekking tot de netwerkmaten. Ten slotte bespreken we de betekenis van de resultaten met betrekking tot het onderzoeksmodel zoals gepresenteerd in figuur 2.1.

\subsubsection{Vergelijking netwerken van gezonden en patiënten}

De eerste hypothese betreft de vergelijking van netwerken van gezonden en patiënten: de netwerken wan patiënten zijn kleiner dan die van gezonden, bevatten relatief minder informele en meer formele netwerkleden en zijn minder evenwichtig, omdat patiënten minder steun geven en meer krijgen.

\section{Grootte}

De resultaten toonden dat deze hypothese wordt bevestigd met betrekking tot grootte en samenstelling, hoewel grootte interactie vertoonde met sociale steun zoeken. De hypothese wordt alleen bevestigd voor die respondenten die laag 
scoren op sociale steun zoeken. Patiēnten die hoog scoren op sociale steun zoeken, noemen zelfs meer netwerkleden dan gezonde patiënten die hoog scoren op sociale steun zoeken. Het lijkt dat patiënten die in staat zijn om, bijvoorbeeld, medegevoel en troost te zoeken en hun gevoelens te tonen, in staat zijn hun persoonlijke netwerk te handhaven en zelfs uit te breiden. Dit is in overeenstemming met de bevindingen van Dunkel-Schetter, Folkman en Lazarus (1987) dat mensen die copen door middel van sociale steun zoeken meer bronnen van steun noemen. Door het zoeken van sociale steun geeft het individu signalen aan zijn netwerkleden met betrekking tot zijn behoeften en wensen omtrent steun, en de onderzoeksresultaten duiden erop dat het netwerk van het individu deze signalen beantwoordt.

\section{Samenstelling}

Zowel gezondheidstoestand alsook sociale steun zoeken blijken een belangrijke invloed te hebben op de samenstelling van het netwerk, maar er is geen sprake van interactie: gezonden noemen een hoger percentage informele netwerkleden in vergelijking met patiënten, onafhankelijk van de score op sociale steun zoeken. Formele netwerkleden bleken, zoals verwacht, alleen genoemd te worden door patiënten. Er is echter slechts een klein aantal patiënten dat een formeel netwerklid noemt. Dit is in overeenstemming met Tilden's (1985) idee dat er eerder aan het wederzijds geven-en-nemen in niet-contractuele interacties wordt gedacht als mensen denken aan sociale steun dan aan de contractuele interactie met professionele werkers in de gezondheidszorg.

\section{Steun en wederkerigheid}

We vonden geen verschil tussen gezonden en patiënten wat betreft het emotionele aspect van de relatie, behalve voor emotionele steun die aan informele netwerkleden wordt gegeven. Deze blijkt lager bij patiënten dan bij gezonden. Dit verband wordt alleen gevonden op $\mathrm{t} 1$. Waarschijnlijk ten gevolge van de toename in netwerkgrootte van $\mathrm{t}$ tot $\mathrm{t} 3$ is dit verband niet langer aanwezig op $\mathrm{t}$ (veranderingsscore grootte - veranderingsscore steun $\mathrm{r}=.38, \mathrm{p}<.01$ ).

Met betrekking tot instrumentele steun vonden we geen verschil in de hoeveelheid ontvangen steun van familieleden alsook van informele netwerkleden tussen gezonden en patiënten. Ze verschillen alleen met betrekking tot instrumentele steun geven aan leden van het familie- en informele netwerk op t3: gezonden geven meer dan patiënten. Dit resulteert ook in hogere scores voor gezonden wat betreft wederkerigheid in het familie- alsook in het informele netwerk vergeleken met patiënten op 13 . Dit verschil tussen de resultaten op $t 1$ en 13 kan niet verklaard worden door de toename in netwerkgrootte van $\mathrm{tl}$ tot $\mathrm{t} 3$. Daarom veronderstellen we een methodologische oorzaak, die wij bespreken in paragraaf 8.4 .

De resultaten duiden erop dat in het geval van chronische somatische afwijking 
van gezondheid het vooral de instrumentele ruil is die wordt beïnvloed, zoals reeds opgemerkt in hoofdstuk 2.

\subsubsection{Vergelijking netwerken van AS- en Crohnpatiënten}

De tweede hypothese betreft de vraag welke rol de aard van de ziekte speelt bij veranderingen in het netwerk. Hiertoe betrokken we twee verschillende groepen patiënten bij het onderzoek: een groep met Spondylitis Ankylopoetica (AS) en een groep met de ziekte van Crohn. AS-patiënten hebben vaak of voortdurend last van pijn in de rug en van bewegingsbeperkingen. De meeste Crohnpatiënten hebben daarentegen jarenlang weinig of geen last van hun ziekte. De grootste hinder bestaat eruit dat ze dagelijks medicamenten moeten slikken en dat ze ervan doordrongen zijn dat hun ziekte ieder ogenblik kan verergeren. Dit bracht ons tot de hypothese dat de netwerken van Crohnpatiënten groter zijn dan die van ASpatiënten, relatief meer informele netwerkleden en minder formele netwerkleden bevatten, alsook een kleinere hoeveelheid ontvangen steun en een grotere hoeveelheid gegeven steun, die leiden tot een hogere wederkerigheidsscore.

\section{Grootte}

Op tl zijn de netwerken van Crohnpatiënten inderdaad groter dan die van ASpatiënten. De toename in netwerkgrootte van $t 1$ tot $\mathbf{t} 3$ echter leidde tot het verdwijnen van dit effect (zie paragraaf 8.4).

\section{Samenstelling}

Ook in verband met samenstelling vonden we alleen een verband op $\mathrm{t} 1$. Het blijkt dat de hypothese bevestigd wordt voor AS- en Crohnpatiënten die geen thuiswonende kinderen hebben. In de groep met thuiswonende kinderen vonden we het tegendeel. Correctie voor wat betreft geslacht gaf hetzelfde resultaat te zien. De verklaring zou kunnen zijn dat de mobiliteit van AS-patiënten significant lager is dan die van Crohnpatiënten en dat AS-patiënten daarom meer aan huis gebonden zijn dan Crohnpatiënten. Het hebben van thuiswonende kinderen speelt dan een belangrijke rol, omdat deze kinderen fungeren als een middel waardoor de patiênt in contact kan komen met anderen, zoals de ouders van de vrienden van zijn kind. Op $\mathbf{t} 3$ is dit verband niet meer aanwezig. Waarschijnlijk is dit het gevolg van de toename van de grootte van het netwerk van AS-patiënten, die positief samenhangt met het percentage informele netwerkleden $(r=.43, p<.001)$.

\section{Steun}

We vonden slechts een interactie-effect tussen gezondheidstoestand en actiegericht copen met betrekking tot instrumentele steun geven aan familie: in de groep die laag scoort op actiegerichte coping geven AS-patiënten meer instrumentele steun 
aan familie dan Crohnpatiẻnten, terwijl in de groep die hoog scoort op actiegerichte coping het tegendeel, in overeenstemming met de hypothese, wordt gevonden. We hebben hier geen verklaring voor.

\section{Wederkerigheid}

Zoals wij verwachtten, vonden wij, dat de score voor emotionele wederkerigheid in het familienetwerk op $\mathbf{3}$ hoger is voor Crohnpatiënten dan voor AS-patiënten.

Voor de andere variabelen met betrekking tot steun en wederkerigheid vonden we geen verbanden. We concluderen daarom dat AS- en Crohnpatiënten verschillen aangaande grootte en samenstelling van het netwerk, maar nauwelijks met betrekking tot steun en wederkerigheid. Dit houdt in dat de netwerkgrootte van AS-patiënten meer wordt beinvloed dan die van Crohnpatiënten en dat het percentage informele netwerkleden verschilt tussen beide groepen, afhankelijk van de aanwezigheid van thuiswonende kinderen. Die netwerkleden die overblijven zijn echter min of meer vergelijkbaar voor AS- en Crohnpatiënten wat betreft steun en wederkerigheid.

\subsubsection{Duur van de afwijking van gezondheid en het persoonlijk netwerk}

Naast een effect van de aard van de ziekte verwachtten we ook een zekere invloed van duur van de afwijking van gezondheid, in die zin dat een langere duur gerelateerd is aan een kleiner netwerk, een lager percentage informele netwerkleden, een grotere hoeveelheid ontvangen steun, een lagere hoeveelheid gegeven steun en een lagere wederkerigheidsscore.

\section{Grootte}

Duur van de afwijking van gezondheid bleek inderdaad negatief samen te hangen met netwerkgrootte, hoewel alleen op $\mathbf{3}$. Dit wijst erop dat na $\mathrm{tl}$ veranderingen in het netwerk optreden die leiden tot de relatie die we op $\mathbf{3}$ vinden. Omdat het merendeel van de patiënten de afwijking van gezondheid reeds een langere tijd ondervindt, is het echter niet aannemelijk dat deze veranderingen tijdens de onderzoeksperiode van één jaar zullen hebben plaatsgevonden. Het is daarom dat onze gedachten uitgaan naar een methodologische verklaring (paragraaf 8.4).

\section{Samenstelling}

Er bleek in relatie tot netwerksamenstelling geen verband te bestaan. De verklaring hiervoor kan zijn dat bijna alle patiënten in ons onderzoek de afwijking van gezondheid reeds langere tijd vertonen en dat de contacten die gevoelig waren voor wegvallen, reeds verdwenen zijn. 


\section{Steun en wederkerigheid}

Ook vonden we geen verband tussen emotionele steun en duur van de afwijking van gezondheid. Emotionele steun lijkt onveranderd te blijven als zich een afwijking van gezondheid voordoet, hoewel we op tl een verband vinden tussen emotionele wederkerigheid en de duur van de afwijking van gezondheid in de verwachte richting: naarmate men de afwijking van gezondheid langer heeft, is de wederkerigheidsscore lager.

Met betrekking tot instrumentele steun en wederkerigheid vonden we alleen verbanden in het familienetwerk. Ook hier zou de verklaring kunnen zijn dat de respondenten hun afwijking van gezondheid al langere tijd hebben ondergaan en de contacten die ontvankelijk zijn voor verandering, reeds zijn gewijzigd. Wat betreft het netwerk van familieleden vinden we dat patiënten meer instrumentele steun ontvangen, zoals verwacht, maar ook meer steun geven, in tegenstelling tot de hypothese, indien de afwijking van gezondheid van langere duur is. De verklaring zou gelegen kunnen zijn in de behoefte van de patiënten aan wederkerigheid (b.v. Wentowski, 1981). Als de patiënt meer steun krijgt, zal hij een manier trachten te vinden teneinde deze steun te beantwoorden omwille van zijn gevoel van eigenwaarde. Beide resultaten worden slechts op één meetmoment gevonden.

We vonden een interactie tussen geslacht en duur van de afwijking wat betreft instrumentele wederkerigheid in het familienetwerk. In de groep mannelijke respondenten hebben patiënten met een kortere duur van de afwijking van gezondheid een hogere wederkerigheidsscore dan patiënten met een langere duur, zoals we ook verwachtten. In de groep vrouwelijke respondenten vonden we geen verschillen tussen patiënten met een kortere of een langere duur van de afwijking van gezondheid. De verklaring hiervan zou kunnen zijn dat instrumentele steun meer aanwezig is in de relaties van mannen dan in die van vrouwen.

\subsubsection{Ervaren niveau van dysfunctioneren en het persoonlijk netwerk}

Een andere belangrijke variabele bij het bestuderen van veranderingen in het netwerk als gevolg van een afwijking van gezondheid is het niveau van dysfunctioneren, doordat, naarmate dit niveau hoger is, hel effect op het persoonlijk netwerk groter zal zijn. We veronderstelden daarom dat, naarmate het ervaren niveau van dysfunctioneren hoger is, het netwerk van de patiënt minder omvangrijk is, het percentage informele netwerkleden lager ligt, de hoeveelheid ontvangen steun groter is, de hoeveelheid gegeven steun kleiner is en de wederkerigheidsscore lager is. 


\section{Grootte}

De resultaten tonen geen verband omtrent de grootte van het netwerk. De verklaring zow weer de duur van de afwijking van gezondheid kunnen zijn. De langere duur resulteerde waarschijnlijk in het verliezen van die contacten die gevoelig waren voor verandering. Dit geldt voor bijna alle respondenten en het gevolg daarvan is dat wij geen uitwerking meer vinden van ervaren niveau van dysfunctioneren.

\section{Samenstelling}

We vinden een interactie-effect voor ervaren niveau van dysfunctioneren en gezinssamenstelling wat betreft het percentage informele netwerkleden. Het blijkt dat voor respondenten zonder thuiswonende kinderen geldt dat een hoger niveau van ervaren dysfunctioneren samenhangt met een lager percentage informele netwerkleden, terwijl voor patiënten met thuiswonende kinderen het omgekeerde wordt gevonden. We verklaren deze bevinding met behulp van de importantie van het gezin. Voor respondenten zonder thuiswonende kinderen zijn relaties met informele netwerkleden relatief belangrijk, maar deze relaties zijn waarschijnlijk voor een groot deel gebaseerd op gezamenlijke manieren van vrijetijdsbesteding. Als de respondent lichamelijk gehandicapt raakt, zal hij een gedeelte van deze activiteiten niet meer kunnen uitwoeren. De personen met wie hij deze activiteiten verrichtte, zullen uitkijken naar andere mensen met wie zij deze kunnen doen met het gevolg dat de relatie met de patiënt verwatert. Met nog thuiswonende kinderen is het gezin belangrijk voor de respondent. Functionele invaliditeit kan echter niet door het gezin alleen worden opgevangen (zie Litwak en Szelenyi, 1969) en niet tot het gezin behorende personen zal worden gevraagd om hulp te bieden. Het gevolg hiervan is dat deze personen, bijyoorbeeld vrienden en kennissen, belangrijker worden in het netwerk van de patiënt. Zoals we al eerder opmerkten, vergroot het hebben van thuiswonende kinderen ook de kans met andere mensen in contact te komen, zoals met ouders van vrienden van de kinderen.

\section{Steun en wederkerigheid}

Zoals we reeds eerder bij de andere variabelen van gezondheidstoestand zagen, wordt emotionele steun op niet belangrijke wijze beïnvloed door lichamelijke afwijking van gezondheid. We vinden zelfs een toename in de emotionele wederkerigheidsscore als het ervaren niveau van dysfunctioneren hoger is. Dit wijst er misschien op dat de afwijking van gezondheid de patiënt belangrijk maakt als een emotionele steunverlener.

Met betrekking tot instrumentele steun vinden we geen correlatie tussen gegeven steun en ervaren niveau van dysfunctioneren, terwijl de hoeveelheid ontvangen steun hoger is wanneer het ervaren niveau van dysfunctioneren hoger is. Dit geldt zowel voor het familie- alsook voor het informele netwerk, hetgeen erop duidt dat de respondent in staat is zijn rol van steunverlener te handhaven, maar 
afhankelijker wordt van anderen ten aanzien van het ontvangen van instrumentele steun. Dit leidt alleen in het familienetwerk tot lagere wederkerigheidsscores. In het informele netwerk blijft de instrumentele wederkerigheid min of meer gehandhaafd. Dit wijst erop dat familieleden belangrijker zijn voor wat betreft steunverlening, of doordat ze meer bereidheid tonen om steun te geven zonder een te vergelijken hoeveelheid terug te ontvangen, of doordat de patiënt een grotere bereidheid toont om meer steun te accepteren van familieleden (zie hoofdstuk 2).

\subsubsection{Beloop van het functioneren en veranderingen in het netwerk}

De laatste hypothese, en waarschijnlijk de interessantste, omdat zij een longitudinaal karakter heeft, betreft de relatie tussen het beloop van het functioneren en de veranderingen in het netwerk. We veronderstelden dat wanneer het functioneel niveau daalt, de netwerkgrootte evenals het percentage informele netwerkleden en de hoeveelheid steun die aan netwerkleden is gegeven, zullen afnemen, terwijl de hoeveelheid ontvangen steun toeneemt, gepaard gaand met het afnemen van de wederkerigheidsscores.

\section{Grootte en samenstelling}

Wat betreft grootte en percentage informele netwerkleden vonden we geen verbanden met beloop van het functioneren. We wijzen er nogmaals op dat de afwijking van gezondheid voor bijna alle patiënten reeds van langere duur is en dat daardoor geen grote veranderingen in grootte en samenstelling meer zullen plaatsvinden.

\section{Steun en wederkerigheid}

Zoals we ook al konden afleiden uit de resultaten met betrekking tot de andere hypothesen veranderen ook emotionele steun en wederkerigheid niet gedurende een onderzoeksperiode van een jaar, terwijl in het familienetwerk de hoeveelheid ontvangen instrumentele steun toeneemt en de hoeveelheid verleende instrumentele steun afneemt, hetgeen resulteert in een lagere score voor instrumentele wederkerigheid, zoals te verwachten viel.

In het informele netwerk vonden we geen effect voor instrumentele steun en wederkerigheid. We vonden slechts een interactie met afwachten/vermijden met betrekking tot ontvangen instrumentele steun. In de groep die hoog scoort op afwachten/vermijden, wordt de hypothese bevestigd dat patiënten meer steun zullen ontvangen als hun niveau van dysfunctioneren toeneemt. In de groep die laag scoort op afwachten/vermijden, geldt het omgekeerde. De verklaring zou kunnen zijn dat patiënten die hoog scoren op afwachten/vermijden, die zich neerleggen bij de situatie, hun dysfunctioneren duidelijker aan hun netwerkleden laten zien, hun netwerkleden een aanwijzing geven dat ze steun nodig hebben. Indien een patiënt 
laag seoort op afwachten/vermijden, is het minder duidelijk voor zijn netwerkleden dat hij dysfunctioneert en daarom steun nodig heeft.

Deze data geven nogmaals een indicatie van het belang van familieleden bij het geven van steun aan patiënten.

\subsubsection{De relatieve sterkte van het verband tussen gezondheidstoestand en persoonlijk netwerk}

We stelden de relatieve sterkte van het verband tussen gezondheidstoestand en persoonlijk netwerk vast door het te vergelijken met de kracht van het verband tussen de beïnvloedende variabelen en het persoonlijk netwerk. Het bleek dat gezondheidstoestand een relatief belangrijke variabele is met betrekking tot grootte, samenstelling en een aantal steun- en wederkerigheidsmaten.

Aangaande netwerkgrootte bleek naast gezondheidstoestand sociale steun zoeken de enige gerelateerde beïnvloedende variabele en de sterkte van dit verband is vergelijkbaar met die wan de maten van de gezondheidstoestand.

In relatie tot het percentage informele netwerkleden bleek het wel of niet hebben van een afwijking van gezondheid de enige gezondheidstoestand-variabele te zijn die belangrijk was. Daarnaast bleken ook geslacht, gezinssamenstelling, actiegerichte coping en sociale steun zoeken gerelateerd te zijn aan het percentage leden uit het informele netwerk. De relatie tussen het wel of niet hebben van een afwijking van gezondheid en het percentage informele netwerkleden is echter veel sterker dan die tussen één van de beïnvloedende variabelen en het percentage informele netwerkleden.

Wat betreft emotionele steun bleek er uitsluitend een relatie te bestaan tussen het wel of niet hebben van een afwijking van gezondheid en de steun die aan leden uit het informele netwerk wordt gegeven. Gelet op de relatie tussen deze netwerkvariabele en de beïnvloedende variabelen, toont de analyse dat sociale steun zoeken een sterkere relatie heeft met steun die gegeven wordt aan leden uit het informele netwerk dan het wel of niet hebben van een afwijking van gezondheid, en gezinssamenstelling een even sterke samenhang.

Aangaande instrumentele steun vonden we een samenhang van duur van de afwijking van gezondheid, ervaren niveau van dysfunctioneren en beloop van functioneren alsook een samenhang van sociale steun zoeken met de mate van steun die vrienden geven. Ervaren niveau van dysfunctioneren blijkt de sterkste samenhang te hebben, terwijl de andere variabelen allemaal even sterk samenhangen. Instrumentele steun ontvangen van leden uit het informele netwerk was slechts gerelateerd aan ervaren niveau van dysfunctioneren. Met betrekking tot instrumentele steun geven aan familie alsook aan leden uit het informele netwerk bleek het al dan niet hebben van een afwijking van gezondheid de belangrijkste variabele. Actiegerichte coping en geslacht tonen eveneens een sterke samenhang, 
maar minder sterk dan de gezondheidstoestand-variabele. Ditzelfde geldt voor beloop van het functioneren met betrekking tot instrumentele steun geven aan familie. Verder bleek sociale steun zoeken samen te hangen met instrumentele steun geven aan familie en zowel leeftijd als afwachten/vermijden met informele steun geven, maar de sterkte van deze relaties is minder dan zowel het wel of niet hebben van een afwijking van gezondheid alsook het beloop van het functioneren.

Wat betreft emotionele wederkerigheid vonden we alleen relaties met gezondheidstoestand-variabelen. De beïnvloedende variabelen bleken niet gerelateerd.

Met betrekking tot instrumentele wederkerigheid in het familienetwerk bleken alle gezondheidstoestand-variabelen gerelateerd, alsmede het geslacht. De sterkste relatie betreft duur van de afwijking van gezondheid. Alle andere relaties zijn even sterk. Instrumentele wederkerigheid in het informele netwerk is gerelateerd aan het wel of niet hebben van een afwijking van gezondheid en aan geslacht. De laatste relatie is het sterkst.

Na vergelijking van de sterkte van de relatie tussen de beïnvloedende variabelen en gezondheidstoestand-variabelen met betrekking tot persoonlijke netwerk-maten kunnen we samenvattend concluderen dat gezondheidstoestand de belangrijkste variabele blijkt te zijn, met uitzondering voor wat betreft emotionele steun gegeven aan informele netwerkleden en instrumentele wederkerigheid in het informele netwerk. Hierbij blijken respectievelijk sociale steun zoeken en geslacht de belangrijkste variabelen.

\subsubsection{Conclusie}

In deze paragraaf keren we terug naar het onderzoeksmodel zoals dit gepresenteerd is in figuur 2.1. We bespreken de relevantie van de variabelen in het onderzoek ten aanzien van netwerkveranderingen ten gevolge van een afwijking van gezond heid.

\section{Gezondheidstoestand}

Zoals we in de voorgaande paragraaf reeds opmerkten, blijken alle gezondheidstoestand-variabelen belangrijk met betrekking tot eén of meer van de netwerkvariabelen. De belangrijkste maat bleek te zijn het wel of niet hebben van een afwijking van gezondheid. Deze variabele is gerelateerd aan grootte, samenstelling, steun alsmede aan wederkerigheid. Verder bleek dat beloop van functioneren alleen gerelateerd is aan functie van het netwerk.

\section{Coping}

Coping werd in het onderzoek opgenomen omdat uit andere onderzoeken aanwijzingen kwamen dat coping de hoeveelheid (netwerkleden die) steun (geven) 
beïnloedt die een individu krijgt bij het doormaken van spanningen. Wij onderscheidden drie dimensies van coping in ons onderzoek: sociale steun zoeken, actiegerichte coping en afwachten/wermijden. Sociale steun zoeken blijkt erg belangrijk voor wat betreft netwerkgrootte. In interactie met het wel of niet hebben van een afwijking van gezondheid beinvloedt dit het aantal netwerkleden dat genoemd wordt door de respondent. De resultaten duiden erop dat sociale steun zoeken belangrijk is bij het handhaven van het netwerk na het optreden van een afwijking van gezondheid.

Actiegerichte coping en afwachten/vermijden hebben beide een interactie-effect ten aanzien van steun. Actiegerichte coping vertoont interactie met diagnose met betrekking tot de hoeveelheid instrumentele steun die gegeven wordt aan familie: in de groep die لlaag scoort op actiegerichte coping geven AS-patiënten een hogere hoeveelheid instrumentele steun aan familie dan Crohnpatiënten, terwijl in de groep die hoog scoort op actiegerichte coping het tegendeel wordt gevonden. Afwachten/vermijden vertoont interactie met beloop van het functioneren met betrekking tot de hoeveelheid instrumentele steun ontvangen van informele netwerkleden: in de groep die hoog scoort op afwachten/vermijden ontvangen patiënten meer steun wanneer hun niveau van dysfunctioneren toeneemt, terwijl in de groep die laag scoort het tegengestelde geldt.

\section{Sociale positie}

Op basis van literatuurstudie namen we geslacht, sociale klasse, leeftijd, burgerlijke staat en gezinssamenstelling op in het onderzoek.

Betreffende geslacht vonden we een interactie met duur van de afwijking van gezondheid ten aanzien van instrumentele wederkerigheid in het familienetwerk. Mannelijke respondenten met een minder lange duur van de afwijking van gezondheid bleken hogere wederkerigheidsscores te hebben dan mannelijke respondenten met een langere duur. In de groep vrouwelijke respondenten vonden we geen verschil tussen respondenten met een korte of een lange duur van de afwijking van gezondheid.

Sociale klasse werd in het onderzoek opgenomen omdat een aantal onderzoeken duidde op een verband tussen sociale klasse en de hoeveelheid ontvangen emotionele alsook instrumentele steun. Wij vonden echter geen verband tussen sociale klasse en de netwerkvariabelen in ons onderzoek.

Met betrekking tot leeftijd vonden we verbanden met emotionele steun ontvangen van familie en instrumentele steun geven aan leden van het informele netwerk. Dit was echter niet van invloed op de relatie tussen gezondheidstoestand en deze netwerkvariabelen.

We hebben geen gegevens wat betreft het effect van burgerlijke stat op de relatie tussen gezondheidstoestand en persoonlijk netwerk. Meer dan $75 \%$ van de respondenten in iedere groep was of getrouwd of samenwonend en daarom lieten wij burgerlijke staat buiten de analyses. 
De laatste variabele die tot sociale positie behoort, gezinssamenstelling, bleek belangrijk in verband met het percentage informelle netwerkleden. In de groep zonder thuiswonende kinderen bleken AS-patiënten een lager percentage informele netwerkleden te hebben dan Crohnpatiënten. Verder blijkt in deze groep een hoger niveau van dysfunctioneren samen te thangen met een lager percentage informele netwerkleden. In de groep met thuiswonende kinderen vinden we het tegenovergestelde.

\section{levensgebeurtenissen anders dan het begin van een afwijking van gezondheid}

Er zijn verscheidene levensgebeurtenissen anders dan afwijking van gezondheid die mogelijk leiden tot veranderingen in het netwerk. Daarom namen we levensgebeurtenissen in het onderzoek op. Er bleek geen relatie te bestaan tussen het beleven van levensgebeurtenissen en netwerkkenmerken.

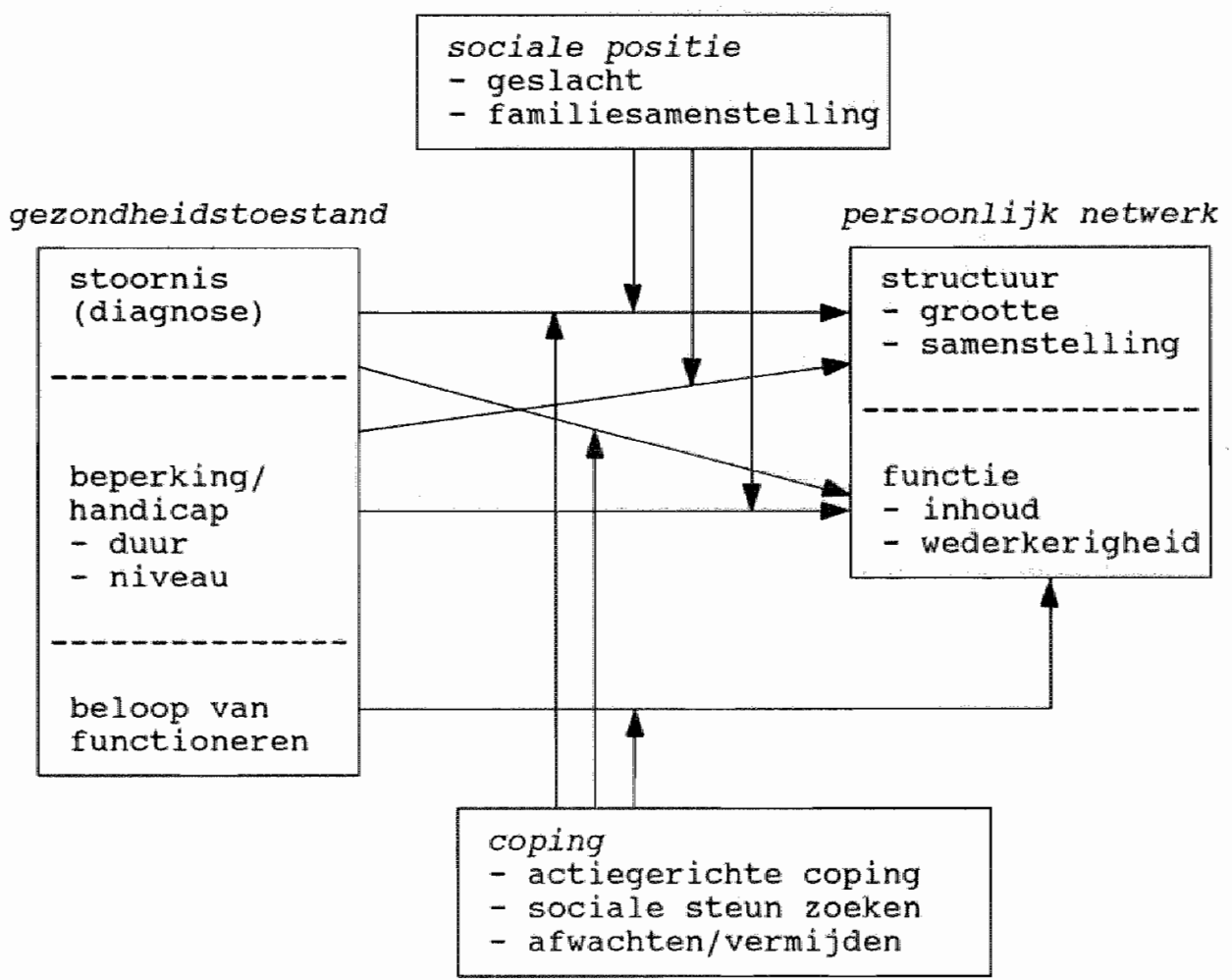

Figuur 8.1 Herzien onderzoeksmodel 
In figuur 8.1 vatten we de resultaten van het onderzoek samen in de vorm van een herzien onderzoeksmodel. Het model geeft de algemene conclusies weer en daarom maken we geen onderscheid tussen de verschillende operationalisaties van gezondheidstoestand en persoonlijk netwerk. De pijlen in het model zijn niet causaal bedoeld maar geven een soort van functionele loop weer, omdat het duidelijk is (hoofdstuk 1) dat netwerkkenmerken ook gezondheidstoestand beïnvloeden.

De meeste resultaten worden evenwel slechts op én van de meetmomenten gevonden. Met het oog hierop verwijzen we naar paragraaf 8.4 , maar eerst willen we aandacht schenken aan de bruikbaarheid van de theorieën die we hebben toegepast op de relatie tussen gezondheidstoestand en persoonlijk netwerk.

\subsection{Theoretische overwegingen}

In deze paragraaf bespreken we de bruikbaarheid van ruil-, interactie- en roltheorie ten aanzien van gezondheidstoestand en persoonlijk netwerk.

Vanuit de optiek van ruiltheorie verwachtten we een vermindering in wederkerigheid tussen patiënten en hun netwerkleden: de patiënt geeft minder, terwijl hij meer ontvangt. In het geval van chronische lichamelijke ziekte werd opgemerkt dat dit gebrek aan wederkerigheid vooral zal gelden voor instrumentele ruil. De verwachting is dat de netwerkgrootte zal verminderen door het gebrek aan wederkerigheid. De resultaten van ons onderzoek laten zien dat het inderdaad de instrumentele ruil is die negatief wordt beïnvloed door afwijking van gezondheid. Wat betreft grootte echter bleek, dat de invloed van gezondheidstoestand op netwerkgrootte wordt beïnvloed door het vermogen van de patiënt sociale steun te zoeken: netwerkgrootte is alleen kleiner bij die patiënten die laag scoren op het punt van sociale steun zoeken. Verder verwachtten we dat een langere duur van de afwijking van gezondheid samenhangt met een kleiner netwerk, omdat de afhankelijkheidsbalans gedurende een langere periode verstoord is en de verwachting dat de gegeven steun ooit zal worden terugbetaald, verdwijnt. We vonden slechts een relatie tussen duur van de afwijking van gezondheid en netwerkgrootte op $\mathbf{3}$. Omdat het merendeel van de patiënten de afwijking van gezondheid reeds langere tijd ondervindt, is het echter niet aannemelijk dat netwerkgrootte afneemt na $t l$, zoals de resultaten indiceren. Daarom denken we aan een methodologische verklaring, hetgeen betekent dat onze verwachtingen met betrekking tot de relatie tussen duur van de afwijking van gezondheid en netwerkgrootte niet voldoende getest zijn. We verwachtten ook dat een hoger niveau van dysfunctioneren en cen negatiever beloop van functioneren samenhangen met een kleiner netwerk, omdat de afhankelijkheidsbalans waarschijnlijk ernstiger verstoord is. We vinden geen bewijs voor deze hypothesen. De langere duur van de afwijking van gezondheid heeft er 
waarschijnlijk toe geleid dat de contacten die gevoelig zijn voor verandering al verdwenen zijn. Omdat dit geldt voor het merendeel van de patiènten vinden we niet langer een effect van ervaren niveau van dysfunctioneren en beloop van functioneren. Wat betreft de inhoud van de relaties tonen ook de data met betrekking tot duur van de afwijking van gezondheid, ervaren niveau van dysfunctioneren en beloop van functioneren aan, dat in het geval van een lichamelijke afwijking van gezondheid de instrumentele ruil wordt beïnvloed, terwijl de emotionele ruil niet belangrijk verandert.

Aan de hand van interactietheorie maakten we een onderscheid tussen leden wit het familie- en informele netwerk ten aanzien van de invloed van afwijking van gezondheid op het persoonlijk netwerk. Er werd gesteld dat familierelaties minder gevoelig zouden zijn voor een gemis aan wederkerigheid dan relaties met informele netwerkleden. Als gevolg hiervan zou het kleiner worden van het netwerk vooral betrekking hebben op leden uit het informele netwerk. De resultaten laten zien dat dit inderdaad blijkt te kloppen, omdat het percentage informele netwerkleden van de patiënten significant kleiner is dan het percentage in het netwerk van de gezonden. Verder tonen de data met betrekking tot het ervaren niveau van dysfunctioneren het belang van gezinssamenstelling aan voor de samenstelling van het netwerk: voor respondenten zonder thuiswonende kinderen geldt dat een hoger niveau van ervaren dysfunctioneren samenhangt met een lager percentage informele netwerkleden, terwijl voor patiënten met thuiswonende kinderen het omgekeerde wordt gevonden. Vanwege de langere duur van de afwijking van gezondheid bij bijna alle patiënten vonden we geen effect van duur van de afwijking van gezondheid en beloop van functioneren met betrekking tot netwerksamenstelling.

Roltheorie werd toegepast op gezondheidstoestand en persoonlijk netwerk teneinde een voorspelling te kunnen doen aangaande de positie van formele netwerkleden, met name gezondheidszorgwerkers, in de netwerken van de patiënten. Het bleek echter dat, hoewel alle patiënten contacten met gezondheidszorgwerkers noemen, formele netwerkleden slechts door een klein aantal patiënten in het persoonlijk netwerk wordt genoemd. Hieruit blijkt dat de professionele hulpverlener wel toetreedt tot het sociaal netwerk, maar niet beschouwd wordt als lid van het persoonlijk netwerk. Vanwege het geringe aantal patiënten dat een formeel netwerklid noemt, was het niet mogelijk geavanceerde statistische analyses uit te voeren met betrekking tot de relatie tussen duur van de afwijking van gezondheid, ervaren niveau van dysfunctioneren en beloop van functioneren met betrekking tot het aantal genoemde formele netwerkleden. Inspectie van de data toont geen bevestiging van de hypothesen dat een langere duur van de afwijking van gezondheid, een hoger ervaren niveau van dysfunctioneren en een negatiever beloop van functioneren samenhangen met het noemen van een groter aantal formele netwerkleden door de patiënt.

De resultaten samenvattend, hebben we gevonden dat, vanwege de langere duur 
van de afwijking van gezondheid, het moeilijk is conclusies te trekken met betrekking tot het effect van duur van de afwijking van gezondheid, ervaren niveau van dysfunctioneren en beloop van functioneren met betrekking tot de netwerkmaten. Met betrekking tot de vergelijking tussen gezonde respondenten en patienten, blijken de verwachtingen gebaseerd op ruil- en interactietheorie bevestigd te worden door de resultaten van ons onderzoek, terwijl dit niet het geval is met de verwachtingen gebaseerd op roltheorie. Vanwege het geringe aantal patiënten dat een formeel netwerklid noemt, was het niet mogelijk het effect van duur van de afwijking van gezondheid, ervaren niveau van dysfunctioneren en beloop van functioneren met betrekking tot het genoemde aantal formele netwerkleden te toetsen.

\subsection{Methodologische opmerkingen}

In deze paragraaf besteden we aandacht aan de respondenten, de procedures, het meetinstrument en de gegevensverwerking. Aangaande elk van deze aspecten kan een aantal opmerkingen worden gemaakt. Deze worden beschreven in de volgende paragrafen.

\subsubsection{Respondenten}

Zoals we in paragraaf 3.1 beschreven, was het oorspronkelijk de bedoeling drie patiëntengroepen in het onderzoek op te nemen: AS, Crohn en Cerebro Vasculair Accident (CVA). Als gevolg van een aantal problemen met het verkrijgen van CVA-patiënten voor het onderzoek werd het onderzoek beperkt tot AS- en Crohnpatiënten. We betreuren deze beperking, omdat ontstaan en beloop van CVA verschillend zijn van ontstaan en beloop van AS en Crohn: AS en Crohn ontstaan langzaam en worden gekenmerkt door een progressief beloop, terwijl CVA van het ene moment op het andere ontstaat en het functioneren van de patiënt meestal na verloop van tijd verbetert. Door deze verschillen zouden de gevolgen van CVA voor het netwerk van de patiënt erg kunnen verschillen van die van AS en Crohn, en zij zouden ons zeer waardevolle extra informatie hebben kunnen geven.

Een andere overweging betreffende de respondenten heeft betrekking op de inclusie-criteria die we gesteld hebben voor deelname aan het onderzoek. We stelden alleen leeftijdsgrenzen aan de respondenten en hielden geen rekening met de duur van de afwijking van gezondheid van de patiënten. De resultaten toonden dat de meeste respondenten hun afwijking van gezondheid reeds gedurende langere tijd hadden, waarschijnlijk uitmondend in een min of meer stabiel netwerk. Dit is waarschijnlijk de verklaring voor het feit dat we wat betreft grootte en samenstelling van het netwerk alleen verschillen vonden tussen patiënten en 
gezonden (op beide metingen). Door de langere duur van de afwijking van gezondheid hebben de meeste veranderingen in het netwerk die veroorzaakt zijn door de afwijking, waarschijnlijk al plaats gehad. Dit duidt erop dat duur van de afwijking van gezondheid moet worden toegevoegd aan de criteria voor deelneming aan het onderzoek.

\subsubsection{Procedures}

Met betrekking tot de gehanteerde onderzoeksprocedures besteden we aandacht aan de gestelde tijdsperiode tussen de afzonderlijke metingen en de onderzoeksopzet.

Gezien de langere duur van de afwijking van gezondheid is het tijdvak van een half jaar tussen de interviews waarschijnlijk te kort om veranderingen in het persoonlijk netwerk te kunnen waarnemen. Een periode van een half jaar zal waarschijnlijk voldoende zijn wanneer de diagnose kort geleden gesteld is, maar deze is te kort als de afwijking van gezondheid al jaren aanwezig is, ondat dan veel veranderingen in het netwerk al hebben plaatsgevonden.

Een ander belangrijk punt betreft de gebruikte onderzoeksopzet. Het onderzoek toonde een verschil in resultaten gevonden op $\mathrm{t} 1$ en $\mathbf{t} 3$, dat niet verklaard kan worden door selectie, doordat de resultaten alleen gebaseerd zijn op de gegevens van de respondenten die deelnamen aan alle metingen. We vermoeden daarom dat het verschil het gevolg is van informatie-bias, veroorzaakt door de opzet. Patiènten werden voor deelneming gevraagd door hun specialist en wisten daarom dat ze geselecteerd waren als patiënt. Gezonden wisten ook dat ze gevraagd werden, omdat ze gezond waren. Patiënten en gezonden wisten dat het onderzoek de persoonlijke relaties van chronische patiënten in vergelijking tot die van gezonden betrof. Dit kan tot een verschil in reacties tussen patiënten en gezonden hebben geleid volgend op 11 . Omdat patiënten zich meer betrokken voelden bij het onderzoek, zijn ze misschien meer dan gezonden gemotiveerd om over hun persoonlijke contacten na te denken, met als gevolg een andere manier van antwoorden op $\mathrm{t} 2$ en $\mathrm{t} 3$. Dit leidt ons tot het door ons gebruikte meetinstrument.

\subsubsection{Meetinstrument}

In deze paragraaf besteden we aandacht aan de vragenlijst betreffende het persoonlijke netwerk die wij gebruikten in ons onderzoek. Zoals opgemerkt in paragraaf 8.4.2 werden patiënten waarschijnlijk gestimuleerd om over hun persoonlijke relaties na te denken naar aanleiding van $t 1$, hetgeen resulteerde in andere antwoorden op $t 2$ en 13 . Dit effect kan versterkt zijn door de manier waarop de netwerkkenmerken werden gemeten. Grootte bijvoorbeeld werd gemeten door aan de respondent te vragen om de namen van die mensen te 
noemen met wie hij regelmatig contact heeft, van wie hij steun krijgt en aan wie hij steun geeft. Het voordeel van deze methode is dat een enkele vraag voldoende is om een lijst van netwerkleden te krijgen. Doordat echter de gehanteerde criteria vrij algemeen zijn, kunnen ze verschillend worden toegepast op verschillende momenten. Daarom kan het nuttig zijn een meer specifieke maat te gebruiken om de grootte van het netwerk te meten. Dit geldt ook voor de manier waarop emotionele en instrumentele steun gemeten zijn. Van Sonderen's (1990) dissertatie met betrekking tot het meten van sociale steun kan als uitgangspunt dienen voor het ontwikkelen van een meer specifieke vragenlijst.

We willen ook een kanttekening plaatsen bij de manier waarop wij levensgebeurtenissen anders dan het ontstaan van een afwijking van gezondheid hebben geoperationaliseerd. Ons onderzoek toonde geen effect van levensgebeurtenissen. Daardoor zouden we kunnen concluderen dat levensgebeurtenissen uit toekomstig onderzoek kunnen worden weggelaten. We willen er echter op wijzen dat we de variabele levensgebeurtenissen gedichotomiseerd hebben, namelijk in het al dan niet ervaren hebben van een levensgebeurtenis. Op die manier wordt er geen rekening gehouden met het verschill in als positief ervaren levensgebeurtenissen en als negatief ervaren levensgebeurtenissen. Dit leidt ertoe dat het mogelijke effect van levensgebeurtenissen op netwerkvariabelen kan verdwijnen, omdat het effect van positieve en negatieve gebeurtenissen tegengesteld kan zijn en elkaar dus kan opheffen. Daarom bevelen wij het gebruik van een 'life event scale" aan, zoals bijvoorbeeld beschreven door Holmes en Rahe (1967).

\subsubsection{Gegevensverwerking}

Deze paragraaf bevat een dieper gaande bespreking van de in dit onderzoek gebruikte vragenlijst met betrekking tot het persoonlijk netwerk, met name de stabiliteit ervan. Verder besteden we aandacht aan het groot aantal geanalyseerde verbanden en de daarmee samenhangende verhoogde kans op het per toeval vinden van significante relaties.

Met betrekking tot de stabiliteit van de netwerk-vragenlijst toonde Appendix A dat deze redelijk tot laag is. Dit is belangrijk waar het de stabiliteit van de data van gezonde respondenten betreft, omdat we aannamen dat de kenmerken van het persoonlijk netwerk min of meer stabiel zijn in deze groep. Pearson-correlaties komen echter nergens boven .73 en de meeste correlaties zijn zelfs aanzienlijk lager, met name die betreffende gegeven en ontvangen steun. Dit bevestigt hetgeen in paragraaf 8.4.3 werd gezegd, namelijk dat de gebruikte vragenlijst een zwak instrument is, met als gevolg dat de kans op het vinden van significante verbanden wordt verlaagd. De lage stabiliteit is waarschijnlijk ook de oorzaak voor de onverwachte schommelingen in de scores op de netwerkvariabelen. 
Daar staat tegenover dat er een groot aantal toetsen is uitgevoerd $(n=126)$, waardoor de kans dat er relaties bij toeval worden gevonden, toeneemt. Daarover willen we opmerken dat het aantal gevonden significante verbanden in de verwachte richting $(n=20)$ aanmerkelijk hoger is dan het aantal significante relaties dat we op grond van het toeval zouden mogen verwachten $(0.05 * 126=6.3)$, hoewel deze manier van statistisch redeneren niet zonder nadelen is. Vanwege het aan elkaar gerelateerd zijn van de toetsen, vinden we het geldig aan te nemen dat het merendeel van de gevonden relaties niet op toeval berust.

\subsection{Praktische aanbevelingen}

Hoewel dit onderzoek niet in de eerste plaats is opgezet om praktische aanbevelingen te doen, leiden de resultaten ons er toch toe. Het belangrijkste in dat opzicht lijkt het belang van sociale steun zoeken voor het behoud van het persoonlijk netwerk en als zodanig de hoeveelheid steun die men ontvangt wit het netwerk. Zoals we al stelden in het inleidend hoofdstuk, speelt sociale steun een belangrijke rol in het beloop van afwijking van gezondheid, onlangs nogmaals bevestigd ten aanzien van beloop van functioneren door De Witte (1991). Daarom menen wij dat professionele hulpverleners in de gezondheidszorg, zoals bijvoorbeeld artsen, verpleegkundigen en fysiotherapeuten, alert moeten zijn op hoe hun patiënten omgaan met problemen. Als ze merken dat de patiënt niet geneigd is sociale steun te zoeken, kunnen ze de patiënt aanmoedigen om, bij voorbeeld, medegevoel en troost te zoeken, zijn gevoelens te tonen of iemands hulp in te roepen. Dit werkt waarschijnlijk het beste wanneer de afwijking van gezondheid pas gediagnostiseerd is, doordat de communicatiekanalen van de patiënt dan nog meer open zullen zijn (zie bijvoorbeeld Maxwell, 1982). Dit zou bij AS-patiënten deel kunnen gaan uitmaken van de revalidatietraining, die deze patiënten meestal krijgen korte tijd nadat de diagnose is gesteld.

Indien het woor de patiënt moeilijk blijkt zijn coping gedrag te veranderen, speelt de professionele hulpverlener een belangrijke rol in het trainen van netwerkleden in het geven van steun aan de patiënt.

\subsection{Aanbevelingen voor verder onderzoek}

Het belangrijkst ten aanzien van verder onderzoek is het voorkomen van het meeteffect dat optrad na $t 1$. Naar onze mening is er slechts éen manier orn dit te bereiken, namelijk, zoals ook al voorgesteld in hoofdstuk 1 , het uitvoeren van een cohort-onderzoek waarbij een steekproef van gezonde merisen op regelmatige tijdstippen bestudeerd wordt wat betreft hun gezondheidstoestand en hun 
persoonlijk netwerk. Dit lijkt de enige manier waarop veranderingen in het netwerk als gevolg van veranderingen in gezondheid kunnen worden vastgelegd, zonder bijvoorbeeld het optreden van informatie-bias. Dit vraagt echter om een grote onderzoekspopulatie alsook om een lange tijdsperiode waarin herhaalde metingen plaatsvinden. Grootte van de onderzoekspopulatie evenals de tijdsperiode kunnen binnen hanteerbare grenzen worden gehouden door een groep gezonden te selecteren van wie bekend is dat ze een hoger risico hebben op het ontwikkelen van een afwijking van gezondheid. Een andere mogelijkheid zou zijn pas gediagnostiseerde patiënten te bestuderen. Het probleem is dan echter dat de meeste patiënten hun gezondheidsklachten reeds gedurende een langere periode hebben, waardoor het netwerk al is beïnvloed voordat de diagnose wordt gesteld. Daarom zou opnieuw een gezonde controle-groep in het onderzoek moeten worden opgenomen, wat wederom het risico van informatie-bias met zich meebrengt.

Ten aanzien van het belang van coping voor het handhaven van het netwerk na het optreden van een afwijking van gezondheid, bevelen we de ontwikkeling van interventie-programma's met betrekking tot de suggesties in paragraaf 8.5 aan, met speciale aandacht voor de evaluatie van de effecten van deze interventies.

Hiertoe verwelkomen we het beleid van de Nederlandse overheid dat speciale aandacht inhoudt voor de positie van chronisch zieke patiënten in de Nederlandse samenleving, een beleid dat vastgelegd is in de notitie 'chronisch-zieken-beleid' (1990-1991). In het licht van dit overheidsbeleid willen we nogmaals het belang onderstrepen van een cohort-onderzoek waarbij de gezondheidstoestand en het persoonlijk netwerk van - bij aanvang - gezonde mensen worden vastgelegd gedurende een langere periode, gebruikmakend van meer specifieke vragenlijsten met betrekking tot persoonlijk netwerk en levensgebeurtenissen anders dan het optreden van een afwijking van gezondheid. 


\section{References}

Adams, B.N. (1967). Interaction theory and the social network. Sociometry, 30, 64-78.

Agthoven, W.M. van (1985). Zorg op maat. Amsterdam.

Agthoven, W.M. van (1986). Thuiszorg op maat. Tijdschrift woor Ziekenverpleging, 39, 130-138.

Barnes, J.A. (1979). Network analysis: orienting notion, rigorous technique or substantive field of study. In Holland, P.W., Leinhardt, S. (eds.). Perspectives on social network research. New York: Academic Press.

Bell, W., Boat, M.D. (1957). Urban neighborhoods and informal social relations. The American Jounal of Sociology, 62, 391-398.

Bergner, M., Bobbitt, R.A., Carter, W.B., Gilson, B.S. (1981). The Sickness Impact Profile: development and final revision of a health status measure. Medical Care, 8, 787-805.

Bergner, M., Bobbitt, R.A., Pollard, W.E., Martin, D.P., Gilson, B.S. (1976). The Sickness Impact Profile: validation of a health status measure. Medical Care, $14,57-67$.

Billings, A.G., Moos, R.H. (1981). The role of coping responses and social resources in attenuating the stress of life events. Journal of Behavioral Medicine, 4, 139-157.

Boissevain, J., Mitchell, J.C. (1973). Network analysis: Studies in human interaction. The Hague: Mouton.

Boissevain, J. (1974). Friends of friends." networks, manipulators, and coalitions. Oxford: Blackwell.

Bott, E. (1971). Fontily and social network. London: Tavistock Publications.

Bruhn, J.G. (1977). Effects of chronic illness on the family. Journal of family Practice, 4, 1057 . 1060.

Bruhn, J.G., Philips, B.U. (1984). Measuring social support: a synthesiss of current approaches. Journal of Behawioral Medicine, 7, 151-169.

Burt, R.S. (1986). A note on sociometric order in the general social survey network data. Social Networks, 8, $149-174$.

Calabro, J.J., Maltz, B.A. (1970). Ankylosing spondylitis. The New England Journal of Medicine, 282, 606-610.

Carette, S., Graham, D., Little, H., Rubenstein, J., Rosen, Ph. (1983). The natural disease course of ankylosing spondylitis. Arthritis and Rheumatism, 26, 186-190.

Chrisman, L.W. (1969). On networks. Cormell Journal of Social Relat., 4, 72-81.

Cohen, S., Syme, S.L. (eds.)(1985). Social support and health. Orlando: Academic Press.

Coleman, J.S. (1988). Social capital in creation of human capital. American Journal of Sociology, 94, S95-S120.

Coulton, C.J. (1979). A study of person-environment fit among the chronically ill. Social Work Health Care, 5, 5-17.

Croog, S.H., Lipson, A., Levine, S. (1972). Help patterns in severe illness. Journal of Marriage and the Family, $34,32-41$.

Davidson, A.W., Young, C. (1985). Repatterning of stroke rehabilitation clients following retum 
to life in the community. 1. Neurosurg. Nurs, $17,123-128$.

Davis, J.A., Leinhardt, $S$. (1972). The structure of positive interpersonal relations in small groups. In: Berger, J., Zelditch,M., Anderson, B. (eds.). Sociological theories in progress. New York: Houghton Mifflin.

Dean, A., Lin, N. (1977). The stress-buffering role of support: problems and prospects for systematic investigation. The Journal of Nervous and Mental Disease, 165, 403-417.

Dechesne, B.H.H. (1985). Handicap; implicaties van een idee. Bewegen \& Hulpverlening, 3, 198-213.

Dunkel-Schetter, C., Folkman, S., Lazarus, R.S. (1987). Correlates of social support receipt. Journal of Personality and Social Psychology, 53, 71-80.

Durkheim, $\mathbb{E}$. (1933). The division of labor in society. New York: Free Press.

Eijk, J.Th.M., wan (1980). De verwerking van enkele levensgebeurtenissen en steun uit sociale netwerken. Gezondheid en Samenleving, 1, 83-99.

Erickson, G.D. (1975). The concept of personal networks in clinical practice. Family Process, $14,487-498$.

Fulayson, A. (1976). Social networks as coping resources. Social Science and Medicine, 10, 97 103.

Fitth, R., Djamour, J. (1956). Kinship in South Borough. In Firth, R. (ed.). Two studies of kinship in London. London.

Fischer, C.S. (1977). Networks and places. New York: Free Press.

Flap, H.D. (1987). De theorie van het sociale kapitaal. Antropologische Verkenningen, 6, 14-27.

Gazzard, B.G., Price, H.L., Libby, G.W., Dawson, A.M. (1978). "The social toll of Crohn's disease. British Medical Journal, 2, 1117-1119.

Gross, E. (1956). Symbiosis and consensus as integrative factors is small groups. American Sociological Review, 21, 174-179.

Holmes, T.H., Rahe, R.H. (1967). The social readjustment rating scalle Journal of Psychosomatic Research, 11, 213-218.

Holzhater, F.F.O., Minden, J.J.R. van (1985). Psychologie. Leiden: Stenfert Kroese.

Homans, G.C. (1961). Social behavior: its elementary forms, London: Routledge and Kegan Paul.

House, J.S., Umberson, D., Landis, K.R. (1988). Structures and processes of social support. Annual Review of Sociology, 14, 293-318.

Hoyt, D.R., Babchuk, N. (1983). Adult kinship networks: the selective formation of intimate ties with kin. Social Forces, 62, 84-101.

Ikels, C. (1988). Delayed reciprocity and the support networks of the childless elderly. Journal of Comparative Fanily Studies, 19, 99-112.

Jaco, E.G. (1979). Patients, Physicians, and Hiness. New York: Free Press.

Janssen, M., Philipsen, H. (1989). Personal networks of chronically ill people. Paper presented on the First European Conference on Social Network Analysis. Groningen.

Janssen, M., Philipsen, H., Halfens, R.J.G. (1990). Personal networks of chronically ill people. Paper presented on the Fitth International Conference on Personal Relationships. Oxford.

Joachim, G., Milne, B. (1987). Inflammatory bowel disease: effects on lifestyle. Journal of Advanced Nursing, 12, 483- 487.

Joosten, J. (1989). The structure of the concept 'health' in the Dutch population. In: d'Houtaud, A., Field, M., Gueguen, R. (eds.). Health representations. Colloque INSERM, 178, 71-84.

Joosten, J. Horst, F. van der, Witte, L. de (1986). Chronische patienten en hun sociale contacten. Paper voor de Nederlands - Vlaamse Sociologendagen.

Kapferer, B. (1973). Social network and conjugal role in urban Zambia: toward a reformulation of the Biott hypothesis. In: Boissevain, J., Mitchell, J.C. (eds.). Network analysis: Studies in 
human interaction. The Hague: Mouton.

Knipscheer, C.P.M. (1980). Oude mensen en hun sociale omgeving: een studie van het primaire sociale netwerk. The Hague: VUGA.

Korst, J.K. van der (1980). Gewrichtsziekten. Utrecht: Bohn, Scheltema and Holkema.

Lazarus, M.S. (1977). Stress and coping. New York: Columbia University Press.

Leinhardt, S. (1973). The development of transitive structure in children's interpersonal relations. Behavioral Science, 12, 260-271.

Lin, N., Dean, A., Ensel, W.M. (1981). Social support scales: a methodological note. Schizophrenia Bulletin, 7, 73-89.

Lindsey, A.M., Ahmed, N., Dodd, M.J. (1985). Social support: network and quality as perceived by Egyptian cancer patients. Cancer Nursing, 8, 37-42.

Litwak, E., Szelenyi, J. (1969). Primary group structures and their functions: kin, neighbors, and friends. American Sociological Review, 34, 465-481.

Litwak, E. (1985). Helping the elderly: the complementary roles of informal netwarks and formal systems. New York: Guilford Press.

Mann, P.H. (1954). The concept of neighborliness. American Joumal of Sociology, 59.

Maxwell, M.B. (1982). The use of sociall networks to help cancer patients maximize support. Cancer Nursing, 5, 275-281.

McFarlane, A.H., Neale, K.A., Norman, G.R., Roy, R.G., Streiner, D.L. (1981). Methodological issues in developing a scale to measure social support. Schizophrenia Bulletin, 7, 90-100.

McGeough, A., Edwards, J., Chamberlain, R.M., Nogeire, Ch. (1980). Social isolation in lung cancer patients. Social Work in Health Care, 5, 433-436.

Milardo, R.M., Johnson, M.P., Huston, T.L. (1983). Developing close relationships: changing patterns of interaction between pair members and social networks. Journal of Personality and Social Psychology, 44, 964-976.

Mitchell, J.C. (1969). Social networks in urban situations. Manchester: Manchester University Press.

Moos, R.H., Tsu, V.D. (1977). Coping with physical illness. New York: Plenum Medical Book Co.

Mootz, M. (1981). De patient en zijn naasten." de inwloed wan houdingen in het persoonlijk netwerk van de patient op zijn medische consumptie. The Hague: Pasmans.

Norbeck, J.S. (1981). Social support: a model for clinical research and application. Advances in Nursing Science, 3, 43-59.

Nota chronisch-ziekenbeleid. Tweede Kamer, vergaderjaar 1990-1991, 22025, nr.1.

Olson, D.H., McCubbin, H.I. (1983). Familles: what makes them work. Beverly Hills.

Oosterbaan, H., Zeldenrust, W. (1985). Gescheiden wegen. sociale nerwerken, protoprofessionalisering, psychische problemen en hulpzoekend gedrag bij gescheiden mensen. Utrecht: Nederlands Centrum voor Geestelijke Volksgezondheid.

Orem, D.E. (1985). Nursing: concepts of practice. New York: McGraw-Hill.

Ormel, J. (1984). Sociale steun: zijn operationalisering en relaties met het ego-gecentreerde sociale netwerk. Subsidie-aanvraag bij de Nederlandse Organisatie voor Wetenschappelijk Onderzoek (NWO).

Parsons, T. (1970). The social system. London: Routledge and Kegan Paul. (1951)

Parsons, T. (1979). Definitions of health and illness in the light of American values and social structure. In Jaco, E.G. (ed.). Patients, Physicians and illness. New York: Free Press. (1958)

Pearlin, L.I., Schooler, C. (1978). The structure of coping. Journal of Health and Social Behavior, 19, 2-21.

Philipsen, H. (1969). Afwezigheid wegens ziekte. Groningen: Walters-Noordhoft. 
Philipsen, H. (1970). Afwijkend gedrag, etikettering door de samenleving en strategieèn wan de afwijkers. Sociologische Gids, 17, 350-367.

Polit, D.F., Hungler, B.P. (1983). Nursing research: principles and methods. Philadelphia: Lippineott.

Pollard, W.E., Bobbitt, R.A., Bergner, M., Martin, D.P., Gilson, B.S. (1976). The Sickness Impact Profile: reliability of thealth status measure. Medical Care, 14, 146-155.

Ross, W. J G. (1989). Sociale Steun buj Kankerpatienten. Dissertation, Utrecht.

Rusbult, C.E. (1980a). Satisfaction and commitment in friendships. Representative Research in Social Psychology", $11,96-105$.

Rusbult; $C . E_{*}$ (1980b). Commitment and satisfaction in romantic associations: $A$ test of the investment model. Journal of Experimental Social Psychology, 16, 172-186.

Schiltmans, M.M.C., Evers, G.C.M. (1989). Zelfzorgvermogen en sociale ondersteuning bij reumapatienten: een onderzoek op basis van Orem"s zelfzorg-tekort theorie. Verpleegkunde, 3 , 195-200.

Schreurs, P.J.G., Tellegen, B., Willige, G. van de (1984). Gezondheid, stress, coping, de ontwikkeling van de Utrechtse Coping-lijst. Gedrag - Tijdschrift voor Psychologie, 12, 101117.

Secord, P.F., Backman, C.W. (1964), Interpersonal congruency, perceived similarity, and friendship. Sociometry, 27, 115-127.

Shulman, N. (1975). Lifecycle variations in patterns of close relationships. Journal of Marriage and the Family, 37, 813-822.

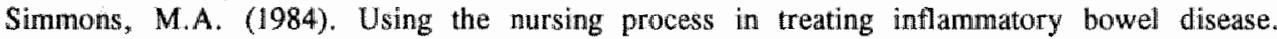
Nursing Clinics of North America, 19, 11-25.

Sonderen, F.L.P. van (1990). Het meten van sociale steun. Dissertation, Groningen.

Sonderen, F. L.P. van (1989). The relationship between sacial network characteristics and social support. Paper presented at the European Conference on Social Network Analysis. Groningen.

Sparacino, L.L. (1984). Psychosocial considerations for the adollescent and young adult with inflammatory bowel disease. Nursing Clinics of North America, 19, 41-49.

Strauss, A.L. (1975). Chronic illness and the quality of life. Saint Louis: Mosby.

Swaan, A. de (1982). De mens is de mens een zorg: opstellen 1971-1981. Amsterdam: Meulenhoff.

Thompson, D.M., Haran, D. (1984). Living with an amputation: what it means for patients and their helpers. Imernational Journal of Rehabilitation Research, 7, 283-292.

Tietjen, A.M. (1985). The social networks and social support of married and single mothers in Sweden. Journal of Marriage and the Family, 47, 489-496.

Tilburg, T. van (1988). Verkregen en gewenste ondersteuning in het licht van eenzaamheidservaringen. Dissertation, Amsterdam.

Tilden, V.P. (1985). Issues of conceptualization and measurement of social support in the construction of nursing theory. Research in Nursing and Health, 8, 199-206.

Tolsdorf, C.C. (1976). Social networks, Support, and Coping: An exploratory study. Family Process, 4, 407-417.

Tytgat, G.N.J., Groote, J. de, Tongeren, J.H.M. van, Vantrappen, G. (1985). Leerboek maag , darm, en lewerziekten. Utrecht: Bohn, Scheltema and Holkema.

Verhaak, P.F.M., Busschbach, J.T. van, Kortenhoeven, D. (1985). Behoefte aan wijhverpleegkundige zorg bif weranderend beleid. NIVEL. Utrecht.

Verwoerdt, A. (1972). Psychopathological responses to the stress of physical illness. In Lipowski, Z.J., Hanover, N.H. (ed.). Psychosocial aspects of physical illness. Basel: Karger.

Vincent, C.E. (1963). The family in health and illness: some neglected areas. Ann. Amer. Acad. Pol. and Soc. Scl, 34, 109-116. 
Vroom, C.W., Net, Th.Z.J. v.d. (1978). Leven met onzekerheid: verslag van een onderzoek naar de sociale revalidatie van 385 mammacarcinoompatienten. Medisch Comact, 33, 10511054 .

Walker, K.N., MacBride, A., Vachon, M.L.S. (1977). Social support networks and the crisis of bereavement. Social Science and Medicine, 11, 35-41.

Warshay, L.H. (1975). The current state of sociological theory. New York: Mckay.

Weeda, I., Groenewold, J. (1986). Scheiden doet lijden? - (voor)oordelen over de gevolgen van echtscheiding. Houten: Unieboek.

Wentowski, G.J. (1981). Reciprocity and the coping strategies of older people: cultural dimensions of network building. The Gerontologist, $21,600-609$.

Westbrook, M.T. (1979). A classification of coping behavior based on multidimensional scaling of similarity ratings. Journal of Clinical Psychology, 35, 407-410.

Westerlaak, J., Kropman, J., Collaris, J. (1975). Beroepenklapper. Nijmegen, ITS.

Whitten, N., Wolfe, A. (1974). Network analysis. In: Honigmann, J. (ed.). Handbook of social and cultural anthropolagy. Chicago.

Willer, D., Anderson, B. (1981). Networks, exchange and coercion: the elementary theory and its applications. New York: Elsevier.

Williams, $\mathbb{R}$. (1983). Concepts of health: an analysis of lay logic. Sociology, 17, 183-205.

Willige, G. van de, Sorbi, M., Kluver, R., Godaert, G., Schreurs, P., Vink, J. (1983). Gedrag en gezondheid: een interactionele benadering. Gezondheid en Samenleving, 4, 35-44.

Wilson, C. (1984). The diagnostic work-up for the patient with inflammatory bowel disease. Nursing Clinics of North America, 19, 51-59.

Witte, L.P. (1991). After the rehabilitation Centre: a study into the course of functioning after discharge from rehabilitation. Dissertation, Maastricht.

Witte, L.P. de, Jacobs, H., Horst, F. van der, Luttik, A., Joosten, I., Philipsen, H. (1987). De waarde van de Sickness. Impact Profile als mat voor het functionaren van patienten. Gezondheid en Samenleving, 8, 120-127.

Witte, L.P. de, Jacobs, H., Luttik, A. (1987). The Sickness Impact Profile: A Dutch Version. Poster presented on the International Conference Quality of Life. The Hague.

Witte, L.P. de, Joosten, J., Horst, F. van der (1986). Chronisch zieken en hun sociale contacten. $\mathrm{Zr}$. Meyboom-studiedag. Heeze.

Wortman, C.B. (1984). Social support and the cancer patient: conceptual and methodologic issues. Cancer, 53 (suppl.), 2339-2360. 


\section{Appendix A}

Network stability for each respondent group

1. Network size (Pearson correlation)

\begin{tabular}{lccc} 
& $\begin{array}{c}\text { healthy } \\
(\mathrm{n}=44)\end{array}$ & $\begin{array}{c}\text { AS } \\
(\mathrm{n}=39)\end{array}$ & $\begin{array}{c}\text { Crohn } \\
(\mathrm{n}=36)\end{array}$ \\
\hline $\mathrm{t} 1-\mathrm{t} 2$ & $.50^{* *}$ & $.54^{* *}$ & $.73^{* *}$ \\
$\mathrm{t}-\mathrm{t} 3$ & & $.80^{* *}$ & $.80^{* *}$ \\
$\mathrm{t} 1-\mathrm{t} 3$ & $.35^{*}$ & $.59^{* *}$ \\
& & \\
\hline *** $\mathrm{p}<.01 * \mathrm{p}<.05$ & &
\end{tabular}




\section{Network composition}

- computed by Pearson correlation

$\begin{array}{lll}\text { healthy } & \text { AS } & \text { Crolhn } \\ (n=44) & (n=39) & (n=36)\end{array}$

kin

$\mathrm{t} 1-\mathrm{t} 2$

$.68 * *$

$.63 * *$

$.85^{\text {*** }}$

$\mathrm{t} 2-\mathrm{t} 3$

$.88 * *$

$\mathrm{t} 1-\mathrm{t} 3$

$.43^{* * *}$

$.82 * *$

$.71^{* * *}$

non-kin informal

t1 $-\mathrm{t} 2$

$.68^{* *}$

$.66 * *$

$.67 * *$

$\mathrm{t} 2-\mathrm{t} 3$

$.78 * *$

$.88 * *$

$\mathrm{t} 1-\mathrm{t} 3$

$.62 * *$

$.67 * *$

$* * p<.01$

- computed by the percentage of network members listed at $2 / t 3$ as well as at $t 1$

$\begin{array}{lll}\text { healthy } & \text { AS } & \text { Crohn } \\ (n=44) & (n=39) & (n=36)\end{array}$

kin

$11-12$

70

65

71

$12-13$

80

75

$\mathrm{t} 1-\mathrm{t} 3$

59

65

non-kin informal

t1 $1-12$

50

37

38

t2 -13

41

45

$\mathrm{t} 1-\mathrm{t} 3$

32

34 
3. Network content: total network (Pearson correlation)

$\begin{array}{ccc}\text { healthy } & \text { AS } & \text { Crohn } \\ (n=44) & (n=39) & (n=36)\end{array}$

mean emotional received

t1 -12

$12-13$

.23

$.69 * * * 38 *$

t1 -13

$.59 * * *$

$.62^{* * *}$

$.33^{*}$

$.37 *$

mean instrum. received

$\mathrm{t} 1 * \mathrm{t} 2$

$12-13$

$.65 * * * *$

$.73 * * *$

34 *

.58 ****

$.66^{\text {* } * * * *}$

$\mathrm{t} 1=\mathrm{t} 3$

$43 * *$

$.47 * *$

mean emotional giwen

$\mathrm{t} 1-\mathrm{t} 2$

$.43^{* * * * *}$

$.72 * * * *$

$.59 * * * *$

$.77^{* * * *}$

.74 ****

$2-13$

$.54^{* * * *}$

$.61^{* * * * * *}$

mean instrumental given

$\mathrm{t} 1 \mathrm{t} 2$

$.62^{* * * * *}$

5 . **

$.54 * * * *$

t2 -13

$.55^{\text {**** }}$

$42 * *$

$\mathrm{t} 1-\mathrm{t} 3$

.39 ** *

$39 * *$

***** $p<.001 * * 2<.01 \quad * p<.05$

4. Network content: network categories (Pearson correlation)

healthy $(n=44)$

kin non-kin inf.
AS $(n=39)$

kin non-kin inf.
Crohn $(n=36)$

kin non-kin inf.

mean emotional received

$11-12$

$12-13$

$.37^{\text {策椋 }}$

$.29 *$

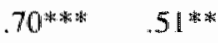

$.74^{\text {ik } * *} \quad .22$

$11-13$

$.52 * * 2 *-.11$

$.21 \quad .77^{* * * * * * 2}$

$.67^{* * * *} \quad .47^{* *}$

mean instrum. received

til -12

$.73^{* * *} \quad .46^{* *}$

$.66^{*}$ 妌* .28

$39^{*}$

$.63^{* * *}$

$12-13$

$.62^{* * *} .13$

t $1-13$

$.46^{* * *} \quad .10$

$.51^{* * *} \quad-.17$

$.51 * * \quad .44^{*}$

mean enotional giwen

$11-\mathbf{t}^{2}$

$12-13$

11 -13

$.39^{* * *} \quad .41^{* * *}$

$.67 * * 29$

.47 **⿻一𠃋十

.24

mean instrumental given

1. -12

t $2-13$

$t 1-t 3$

$.56 * * * \quad .56 * * *$

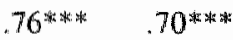

$.46 * \quad .75 * * *$

$.56^{* * *} \quad .17$

$.57 * *$

$.52 *$

$.51^{* *} \quad .30$

$.66^{* * *} \quad .35$

$.62 * * * \quad .49 * *$

*** $p<.001 * * 20.01 * p<.05$

$.61^{\text {水*** }}-\quad-.01$

$.43^{* * *}-.16$

$.46^{* *} \quad .69^{* * *}$ 


\section{Appendix B}

Number of respondents per network size

\begin{tabular}{|c|c|c|c|}
\hline & $\mathrm{n}$ & $\mathrm{n}$ & $\mathrm{n}$ \\
\hline 0 & 1 & 1 & \\
\hline 1 & 1 & & 2 \\
\hline 2 & 1 & $\mathbb{1}$ & 1 \\
\hline 3 & 8 & 4 & 5 \\
\hline 4 & 7 & 10 & 5 \\
\hline 5 & 4 & 4 & 7 \\
\hline 6 & 17 & 3 & 12 \\
\hline 7 & 11 & 4 & 8 \\
\hline 8 & 3 & 2 & 7 \\
\hline 9 & 13 & 6 & 8 \\
\hline 10 & 9 & 4 & $\mathbb{1 1}$ \\
\hline 11 & 4 & 8 & 7 \\
\hline 12 & 3 & 3 & 10 \\
\hline 13 & 3 & 5 & 4 \\
\hline 14 & 10 & & 6 \\
\hline 15 & 6 & 5 & 5 \\
\hline 16 & 1 & 3 & 3 \\
\hline 17 & 3 & 1 & 2 \\
\hline 18 & 5 & 2 & 4 \\
\hline 19 & 4 & 3 & 2 \\
\hline 20 & 5 & 6 & 10 \\
\hline total & 119 & 75 & 119 \\
\hline
\end{tabular}




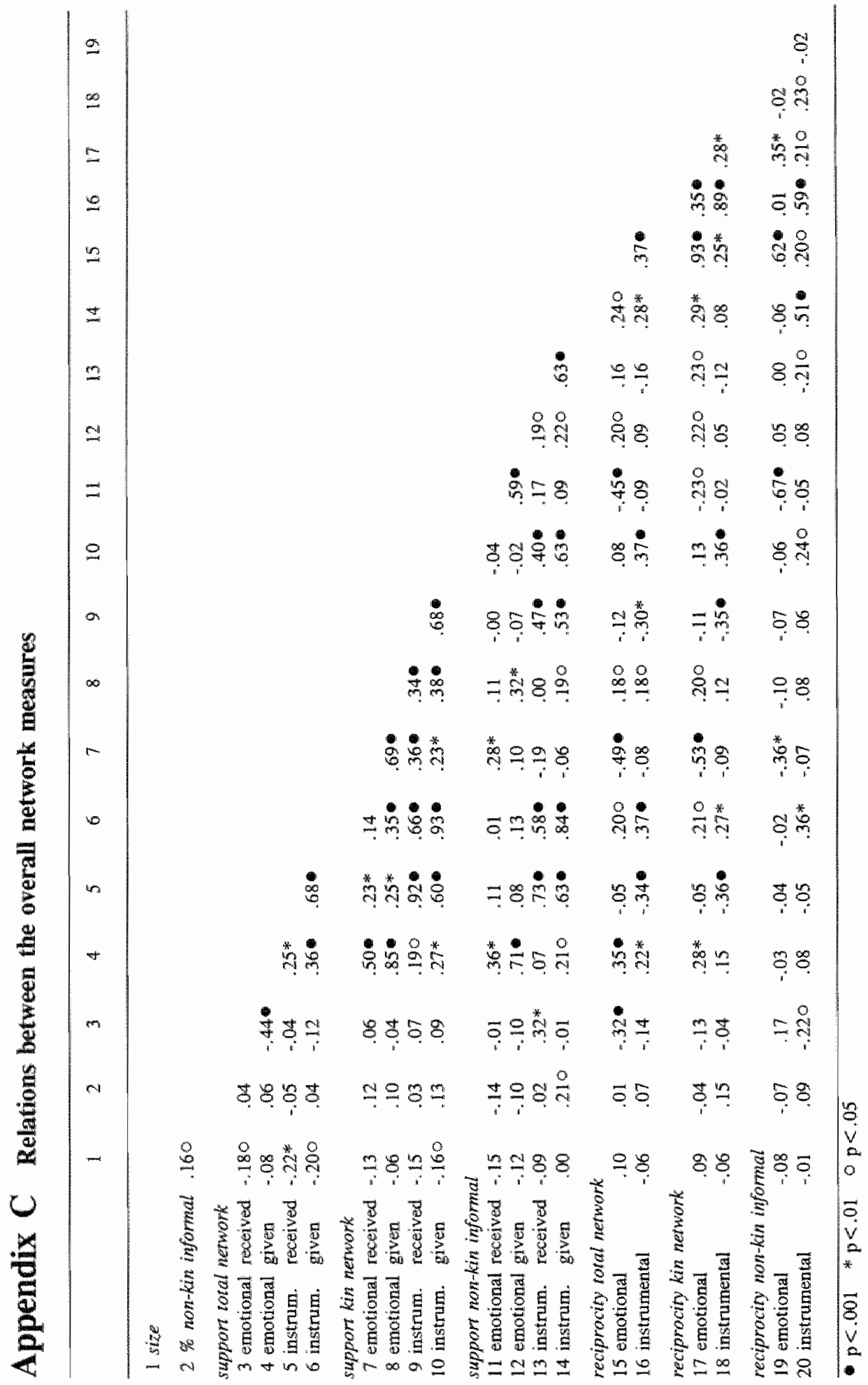




\section{Appendix D}

Pearson correlations for SIP scores for AS and Crohn patients

$$
\begin{array}{cr}
\text { AS } & \text { Crohn } \\
(n=39) & (n=36)
\end{array}
$$

$\begin{array}{llll}\text { physical score } & \mathrm{t} 1-\mathrm{t} 2 & .90^{* *} & .45^{* *} \\ \mathrm{t} 2-\mathrm{t} 3 & .90^{* *} & .31^{*} \\ \mathrm{t} 1-\mathrm{t} 3 & .89^{* *} & .19 \\ \text { psychosocial score } & \mathrm{t} 1-\mathrm{t} 2 & .87^{* *} & .74 * * \\ & \mathrm{t} 2-\mathrm{t} 3 & .94^{* *} & .71^{* *} \\ \mathrm{t} 1-\mathrm{t} 3 & .79^{* *} & .50^{* *}\end{array}$

** $\mathrm{p}<.01 * \mathrm{p}<.05$ 


\section{Appendix E}

Pearson correlations for subjective health for AS and Crohn patients

$\begin{array}{cr}\text { AS } & \text { Crohn } \\ (n=39) & (n=36)\end{array}$

$\mathrm{t} 1-\mathrm{t} 2$

$12-13$

tl-t 3

$11-12$

$12-1$

t1- 13
$.78 * *$

$.86 * *$

$.71 * *$

$.72 * *$

$.81 * *$

$.70 * *$ physical score

$.66^{* *}$ $55^{* * *}$ $.42 * *$

psychosocial score

*** $p<.01$ 


\section{Appendix F}

\section{Factor loadings $(\geq .40)$ Utrecht Coping Questionnaire $(n=119)$}

item $^{1}$

$$
\begin{array}{lll}
\text { factor } 1 & \text { factor2 } & \text { factor3 } \\
(\alpha=.80) & (\alpha=.67) & (\alpha=.68)
\end{array}
$$

Using a direct approach in order to solve the problem $\quad .78$

Considering different solutions to the problem $\quad .75$

Finding out all about the problem $\quad .70$

Making several alternative plans for handling the problem $\quad .66$

Considering problems as a challenge $\quad 65$

Making a direct intervention, when a problem occurs .58

Realising every cloud has a silver lining

Seeking sympathy and comfort from somebody

Showing that there are things which are bothering you .63

Showing one s feelings $\quad .59$

Asking someone to help $\quad .52$

Showing one"s anger with those responsible for the problem

Sharing one's worries with someone

Trying to dispell one's worries temporarily by taking a break

Being totally preoccupied with the problem

Showing one"s annoyance

Taking a gloomy view of the situation

Feelling unable to do anything

Trying to awoid difficult situations as much as possible

Giving-in in order to avoid difficult situations $\quad .65$

Resigning oneself to the situation .64

Trying to make oneself feel better one way or the other

Telling oneself that other people also have their problems from time to time

Looking for distraction

Worrying about the past

Directing one's thoughts towards other matters

"items forming the 15-item scale are printed in italic type 


\section{Appendix G}

Pearson correlations for duration of the health deviation and network size and percentage of non-kin informal network members $(n=75)$

duration of the health deviation

tl

t3

network size

$-.10$

$-.21 *$

\% non-kin informal members

.08

$-.10$

* $p<.05$ 


\section{Appendix $\mathrm{H}$}

Pearson correlations between the influencing variables $(n=119)$

\begin{tabular}{|c|c|c|c|c|c|c|c|c|c|}
\hline & 1 & 2 & 3 & 4 & 5 & 6 & 7 & 8 & 9 \\
\hline \multicolumn{10}{|l|}{1 gender } \\
\hline 2 social class & -.07 & & & & & & & & \\
\hline 3 family comp. & .11 & -.11 & & & & & & & \\
\hline 4 age & -.12 & -.01 & .00 & & & & & & \\
\hline 5 life event $t 1$ & .14 & $-.23^{*}$ & -.01 & -.09 & & & & & \\
\hline 6 life event $t 2$ & .01 & .03 & -.01 & .00 & .08 & & & & \\
\hline 7 life event 13 & .06 & -.02 & -.06 & -.02 & .04 & $.24 *$ & & & \\
\hline 8 action-directed & $-.41 \bullet$ & $.34 \bullet$ & -.11 & -.07 & -.11 & -.09 & .04 & & \\
\hline 9 seek soc. supp. & $.21 *$ & $.20^{*}$ & .09 & $-.21 *$ & .04 & -.00 & .09 & $.19^{*}$ & \\
\hline 10 await/avoid & 12 & .08 & -.10 & -.01 & .07 & .17 & -.00 & -.14 & $.36 \circ$ \\
\hline
\end{tabular}




\section{Appendix I}

Comparison of healthy respondents and patients with regard to influencing variables $^{1}$

$\begin{array}{ccc}\text { healthy } & \text { patients } & \text { test- } \\ n=44 & n=75 & \text { statistic }\end{array}$

\begin{tabular}{|c|c|c|c|c|c|}
\hline gender & $\begin{array}{l}\text { male } \\
\text { female }\end{array}$ & $\begin{array}{l}52 \% \\
48 \%\end{array}$ & $\begin{array}{l}56 \% \\
44 \%\end{array}$ & $X^{2}=$ & .04 \\
\hline social class & $\begin{array}{r}\text { low } \\
\text { average } \\
\text { high }\end{array}$ & $\begin{array}{l}16 \% \\
52 \% \\
32 \%\end{array}$ & $\begin{array}{l}35 \% \\
47 \% \\
19 \%\end{array}$ & $\mathrm{X}^{2}=$ & $4.26^{*}$ \\
\hline age & $\begin{array}{r}\text { mean } \\
\text { sd }\end{array}$ & $\begin{array}{r}35.7 \\
6.7\end{array}$ & $\begin{array}{r}36.9 \\
6.8\end{array}$ & $T=$ & -.88 \\
\hline $\begin{array}{r}\text { family composition } \mathrm{c} \\
\text { no } \mathrm{c}\end{array}$ & $\begin{array}{l}\text { ld home } \\
\text { ld home }\end{array}$ & $\begin{array}{l}59 \% \\
41 \%\end{array}$ & $\begin{array}{l}56 \% \\
44 \%\end{array}$ & $X^{2}=$ & .02 \\
\hline life events & $\begin{array}{l}\mathrm{t} 1 \\
\mathrm{t}\end{array}$ & $\begin{array}{l}27 \% \\
34 \%\end{array}$ & $\begin{array}{l}43 \% \\
31 \%\end{array}$ & $\begin{array}{l}\mathrm{T}= \\
\mathrm{T}=\end{array}$ & $\begin{array}{r}-1.69 \\
.38\end{array}$ \\
\hline action-directed coping & $\begin{array}{r}\text { mean } \\
\text { sd }\end{array}$ & $\begin{array}{r}11.0 \\
1.9\end{array}$ & $\begin{array}{r}10.7 \\
2.2\end{array}$ & $\mathrm{~T}=$ & .78 \\
\hline seeking social support & $\begin{array}{r}\text { mean } \\
\text { sd }\end{array}$ & $\begin{array}{l}9.7 \\
1.7\end{array}$ & $\begin{array}{l}8.4 \\
1.7\end{array}$ & $\mathrm{~T}=$ & $4.13^{* *}$ \\
\hline awaiting/avoidance & $\begin{array}{r}\text { mean } \\
\text { sd }\end{array}$ & $\begin{array}{l}5.7 \\
1.7\end{array}$ & $\begin{array}{l}5.0 \\
1.4\end{array}$ & $\mathrm{~T}=$ & $2.28^{*}$ \\
\hline
\end{tabular}

$* * 0.01 * p .05$

I marital status is left out of the analyses because more than $75 \%$ of the respondents in every group are either married or living together;

because of the small numbers in two of the four cells family composition is divided into 'no child living at home' and 'child living at home'. 
Relation between health status measures and influencing variables $(n=67)$

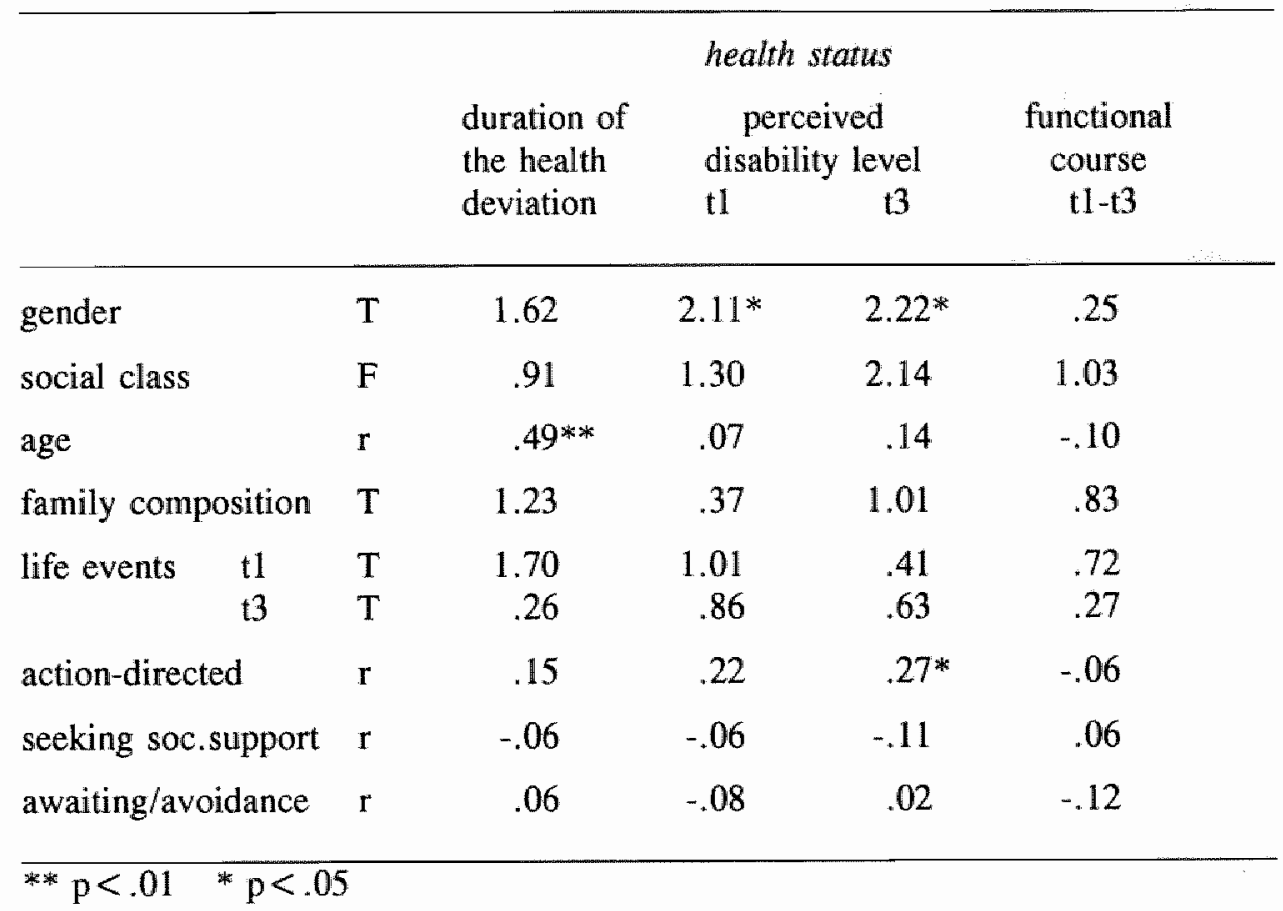




\section{Appendix $\mathbf{J}$}

Relation between coping, social position and life events and network wariables for the total respondent group

$n=119$ for size and percentage of non-kin informal network members; $n=114$ for kin support and reciprocity; $n=74$ for non-kin informal support and reciprocity.

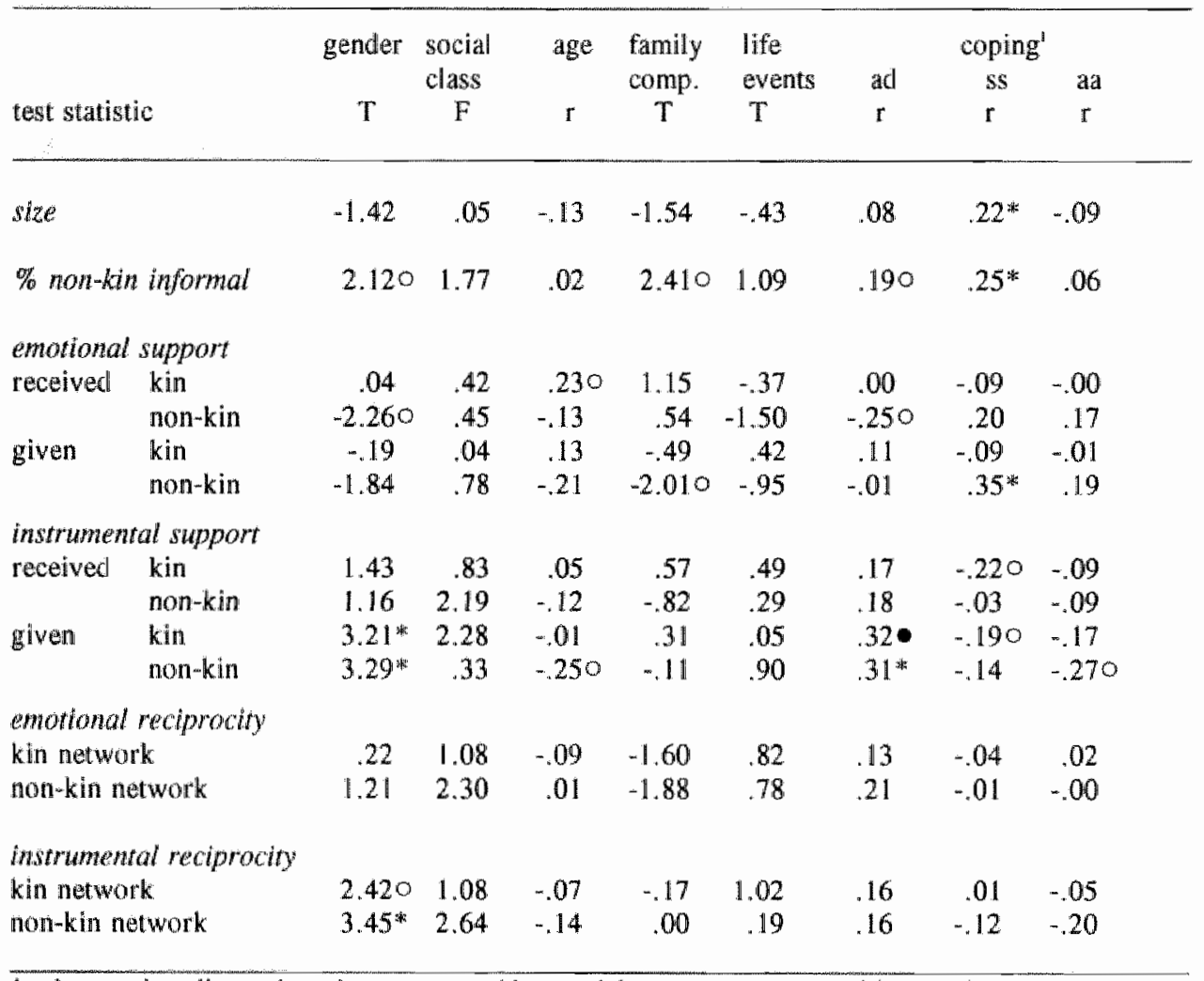

1 ad $=$ action-directed coping; $\mathrm{ss}=$ seeking social support; $\mathrm{ad}=$ awaiting/avoidance

$-p<.001 * p<.01 \quad 0<<.05$ 
Relation between coping, social position and life events and change scores of the network variables for the patient group

$\mathrm{n}=75$ for network size and percentage of non-kin informal network members; $n=73$ for kin support and reciprocity; $n=37$ for non-kin informal support and reciprocity

\begin{tabular}{|c|c|c|c|c|c|c|c|c|}
\hline \multirow[b]{3}{*}{ test statistic } & \multirow[t]{2}{*}{ gender } & \multirow{2}{*}{$\begin{array}{l}\text { social } \\
\text { class }\end{array}$} & \multirow[t]{2}{*}{ age } & \multirow{2}{*}{$\begin{array}{l}\text { familly } \\
\text { comp. }\end{array}$} & \multirow{2}{*}{$\begin{array}{l}\text { life } \\
\text { events }\end{array}$} & \multicolumn{3}{|c|}{ coping' } \\
\hline & & & & & & $\mathrm{ad}$ & ss & ats \\
\hline & $\mathrm{T}$ & F & r & $\mathrm{T}$ & $\mathrm{T}$ & $r$ & $\mathbf{r}$ & nt \\
\hline
\end{tabular}

change scores $11-\mathrm{t} 3$

\begin{tabular}{|c|c|c|c|c|c|c|c|c|c|}
\hline size & & -1.05 & 2.02 & -.03 & -1.05 & -1.01 & -.200 & .02 & .15 \\
\hline$\%$ non-ki & informal & .09 & 4.510 & .02 & -1.49 & -.02 & -.08 & -.06 & -.13 \\
\hline emotiona & supp & & & & & & & & \\
\hline received & kin & -.31 & .23 & -.04 & .61 & -.63 & .12 & .09 & 00 \\
\hline & non-kin & -1.11 & 10 & .12 & 2.390 & -1.09 & .06 & -.08 & -.16 \\
\hline given & kin & 1.64 & 1.69 & .08 & -.14 & -.89 & .13 & .11 & -.04 \\
\hline & non-kin & .07 & 1.21 & -.01 & .50 & .27 & .15 & .04 & .09 \\
\hline
\end{tabular}

instrumental support

$\begin{array}{llrrrrrrrr}\text { received } & \text { kin } & -1.28 & .61 & -.11 & .73 & -.49 & .10 & -.01 & -.09 \\ & \text { non-kin } & -1.48 & 1.85 & -.20 & .42 & .97 & .24 & -.12 & -.270 \\ \text { given } & \text { kin } & -1.59 & .18 & -.190 & .44 & -1.67 & -.05 & .16 & .19 \\ & \text { non-kin } & .30 & 1.80 & -.11 & .43 & .27 & -.06 & .20 & .20\end{array}$

emotional reciprocity

$\begin{array}{lrrrrrrrr}\text { kin network } & 1.66 & 2.01 & .15 & -.55 & -.36 & -.03 & .01 & -.01 \\ \text { non-kin network } & .82 & 1.44 & -.09 & -2.070 & 1.26 & .03 & -.07 & .12 \\ & & & & & & & & \\ \begin{array}{l}\text { instrumental reciprocity } \\ \text { kin network }\end{array} & .60 & .47 & -.12 & .25 & .29 & .01 & .11 & .18 \\ \text { non-kin network } & 1.57 & 5.69^{*} & -.03 & -.20 & -.22 & -.14 & .16 & .23\end{array}$

$1 \mathrm{ad}=$ action-directed coping; $\mathrm{s}=$ seeking social support; a $=$ awaiting/avoidance $\bullet p<.001 * p<.01 \quad 0 \mathrm{p}<.05$ 


\section{Curriculum vitae}

I was born in Beek on September 28, 1963. After attending Atheneum from 1975 to 1981 in Stein, I studied Health Sciences at the University of Limburg in Maastricht. I graduated in 1985, specializing in Nursing Science. In September 1985 I started my research into the personal networks of chronic patients at the Department of Nursing Science of the University of Limburg. Since August 1990 I have been employed as a researcher at the Department of Clinical Psychology and Health Psychology of the University of Utrecht. As such I am working on a project funded by the Netherlands Cancer Society (NKB) aiming at the improvement of the communication skills of medical specialists in oncology and as a consequence at an increase in the amount of emotional and informational support these physicians give to their patients. 